NBER WORKING PAPER SERIES

\title{
DOES EXPORTING IMPROVE MATCHING? EVIDENCE FROM FRENCH EMPLOYER-EMPLOYEE
} DATA

\author{
Matilde Bombardini \\ Gianluca Orefice \\ Maria D. Tito \\ Working Paper 21225 \\ http://www.nber.org/papers/w21225
}

\author{
NATIONAL BUREAU OF ECONOMIC RESEARCH \\ 1050 Massachusetts Avenue \\ Cambridge, MA 02138 \\ May 2015
}

This work benefited from a State aid managed by the National Agency for Research, through the program "Investissements devenir" with the following reference: ANR-10-EQPX-17 (Remote Access to data CASD). Bombardini acknowledges support from CIFAR and SSHRC. We would like to thank Kristian Behrens, Mikael Carlsson, Andrew Chang, Leland Crane, Nils Gottfries, Keith Head, Hiroyuki Kasahara, Christopher Kurz, Julien Martin, Teodora Milicevic, Justin Pierce, JohnRomalis, Gisela Rua, Oskar Nordstrom Skans, Tomasz Swiecki, Francesco Trebbi, Farid Toubal and seminar participants at the University of British Columbia, Universita' Bocconi, IES Summer Trade Workshop at Princeton University, EIIT at the University of Oregon, Peter B. Gustavson School of Business, UQAM, HEC Montreal, Uppsala University, Federal Reserve Board, University of Sydney, the West Coast Trade Workshop at Stanford University, Universite' d'Orleans and Rice University. The views expressed herein are those of the authors and do not necessarily reflect the views of the National Bureau of Economic Research

NBER working papers are circulated for discussion and comment purposes. They have not been peerreviewed or been subject to the review by the NBER Board of Directors that accompanies official NBER publications.

(C) 2015 by Matilde Bombardini, Gianluca Orefice, and Maria D. Tito. All rights reserved. Short sections of text, not to exceed two paragraphs, may be quoted without explicit permission provided that full credit, including $(\mathrm{C}$ notice, is given to the source. 
Does Exporting Improve Matching? Evidence from French Employer-Employee Data

Matilde Bombardini, Gianluca Orefice, and Maria D. Tito

NBER Working Paper No. 21225

May 2015

JEL No. F16,J2

\begin{abstract}
$\underline{\text { ABSTRACT }}$
Does opening a market to international trade affect the pattern of matching between firms and workers? And does the modified sorting pattern affect welfare? This paper answers these questions both theoretically and empirically in three parts. We set up a model of matching between heterogeneous workers and firms where variation in the worker type at the firm level exists in equilibrium only because of the presence of search costs. When firms gain access to the foreign market their revenue potential increases. When stakes are high, matching with the right worker becomes particularly important because deviations from the ideal match quickly reduce the value of the relationship. Hence exporting firms select sets of workers that are less dispersed relative to the average. We then document a novel fact about the hiring decisions of exporting firms versus non-exporting firms in a French matched employer-employee dataset. We find that exporting firms feature a lower type dispersion in the pool of workers they hire. The matching between exporting firms and workers is even tighter in sectors characterized by better exporting opportunities as measured by foreign demand or tariff shocks. In a calibrated general equilibrium version of the model we show that trade opening increases welfare by more when search costs are high, pointing to an additional source of gains from trade.
\end{abstract}

\author{
Matilde Bombardini \\ Department of Economics \\ University of British Columbia \\ 997-1873 East Mall \\ Vancouver, BC V6T 1Z1 \\ CANADA \\ and CIFAR and RCEA \\ and also NBER \\ matildeb@interchange.ubc.ca \\ Gianluca Orefice \\ CEPII \\ 113 rue de Grenelle \\ 75007 Paris, France \\ gianluca.orefice@cepii.fr
}

\author{
Maria D. Tito \\ University of British Columbia \\ 997-1873 East Mall \\ Vancouver, BC V6T 1Z1 \\ mariadomenica.tito@gmail.com
}

A data appendix is available at:

http://www.nber.org/data-appendix/w21225 


\section{Introduction}

The pattern of sorting of workers across firms has fundamental implications for the efficiency of the economy as well as for the inequality of wages in the labor force. The first implication has been a concern of the literature on assignment starting from Shapley \& Shubik (1971) and Becker (1973). From those contributions we know that when firms and workers are complementary in production, then the allocation of the right worker to the right job maximizes output. The second implication has received attention more recently for example by Card et al. (2013), who show that sorting of good workers to good firms can explain as much as $35 \%$ of the recent increase in wage inequality in West Germany. The logic by which highly skilled workers are paid more not only because of their innate higher productivity, but also because they work with highly productive firms and co-workers, is common to the contribution by Kremer \& Maskin (1996) as well.

In this paper we start from the premise that the optimal allocation of workers cannot be reached because of the presence of search costs, and therefore firms accept some degree of mismatch in equilibrium because the cost of search exceeds the benefit from a more suited partner. We then explore whether the matching of firms and workers is affected by access of the former to the export market. But how can market integration affect how firms and workers are matched? When firms gain access to the foreign market their revenue potential increases. When stakes are high, matching with the right worker becomes particularly important because deviations from the ideal match quickly reduce the value of the relationship.

Using matched employer-employee data from France, we show that exporters select pools of workers characterized by a higher average type and, more importantly, a lower type dispersion than non-exporting firms. While the first effect is predicted by other models (Helpman et al., 2010 and Sampson, 2012) we believe we offer a novel way of testing this prediction, which disentangles pure exporter wage premia (deriving from profit-sharing with workers as in Amiti \& Cameron, 
2012) from the selection of better workers by exporting firms. The second effect, i.e. the influence of exporting on worker type dispersion, is unexplored in the literature and is quantitatively as strong as the effect of exporting on worker average type. We explore further the effect of exporting by building measures of the exporting opportunities in different sectors using tariffs and aggregate imports from the rest of the world of the various countries that France exports to. Whether we build these measures at the firm or at the sector level (using previous period export shares), we find that when exporters face lower tariffs or larger demand for imports in a foreign market, the dispersion of types in their pool of workers declines further. We believe this result is harder to reconcile with a view that the exporting and tightening of the matching are both driven by a common excluded factor.

To study the impact of exporting on matching we employ the model proposed by Eeckhout \& Kircher (2011), where we show that exporting is identical to an increase in the firm's type. Heterogeneous workers and firms face a dynamic problem where in the first period they meet at random and decide whether to accept the match or not. If they do not accept the match they pay a search cost and proceed to the second period where perfect assortative matching prevails. The second period, rather than an infinite horizon, approximates the long-run outside option for both worker and firm. The presence of search costs creates an acceptance set, rather than a unique assignment outcome that prevails in the frictionless model. As shown by Eeckhout \& Kircher (2011), the boundaries of such acceptance set are increasing in firm type, confirming the pattern of positive assortative matching in a model with frictions. We focus on a different dimension and we take the width of the acceptance set as a measure of the variability in worker type tolerated by the firm.

On the one hand, because of complementarity, a worker with type below the firm's ideal creates a reduction in output that is larger when the firm is very productive. On the other hand a worker 
type that is above the average type requires an increasing compensation due to her outside option. Such compensation rises much faster at firms that are more productive because they employ on average more productive types. The result is that firms that are more productive, or that have access to the export market, tolerate less relative dispersion from their ideal worker type.

In order to assess the welfare implications of this novel empirical finding, we present two sets of results. First, we derive a measure of the average revenue deviation for each firm type relative to the optimum assignment. We show that, according to this measure, a more productive firm (or an exporting firm) features a lower deviation from the optimal level of revenues created under perfect assortative matching. This is only a partial equilibrium result and cannot inform us as to whether there are overall gains from trade opening related to this matching channel. In particular there are two counteracting forces when an economy is opened to trade. On the one hand, importcompeting firms receive a negative shock to their revenues and therefore their matching range tends to widen. On the other hand, exporting firms receive a positive shock and choose smaller deviations from the optimal. We therefore proceed to simulate an infinite horizon version of the model with two symmetric countries and calibrate it to French moments of the data in order to recover the parameters for costs of search, transport costs and elasticity of demand. We numerically show that the gains from trade are larger as we increase the cost of search. We interpret this result as providing support to the idea that when an economy is characterized by high frictions, trade opening can be more beneficial than when the economy is essentially very close to the optimal worker and firm allocation. This explicit result on welfare is novel in the literature and we believe could be further explored in a richer model.

This paper contributes to the growing literature on international trade with heterogeneous workers and firms, which is surveyed in a recent chapter by Davidson \& Sly (2012). More specifically it belongs to a strand of research that investigates the effect of openness on the process of matching 
between firms and workers, which is at the core contribution by Sampson (2012), who studies its consequences for wage inequality. ${ }^{1}$

The most closely related work is a recent paper by Davidson et al. (2012), which shows, using Swedish data, that export-oriented sectors display a higher correlation between firm and worker types, estimated as firms' and workers' fixed effects in a wage regression as in Abowd et al. (1999)(henceforth AKM).

Our approach shifts the focus on the firm-level decision rather than looking at the aggregate strength of matching and therefore relies on a different type of variation to detect different matching behaviour by firms that are differentially exposed to international trade. In particular, it exploits within-sector variation between exporting and non-exporting firms, therefore isolating and controlling for other sector-level characteristics of the labor market that may affect the sorting of workers across firms.

Moreover, because Eeckhout \& Kircher (2011) prove that firms fixed effect deriving from a wage regression a la AKM might be negatively or not correlated with the true firm type, we are careful to avoid using those fixed effects as a proxy for the firm's type. We use instead variables constructed from firm-level data, such as sales, value added and total employment.

From a theoretical standpoint our approach differs from Davidson et al. (2008) in that we have a different focus. We are interested in deriving predictions at the firm level, rather than at the aggregate level and therefore we allow for a rich heterogeneity on both the worker and the firm side. Davidson et al. (2008) simplify those dimensions in order to obtain clean aggregate results. In particular they have high and low types of workers and high and low technology which is chosen endogenously by ex-ante homogeneous firms. Globalization can take the economy from an equilibrium in which high-tech firms employ high type workers and low-tech firms employ both

\footnotetext{
${ }^{1}$ Our paper is also related to the large literature on the impact of trade on inequality, which includes, among many others, Feenstra \& Hanson (1999), Costinot \& Vogel (2010), Bustos (2012), Amiti \& Cameron (2012), Verhoogen (2008), Krishna et al. (2014) and Frías et al. (2012).
} 
high and low type workers to an equilibrium where there is perfect assortative matching. The firm-level predictions in their set-up between exporters and non-exporters are stylized in that there is no predicted variation in the type of workers hired by different types of firms under trade.

The relationship of this paper to the theoretical framework in Helpman et al. (2010) and Helpman et al. (2013) deserves a more detailed analysis, since both models describe the matching of heterogeneous firms to heterogeneous workers in the presence of search frictions. The main conceptual difference between the two theoretical approaches is the nature of workers heterogeneity. In Helpman et al. (2010) workers are not ex-ante different, but they have a productivity draw that is firm specific. Therefore there is no sense in which an ex-ante a high-type worker is more likely to match with a high-type firm, since a firm simply select the workers that have better productivity draws relative to that firm only. In general our estimation procedure, which presumes the existence of a fixed worker type is incompatible with their view of ex-ante identical workers. Let us for a moment set aside this difference and investigate the predictions of their model in terms of the dispersion of worker types within firms. Under the assumption of a Pareto distribution, exporters (and more productive firms in general) choose a higher cut-off for hiring workers. This results in a distribution of workers within firm that has higher standard deviation, higher mean and a constant coefficient of variation (the ratio of standard deviation to mean). Therefore we need an alternative theoretical framework to investigate the impact of exporting on matching of permanently heterogeneous workers and firms that also face the possibility of exporting.

The remainder of the paper is divided in four sections. Section 2 introduces the theoretical framework and derives the main result on the dispersion of worker types at the firm level. Section 3 presents the estimation of worker types and presents empirical results linking export status and dispersion of worker type in the firm. Section 4 presents the model calibration and the numerical results on welfare. Section 5 concludes. 


\section{Theoretical framework}

The role of the theoretical framework is to understand why exporting firms may match with a different pool of workers from non-exporters. In particular, we are interested in two characteristics of the pool of workers hired by exporters: the average worker type and, most importantly, the variation in worker type at the firm level.

The setup is borrowed from Eeckhout \& Kircher (2011), a dynamic model where heterogeneous firms and heterogeneous workers match in the presence of search frictions. There is a unit mass of workers and a unit mass of firms. A worker's type $\theta$ is distributed according to a smooth density $g(\theta)$ on the interval $[0,1]$, while a firm's type $\psi$ is distributed according to smooth density $h^{\prime}(\psi)$ on the interval $[0,1]$.

Output is produced by a firm that employs one worker, according to the production function $f(\theta, \psi)=(\theta \psi)^{\sigma}$ where $\sigma>0 .{ }^{2}$ We embed the matching problem in a monopolistic competition model à la Krugman (1979). Each firm produces a differentiated variety of a product. Demand for an individual variety is isoelastic with elasticity $\eta>1$. Therefore firms selling their output in the domestic market obtain total revenues:

$$
R_{d}(\theta, \psi)=(\theta \psi)^{\frac{\sigma(\eta-1)}{\eta}} E^{\frac{1}{\eta}}
$$

where $E$ represents domestic total real expenditures. Firm revenues are increasing in the type of the firm and the worker and feature complementarity between the two types, i.e. $f_{\theta \psi}>0$. Complementarity is key for whether there is positive assortative matching in equilibrium between firms and workers.

\footnotetext{
${ }^{2}$ An extension to a firm with $n$ is trivial if there are no complementarities among workers. In this case the firm solves the same problem $n$ times. If we allow complementarities between workers we can show that our basic result is confirmed. See section 2.1.4.
} 
Under these assumptions, in the absence of frictions, we would observe perfect positive assortative matching. Under that scenario every type of firm would be matched with a unique type of worker. In particular, a more productive firm would be matched with a more productive worker, but there would be no variation within the set of workers matched with firms of a given type $\psi$, as in Sampson (2012).

We are interested in analyzing the variation between workers employed by the same type of firm. We therefore introduce frictions in the spirit of Atakan (2006), although we follow the timing simplification proposed by Eeckhout \& Kircher (2011). ${ }^{3}$ There are two periods. In the first period workers and firms meet at random, they perfectly observe one another's type and decide whether to produce. If they do not produce they pay a cost $c$ to search again in the second period. In the second period matching happens in a frictionless and competitive setting, therefore perfect assortative matching is the equilibrium outcome as in Becker (1973). Before describing how the equilibrium matching is determined we describe how we interpret the exporting decision in this simple set-up.

We introduce exporting in the simplest possible way, yet one that has similar features to the rest of the literature. There are different options when introducing a firm-level exporting decision. The original contribution by Melitz (2003) simply introduces a fixed cost of exporting common to all firms. This modelling choice implies that we should never observe two firms of the same productivity, but different export status. The stark prediction that all exporters should be more productive than non-exporters is clearly not supported by the data, as argued for example byBernard et al. (2003) and Helpman et al. (2013). In both US and Brazilian data the distribution of productivity of exporters has a higher mean, but also displays a substantial overlap with the productivity distribution of non-exporters, a feature that is clearly shared by our French sample as

\footnotetext{
${ }^{3}$ Extending the model to an infinite horizon framework does not alter the qualitative predictions of the equilibrium. The analytical characterization, however, requires that workers and firms have the same distribution. In the appendix we also include a numerical simulation without assuming equal distributions of worker and firm types.
} 
shown in Figure A4.

Because, similarly to Helpman et al. (2013), in our exercise we focus on the effect of exporting separately from that of firm productivity, we adopt a similar strategy of allowing different firms to have different costs of exporting. This may reflect various idiosyncratic factors such as better knowledge of the export market that makes setting up an export operation less costly. Because our interest in this paper is exclusively in comparing exporters and non-exporters and not in the endogenous sorting into exporting or the estimation of the fixed cost of exporting, we make one further simplifying assumption. We assume that some firms draw a prohibitively high fixed cost of exporting, while the rest of the firms draw a negligible fixed cost. All firms that export face an iceberg transport $\operatorname{cost} \tau>1$. This is the simplest way of introducing heterogeneous exporting behaviour among firms of identical type.

When a firm exports, its revenues increase even if the firm is not allowed to adjust its workforce. The firm sells its output in a market where the first unit sold of its differentiated variety is valued much more by foreign consumers than the last unit sold in the home market was valued by domestic consumers. The firm allocates output produced between the two markets so that marginal revenues are equalized in the two markets. This implies that, similarly to Helpman et al. (2010), total revenues of a firm $\psi$ that exports can be written as follows:

$$
R_{x}(\theta, \psi)=(\theta \psi)^{\frac{\sigma(\eta-1)}{\eta}}\left(E+E^{*} \tau^{1-\eta}\right)^{\frac{1}{\eta}}
$$

where $E^{*}$ is foreign real expenditure.

It is straightforward to verify that, for given $\theta$ and $\psi$, revenues of an exporting firm are larger than those of a non-exporting firm. It is useful to rewrite revenues of an exporting firm and a 
non-exporting firm with given productivity $\psi$ as follows:

$$
\begin{aligned}
& R_{d}(\theta, \psi)=\left(A_{d} \theta \psi\right)^{\frac{\sigma(\eta-1)}{\eta}}, \\
& R_{x}(\theta, \psi)=\left(A_{x} \theta \psi\right)^{\frac{\sigma(\eta-1)}{\eta}}
\end{aligned}
$$

where $A_{d}=E^{\frac{1}{\sigma(\eta-1)}}$ and $A_{x}=\left(E+E^{*} \tau^{1-\eta}\right)^{\frac{1}{\sigma(\eta-1)}}$ and $A^{*}>A$. We therefore establish the following property.

Remark 1 Exporting is isomorphic to an increase in productivity for a firm of initial productivity $\psi$.

Based on Remark 1 we are going to analyse the effect on matching of export status by characterizing the matching behaviour of more productive versus less productive firms.

Until now we have not discussed the distribution of worker types and, more importantly, of firm types. In principle we could start with a specific distribution of firm types $h^{\prime}(\psi)$, introduce export opportunities and derive a distribution of types based on adjusted firm type $A_{i} \psi$ where $i=d, x$. For the sake of tractability we instead make an assumption directly regarding the distribution of adjusted firm types, $\varphi=A_{i} \psi$, and assume that such distribution $h(\varphi)$ is uniform. We assume that the distribution of worker types $g(\theta)$ is also uniform as in Eeckhout \& Kircher (2011). ${ }^{4}$ In section 4.2 we introduce actual type distributions from the data in a numerical exercise.

\subsection{Matching problem}

We now solve the matching problem and derive predictions regarding the matching behaviour of exporters versus non-exporting firms. We start by characterizing second period wages, profits and assignment and then analyse period one firms' and workers' decisions. Once again, the problem is

\footnotetext{
${ }^{4}$ Although the problem remains tractable as long as worker and firm types are distributed according to the same distribution, the measures of dispersion that we will adopt will not be meaningful for generic distributions.
} 
analysed in terms of adjusted firm type $\varphi$ and worker type $\theta$. We rewrite the revenue function as $R(\theta, \varphi)=(\theta \varphi)^{\alpha}$ where $\alpha=\frac{\sigma(\eta-1)}{\eta}$.

\subsubsection{Second period: frictionless market}

In the second period, assignment is positive assortative. The matching function, $\mu(\theta)=\varphi$, which assigns firm $\varphi$ to worker $\theta$ is therefore $\mu(\theta)=\theta$. In a competitive equilibrium the wage function $w(\theta)$ must be such that the marginal revenues for a firm from hiring a better worker is equal to the marginal increase in the wage paid. The equilibrium wage is therefore given by:

$$
w^{*}(\theta)=\int_{0}^{\theta} \frac{d R(t, \mu(t))}{d t} d t=\frac{1}{2} \theta^{2 \alpha}
$$

By symmetry equilibrium profits in the second period take the same form:

$$
\pi^{*}(\varphi)=\frac{1}{2} \varphi^{2 \alpha}
$$

\subsubsection{Acceptance sets}

We now determine the matching behaviour of firms and workers in the first period. When a worker $\theta$ and a firm $\varphi$ meet, they produce $R(\theta, \varphi)$. The outside option for the worker is $w^{*}(\theta)-c$, while the outside option for the firm is $\pi^{*}(\varphi)-c$. Regardless of how surplus is split, the worker and the firm will accept to match if the surplus from the relationship is positive, i.e. if the following surplus condition holds:

$$
(\theta \varphi)^{\alpha}-\frac{1}{2} \varphi^{2 \alpha}-\frac{1}{2} \theta^{2 \alpha}+2 c \geq 0
$$

The surplus condition (5) defines the acceptance set, i.e. the set of pairs $(\theta, \varphi)$ where a match is mutually acceptable. The set of workers that match with firm $\varphi$ are denoted by $A(\varphi)$. The 


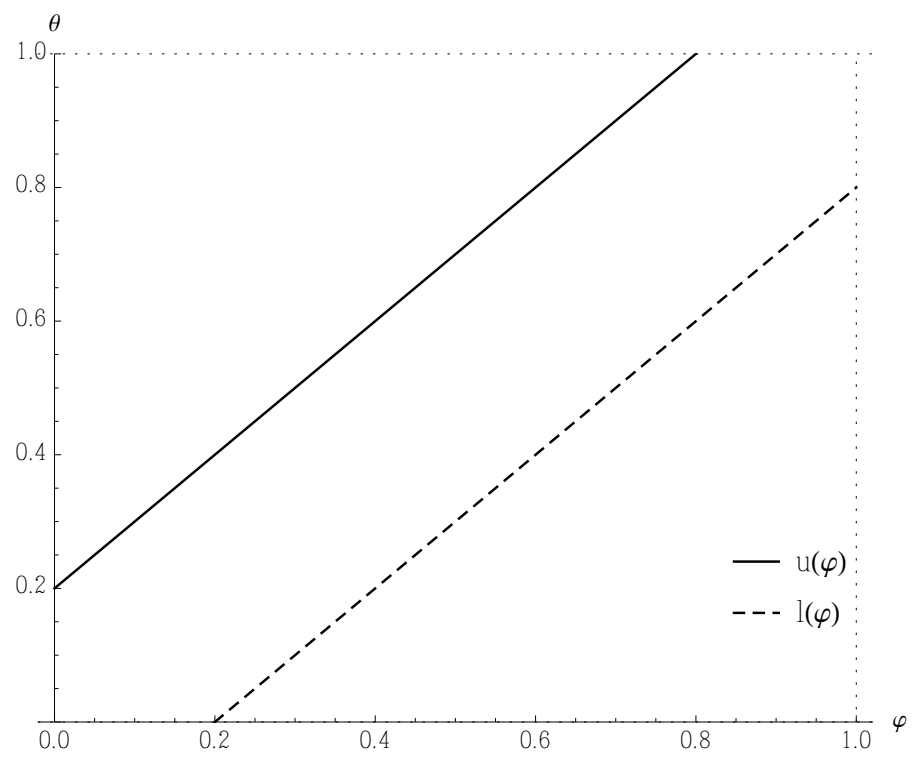

Figure 1: Acceptance set $\alpha=1, c=0.01$

boundaries of set $A(\varphi)$ are shown by Eeckhout \& Kircher (2011) to be monotonically increasing in $\varphi$, which proves that positive assortative matching holds in the presence of constant search costs. ${ }^{5}$ Let us define $u(\varphi)$ and $l(\varphi)$, respectively, the highest and the lowest worker type that matches with firm type $\varphi$. Figure 1 illustrates the acceptance set for $\alpha=1$ and $c=0.01$.

\subsubsection{Exporting and the Width of the Acceptance Set}

We now investigate whether exporting (or more productive) firms tolerate higher or lower variation in the set of workers they match with. We adopt the matching range of firm type $\varphi, d(\varphi)$, as a measure of the dispersion of workers types tolerated by the firm. The matching range $d(\varphi)$ is defined as the difference between $u(\varphi)$ and $l(\varphi)$. At this point it is important to discuss whether the absolute measure $d(\varphi)$ is an appropriate measure by which we can compare dispersion of worker types within firms that exhibit differences also in the average type of worker hired. Let us take for example the parametrization in figure 1 and consider two firms. Firm $\varphi_{H}$ hires on average very high worker types and firm $\varphi_{L}$ hires on average very low worker types. Figure 1 implies that we

\footnotetext{
${ }^{5}$ Positive assortative matching requires stronger restrictions on the production function if search costs are due to output loss as in Shimer \& Smith (2000).
} 
should observe the same $d(\varphi)$ for both firms, but we would probably not conclude that the two firms tolerate the same degree of worker variation. This is because, in relative terms, firm $\varphi_{H}$ tolerates less variation relative to the average worker hired than firm $\varphi_{L}$. Hence we argue that the correct way to analyse the matching range is to adopt scale-free dispersion measures and we propose two alternatives:

(i) a normalized matching range $d_{1}(\varphi)$ where we divide the matching range by the average worker type hired by firm $\varphi$, i.e. $a(\varphi)$. Define $d_{1}(\varphi)=u_{1}(\varphi)-l_{1}(\varphi)$ where $u_{1}(\varphi)=\frac{u(\varphi)}{a(\varphi)}$ and $l_{1}(\varphi)=\frac{l(\varphi)}{a(\varphi)}$

(ii) a logarithmic matching range $d_{2}(\ln \varphi)$ i.e. a measure defined on a logarithmic scale so that dispersion is defined in relative revenue deviations. Define $d_{2}(\ln \varphi)=u_{2}(\varphi)-l_{2}(\varphi)$ where $u_{2}(\varphi)=\ln u(\varphi)$ and $l_{2}(\varphi)=\ln l(\varphi)$.

The following proposition establishes the main result regarding variability of worker types at more productive firms and exporters.

Proposition 1 Dispersion of worker types working at firm $\varphi$, as measured by

(i) normalized matching range $d_{1}(\varphi)$ and

(ii) logarithmic matching range $d_{2}(\ln \varphi)$

is decreasing in firm type (and is therefore lower for exporting firms relative to non-exporting firms of identical initial productivity).

Proof. (i) It is immediate to show that $u_{1}(\varphi)=\frac{\left(\varphi^{\alpha}+2 \sqrt{c}\right)^{\frac{1}{\alpha}}}{\varphi}=\left(1+\frac{2 \sqrt{c}}{\varphi^{\alpha}}\right)^{\frac{1}{\alpha}}$ is a decreasing function of $\varphi$. Similarly one can show that $l_{1}(\varphi)$ is an increasing function of $\varphi$. Therefore the difference between $u_{1}(\varphi)$ and $l_{1}(\varphi)$ is decreasing.

(ii) In order to prove that $d_{2}(\ln \varphi)$ is decreasing, we are going to show that $\frac{d u_{2}(\varphi)}{d \ln \varphi}<1$ and that $\frac{d l_{2}(\varphi)}{d \ln \varphi}>1$. Starting from $u(\varphi)=\left(\varphi^{\alpha}+2 \sqrt{c}\right)^{\frac{1}{\alpha}}$ it is immediate to show that $u_{2}(\varphi)=$ 
$\frac{1}{\alpha} \ln \left(e^{\alpha \ln \varphi}+2 \sqrt{c}\right)$ and that $\frac{d u_{2}(\varphi)}{d \ln \varphi}=\frac{e^{\alpha \ln \varphi}}{e^{\alpha \ln \varphi}+2 \sqrt{c}}$ which is always smaller than one. Similar steps imply that $\frac{d l_{2}(\varphi)}{d \ln \varphi}>1$.

In Appendix section A.1.1 we show that this proposition holds more in general as long as the production function is increasing, symmetric, homogeneous and supermodular. Figure 2 presents the two normalized measures with the same parametrization as figure 1.
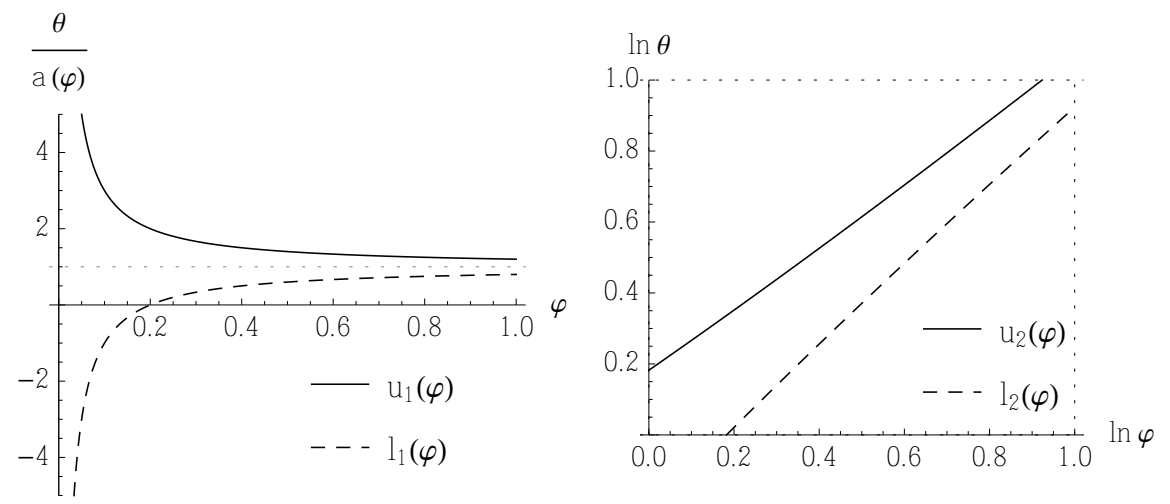

Figure 2: Normalized matching range $\alpha=1, c=0.01$

The result in proposition 1 is easy to explain once we express the surplus condition (5) in terms of normalized worker types. Let us define $\widehat{\theta}=\frac{\theta}{a(\varphi)}=\frac{\theta}{\varphi}$, the type of a worker, relative to the average type employed by a firm $\varphi$. Condition (5) can be rewritten as a function of $\widehat{\theta}$ as follows:

$$
\underbrace{\left[\widehat{\theta}^{\alpha}-\frac{1}{2} \widehat{\theta}^{2 \alpha}-\frac{1}{2}\right] \varphi^{2 \alpha}}_{S(\widehat{\theta}, \varphi)}+2 c \geq 0
$$

We analyse the behaviour of the function $S(\widehat{\theta}, \varphi)$ and the search costs in figure 3 . The function $S(\widehat{\theta}, \varphi)$ is maximized at $\widehat{\theta}=1$ and drops as one moves away from this perfect PAM allocation. The important feature for our purpose is that $S(\widehat{\theta}, \varphi)$ drops more steeply on either side of $\widehat{\theta}=1$ when $\varphi$ is higher. This means that the same proportional deviation from the optimal worker produces a larger loss in surplus at larger firms. Higher type firms therefore have a narrower range over which 
$S(\widehat{\theta}, \varphi)>-2 c$ as figure 3 clearly shows.

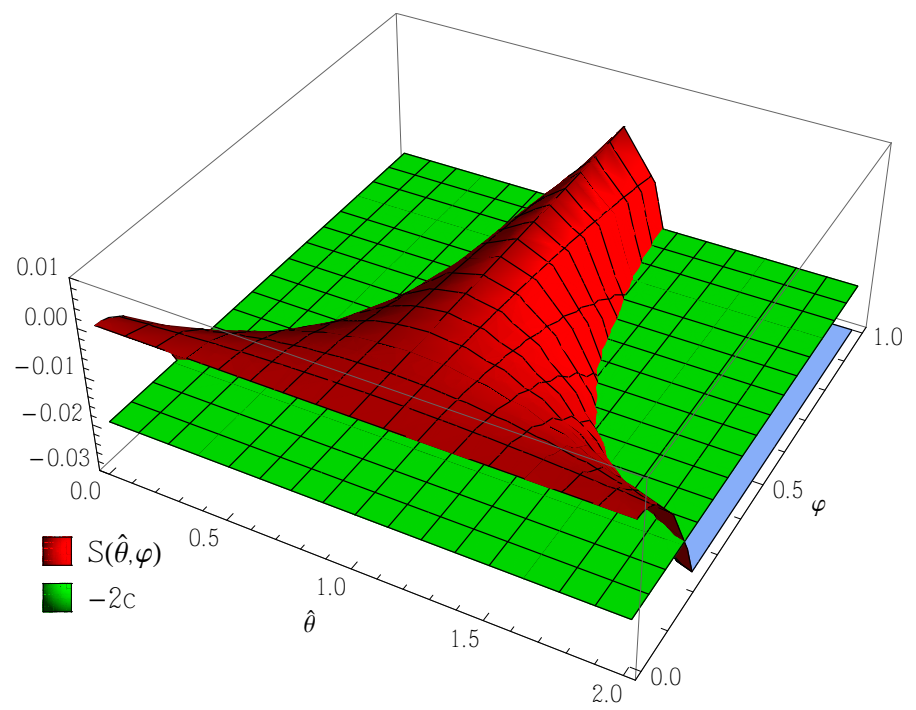

Figure 3: Surplus condition as a function of normalized worker types for $\alpha=1, c=0.01$

\subsubsection{One firm with multiple workers}

The model we have analysed so far entails only one worker. In that context we have said that we can interpret a firm as a collection of hiring decisions that are independent from one another.

One may wonder whether adding more workers to the problem modifies the results. In principle there is a somewhat distinct reason why firms may not want to hire very heterogeneous sets of workers and that is because workers types are complementary to one another, and not just to the firm. Nevertheless, because of complementarity with the firm type this effect is stronger for more productive firms. As a result this effect will strengthen the logic that we have illustrated in the oneworker set-up. Consider for example the case of two workers (each drawn from a distinct uniform productivity distribution): $\theta_{1}$ and $\theta_{2}$ where the production function is $R\left(\varphi, \theta_{1}, \theta_{2}\right)=\left(\varphi \theta_{1} \theta_{2}\right)^{\alpha}$ Assuming, as in this production function, that in case of disagreement the firm cannot produce with only one worker, the surplus condition is very similar to (6) and we can write it in normalized 
terms analogously to (6):

$$
\left[\left(\widehat{\theta}_{1} \widehat{\theta}_{2}\right)^{\alpha}-\frac{1}{3} \widehat{\theta}_{1}^{3 \alpha}-\frac{1}{3} \widehat{\theta}_{2}^{3 \alpha}-\frac{1}{3}\right] \varphi^{3 \alpha}+3 c \geq 0
$$

where $\widehat{\theta}_{i}=\frac{\theta_{i}}{\varphi}$. It is immediate to verify that the same logic applies in this case. Surplus declines faster for more productive firms as they consider worker types that are further away from their ideal. Hence a higher $\varphi$ firm will accept a narrower set of workers than a lower $\varphi$ firm.

In the next section we introduce data and methodology aimed at verifying the empirical content of the results in proposition 1.

\section{$3 \quad$ Empirical analysis}

Our empirical analysis proceeds in two steps. First, following the theory, we construct worker types using the average wage of the worker over her job spells. As a robustness check, we also estimate the worker types employing a methodology pioneered by Abowd et al. (1999) (AKM) and recently enriched by Card et al. (2013). We are careful to separately construct measures of the firm type that are not derived as firm fixed effects, due to considerations on the AKM methodology by EK. In a second step we propose various measures that approximate the matching range of individual firms and show that those measures are systematically different between exporters and non exporters, both in the cross section and when export markets are subject to shocks that affect the profitability of exporting.

Before describing our empirical strategy in details, we offer a brief overview of the features of the wage-setting institutions in France and of the data employed in this paper. 


\subsection{Institutional Background}

It is important to discuss whether the features of the French institutional setting match the assumptions made in the theoretical framework. Our model assumes that wages are the outcome of a bargaining game between firms and workers. This condition is key to the empirical analysis in order for wage outcomes to reflect workers' and firms' characteristics. We argue that the French institutional background provides a good approximation of this feature.

Since 1950, wage-setting institutions in France are organized according to a hierarchical principle. Wages are bargained at three different levels: (i) at the national level, a binding minimum wage (called Salaire Minimum Interprofessionnel de Croissance, or SMIC hereafter) is set by the government; ${ }^{6}$ (ii) at the industry level, employers' organisations and unions negotiate pay scales; wages are, then, negotiated occupation by occupation; (iii) at the firm level, employers and unions usually negotiate wage increases.

Typically, in the 1970's and 1980's collective agreements were negotiated within different sectors between unions and employer associations, then extended by the Ministry of Labour to the entire industry, becoming binding also for workers and firms not part of the original negotiation. At the end of the 1980s, more than $95 \%$ of the workforce was covered by those collective agreements. However, different laws have strengthened the decentralization of the wage bargaining process in France over the last thirty years. Three channels have been used to promote firm-level agreements: (i) the obligation for firms to negotiate on wages each year, (ii) more possibilities offered to firms to deviate from industry-level agreements (escape clauses), and (iii) fiscal incentives. ${ }^{7}$ In 1982 , the Auroux Law introduced the duty for firms with at least 50 employees and an elected union representative to negotiate wages with unions every year, although not the obligation to reach an

\footnotetext{
${ }^{6}$ Until 2010, the SMIC was raised each year in July according to a legal formula based on partial indexation to past inflation and to past wage growth.

${ }^{7}$ In 2008 , reduction of social security contributions paid by the employers became conditional upon wage negotiations occurring within the firm.
} 
agreement. Subsequent legislations concerning the working time reduction (Robien's laws in 1996, the first Aubry's law in 1998, the second Aubry's law in 2000) allowed the application of escape clauses to working hours' arrangements, reinforcing the trend towards decentralization.

Since the 1980s, firm-level negotiations acquired progressively more importance. By 2005, 41\% of the workers employed in private firms with more than 10 employees were covered by a wage agreement signed that very same year (Naboulet \& Carlier, 2007). ${ }^{8}$.

\subsection{Data}

The data for our project come from three main sources, the Déclaration Annuelle des Données Sociales (DADS), the Enquete Annuelle d'Entreprises (EAE) and the French Customs Data. ${ }^{9}$

DADS is an administrative database of matched employer-employee information collected by the INSEE (Institut Nationale de la Statistique et des Etudes Economique). The data are based on the mandatory reports, filed by employers, of the gross earnings of each employee in compliance with French payroll taxes. All wage-paying individuals and legal entities established in France are required to file payroll declarations; only individuals employing civil servants are excluded from filing such declarations. The INSEE prepares extracts of the original database for research purposes. We rely on the panel version of DADS, which covers all individuals employed in French enterprises born in the month of October of even-numbered years until 2001 and every year after that. ${ }^{10}$ This choice is motivated by the need to follow workers across years and job positions in order to recover their type (see 3.3).

Our extract stretches from 1995 to 2007. The initial data set contains around 24 million observations (corresponding to the triplet worker-firm-year) which are identified by worker and

\footnotetext{
${ }^{8}$ In 1992, 40\% of the workforce was covered by some firm-level agreement. Source: Abowd et al. (2005); authors' calculation based on data from wage structure survey in 1992.

${ }^{9}$ These data are subject to statistical secrecy and have been accessed at CEPII

${ }^{10}$ In 2002, the sampling methodology has been extended to include all individuals born in the month of October of every year. Currently, the DADS panel represents $1 / 12$ th of the total French workforce.
} 
firm ID (respectively, nninouv and siren).

For each observation we have information on the individual's gender, year and place of birth, occupation (both 2-digit CS and 4-digit PCS-ESE classification), job spell, ${ }^{11}$ full-time/part-time status, annualized real earnings, total number of hours worked as well as the industry of the employing firm (NAF700, 4-digit industry classification). We restrict our sample to full-time employees in manufacturing (NAF 10-33), reducing the total number of observations to 2,662,411. Most full-time workers are employed at a single firm during the year. Only $6 \%$ has more than one employer in a given year; for those, we selected the enterprise at which the individual worked the largest number of days during the year. Finally, to control for possible outliers, we remove those observations whose log annualized real earnings are more than 5 standard deviation away from the predicted wage, based on a linear model including gender, an ile-de-France dummy and in-firm experience. We obtain a final sample of $2,579,414$.

Following EK, we have to find an alternative proxy for the type of the firm to the standard estimated firm fixed effects. So we enrich the available set of firm-level variables by merging DADS with EAE, a survey-based dataset containing balance-sheet information on French firms in manufacturing over the period 1995-2007. The unit of observation in EAE is a firm-year combination; the firm identifier is the same as the firm ID in DADS (siren). EAE samples only medium-large enterprises with at least 20 employees. From EAE we collect information on sales (domestic and exports), total employment, value added and also on the main sector of the firm (NAF700 4-digit classification). ${ }^{12}$ The merge with EAE further reduces the sample availability. We restrict our sample to individuals working for firms whose characteristics are available from EAE. Furthermore, we remove those firms whose number of sampled employees from DADS is larger than the effective

\footnotetext{
${ }^{11}$ DADS records both the job start date and the number of days the individual worked in a given firm during the calendar year.

${ }^{12}$ We compare the firm's industry classification between EAE and DADS and keep only those observations whose industry information coincides between the two sources.
} 
employment reported in EAE. This provides us a final sample of 1,673,992 observations on which we implement our empirical strategy.

Export-related information on French firms come from the French Customs. The customs data includes export records at the firm-product-destination level for the universe of exporters located in France.

Finally, aggregated trade flows and applied tariff levels come from standard sources, respectively COMTRADE and WITS. Aggregated trade flows are used to compute aggregated market shocks as (weighted) import demand by all potential French trade partners, while applied tariff levels are used as a second proxy for foreign market openness - average tariff reduction (across all French trade partners) representing a measure of higher market access for French firms.

\subsection{Constructing worker types}

We propose two strategies to construct worker types.

\section{Worker type proxy: Average Lifetime Wage}

Our preferred methodology follows the model and uses the average wage of the worker over her job spells - hereafter, average lifetime wage- to proxy for the worker type. In fact, the average lifetime wage is monotonically related to the worker type $\theta$ : a more productive worker makes larger contributions to revenues and expects to match with a better firm in the frictionless equilibrium,

obtaining, on average, a higher wage. From the model, the average lifetime wage of a worker of type $\theta$ takes the following expression

$$
\bar{w}(\theta)=\frac{\int_{\left(\theta^{\alpha}-2 \sqrt{c}\right)^{1 / \alpha}}^{\left(\theta^{\alpha}+2 \sqrt{c}\right)^{1 / \alpha}}\left[\frac{\theta^{2 \alpha}}{4}+\frac{\theta^{\alpha} y^{\alpha}}{2}-\frac{y^{2 \alpha}}{4}\right] \mathrm{d} y}{\left(\theta^{\alpha}+2 \sqrt{c}\right)^{1 / \alpha}-\left(\theta^{\alpha}-2 \sqrt{c}\right)^{1 / \alpha}}
$$


In appendix section A.2 we formally show that the average lifetime wage is increasing in the worker type $\theta$. However, the expression for the average lifetime wage (8) also captures the measure of the matching set and the average productivity of the firms within the matching set of a worker of ability $\theta$. To remove the effect of the average firm productivity, we construct worker types employing a second strategy, the AKM methodology.

\section{Worker type proxy: Worker Fixed Effects}

This methodology aims at decomposing individual workers' wages into a firm component and a worker component. ${ }^{13}$ The basic specification relates a measure of log compensation for worker $i$ employed in firm $j$ at time $t$ to workers and firms' effects:

$$
\ln w_{i t}=x_{i t}^{\prime} \beta+\theta_{i}+\psi_{J(i, t)}+\varepsilon_{i t}
$$

where $\theta_{i}$ is worker $i$ 's component and $\psi_{J(i, t)}$ is the firm component. The function $J(i, t)=j$ identifies the firm employing worker $i$ at time $t$. The vector $x_{i t}$ includes time-varying worker characteristics, therefore the component $\theta_{i}$ captures persistent differences in compensation explained by ability and other time-invariant worker characteristics. We assume that the error term $\varepsilon_{i t}$ is i.i.d. across time and workers with mean zero. This assumption requires that employment mobility is exogenous, depending only on observable characteristics, person and firm effects. More precisely, the fixed effects estimator conditions on the whole sequence of establishments at which each worker is observed; this implies that the exogenous mobility assumption is not violated in presence of systematic mobility patterns driven by the person effect $\theta_{i}$ and/or the sequence of firm effects $\left(\psi_{J(i, t)}, \psi_{J(i, t+1)}, \ldots, \psi_{J(i, T)}\right)$. The assumption is, instead, violated if mobility depends, for

\footnotetext{
${ }^{13}$ The AKM methodology has seen a very large number of applications, e.g. Abowd et al. (2003), Abowd et al. (2005), Abowd et al. (2006) Abowd et al. (2007), Abowd et al. (2008), Abowd et al. (2009), Abowd et al. (2009), Carneiro et al. (2012) Torres et al. (2012).
} 
example, on match-specific components of wages. ${ }^{14}$

We follow AKM for the explicit specification of (9). Our dependent variable is the log of annualized real wages. ${ }^{15}$ We include as time-varying controls a quartic in employer-specific experience, ${ }^{16}$ time-dummies, a dummy for workers residing in Ile-de-France and time-varying gender effects (exactly, the interactions of sex with all the other variables).

The panel version of DADS does not contain information on education. AKM obtain information on the highest degree attained from the permanent demographic sample (Echantillon Démographique Permanent, EDP). However, this information would be available, in our case, only for about $20 \%$ of the workers in our sample. Thus, we decided not to include a control for schooling in our decomposition. ${ }^{17}$

As described in Abowd et al. (2002), fixed effects for workers and firms can be separately identified only for sets of firms and workers that are 'connected' by moving workers. In fact, the person effect is common to all of the individual's job spells; its identification requires observing the individual at different employers. Similarly, a firm effect is common to all employees of the firm; identifying the firm effect requires observations on multiple employees of the firm. Identifying both effects requires mobility of workers across firms. ${ }^{18}$ The movement of workers between firms characterizes a connected group. A connected group is defined by all workers who ever worked for any firm in the group and all firms whose workforce is included in the group. A second group is

\footnotetext{
${ }^{14}$ The results estimated under the assumption that the error term $\varepsilon_{i t}$ includes a match effect $\eta_{i J(i, t)}$ and an idiosyncratic term as in Card et al. (2013) and Woodcock (2008) are qualitatively similar to those in Tables 3 and 4.

${ }^{15}$ Working hours are often not reported. The restriction to full-time workers absorbs possible differences in hours worked across individuals.

${ }^{16}$ DADS contains information on the job starting date at a certain firm - we compute the employer-specific experience as a difference between the current year and the first year of employment at the firm.

${ }^{17}$ In addition, most of the effect of schooling would be absorbed by the person effect. AKM mention that schooling does not time-vary over their sample.

${ }^{18}$ Let us consider a simple example of how to implement the AKM methodology. Consider a connected group with 2 firms and $\mathrm{N}$ workers and suppose that at least one worker, individual 1, is employed in both firms over the sample period. The observed wage differential for individual 1 is entirely attributed to the difference between firms fixed effects. Normalizing the mean firm effect to zero, it is possible to identify one of the fixed effects. A similar argument applies to the identification of the person effect.
} 
unconnected to the first if no firm in the first group has ever employed any worker from the second group and no firm in the second has ever employed workers from the first. Within each group, we normalize the mean of the fixed effects to zero, therefore it is not possible to identify 1 individual and 1 firm effects per group.

Due to the normalization, comparing fixed effects between groups has no real meaning. Therefore, when comparing workers and firms, we only employ estimated fixed effects from the largest connected group, which represents $88 \%$ of the workers in our final sample.

The estimation of the fixed effects is performed using the Gauss-Seidel algorithm, proposed by Guimaraes \& Portugal (2010). Such algorithm consists in solving the partitioned set of normal equations, associated to (9), given an initial guess on the coefficients. Workers' and firms' fixed effects are recovered as coefficients on the dummy variables identifying the worker and the firm at which the worker is employed. According to Smyth (1996), the Gauss-Seidel algorithm achieves a stable, but slow convergence, depending on the correlation between the parameter estimators. This implementation has the advantage of not requiring an explicit calculation of inverse matrices to determine the vector of coefficients nor forces us to drop small firms, due to the large number of firm effects to estimate. ${ }^{19}$

We recover estimates for the fixed effects for 406404 individuals and 31649 firms. In the appendix, we include the distribution of the worker fixed effects (Figure A5) and firm fixed effects (figure A6) for the largest connected group.

With estimates of worker types at hand, we now proceed to construct measures of the average worker type and dispersion of worker type at the firm level. Specifically, we construct the variables

\footnotetext{
${ }^{19}$ The number of firms' fixed effect is too large for e.g. the felsdv estimator. In such case, Andrews et al. (2006) suggest pooling small plants into a single superplant. However, we prefer not to implement a similar strategy, as, in our case, firms - not plants - are the units of observation.
} 
AvWorkerType $_{j t}$, SdWorkerType $_{j t}$ and IQR WorkerType SW: $_{j t}$ as:

$$
\begin{aligned}
\text { Av }_{\text {WorkerType }} t & =\frac{1}{n_{j t}} \sum_{i \in I_{j t}} \bar{w}_{i} \\
\text { SdWorkerType }_{j t} & =\frac{1}{n_{j t}} \sqrt{\sum_{i \in I_{j t}}\left(\bar{w}_{i}-\text { AvWorkerType }_{j t}\right)^{2}} \\
\text { IQR WorkerType }_{j t} & =\bar{w}^{j, 75 t h}-\bar{w}^{j, 25 t h}
\end{aligned}
$$

where $I_{j t}$ is the set of workers employed by firm $j$ at time $t, \bar{w}^{j, 75 t h}$ and $\bar{w}^{j, 25 t h}$ are the types of the workers at the 75 th and 25 th percentile of firm $j$ 's employee type distribution.

We build these measures only for firms with more than 5 sampled workers. The choice of the threshold is a compromise between retaining a sample of satisfactory size and constructing sample measures that approximate the true underlying measures. On the one hand, a larger threshold forces us to cut a larger percentage of the sample. On the other hand, a larger number of sampled workers reduces the noise in the estimation of a firm's matching set. We consider each employment relation to be a realization of a match along the set of acceptable matches within a firm's matching set. In the limit, increasing the number of match realizations, the constructed statistics of worker types converges to the true measure. Choosing a higher threshold does not affect the results. If including firms with less than 5 sampled workers, instead, the coefficients on our variables of interest are of the correct sign but in some specifications are not significant. ${ }^{20}$

\subsection{Firm types}

For the purpose of comparing matching choices of exporting and non-exporting firms, we need to control for the type of the firm. EK show that the relationship between true firm type and firm fixed effects estimated from a AKM-style wage regression is theoretically ambiguous, i.e. it can be

\footnotetext{
${ }^{20}$ In the appendix, we report the results from GLS regressions including also firms with less than 5 workers, weighting by the number of workers. See Tables A7-A10.
} 
positive, negative or zero. ${ }^{21} \mathrm{EK}$ also argue that the ideal firm component is a measure of firm type that is specific to every job within the firm, but measurable variables such as output and profits are obviously only observed at the aggregate firm level, not for each relationship within the firm. We therefore adopt three proxies for firm type to investigate the behaviour of firms fixed effects $\psi$ : value added per worker of firm $j, V A p w_{j}$, the logarithm of total employment in firm $j, \log E m p_{j}$ and share in the domestic market DomShare $_{j}$, defined as the ratio of firm $j$ 's domestic sales to total domestic sales in the firm's sector (each firm is classified as belonging to only one sector in each year). ${ }^{22}$ While the first two proxies are standard measures of the productivity or demand intensity for a firm product, the third is motivated by Eaton et al. (2011). In particular, while the first two proxies contain a measure of success over all markets, including the foreign ones, the third variable better captures the success of the firm with respect to the domestic market, before the choice of exporting. We average each proxy over the years the firm appears in the sample to smooth out the effect of changes in the workforce. ${ }^{23}$

We first confirm the hypothesis put forward by EK regarding the ability of the AKM firm fixed effects to capture the firm type. Table 1 shows the pairwise correlation between the AKM firm fixed effect, the three proxies for firm type and the average worker type at firm $j$ as measured by the average AKM worker fixed effect, AvWorkerType ${ }_{j}$ over the sample period at firm $j$. The first striking fact is the negative and large correlation $(-0.80)$ between average worker type and the AKM firm fixed effects $\psi$, confirming previous findings by Abowd et al. (2004). If instead we employ the three proxies for firm type, we observe for each of them a positive and significant

\footnotetext{
${ }^{21}$ In a recent contribution Hagedorn et al. (2012) show how to complement wage data with labour market transitions to identify the pattern of sorting.

${ }^{22}$ We consider sectors at the 4-digit level for the constructions of market shares.

${ }^{23}$ Our model confirms the positive correlation between productivity, value added per worker and domestic market share. According to our theory, more productive firms tend to match with better workers, realizing on average larger revenues. Therefore, firms of higher productivity should display larger value added per worker and a larger share in the domestic market. The model is silent about employment differences due to variations in productivity, since we focus on one firm-one worker matching. If we introduce homogeneous labour in the production function, the model will also address the implication that more productive firms hire a larger workforce.
} 
correlation with the average worker type, proxied either with the average lifetime wage or the average of the worker fixed effects. The three firm type proxies are in turn all positively correlated with one another, but display small and sometimes opposite correlations with the AKM fixed effect $\psi$. In particular Dom Share $_{j}$ and $V A p w_{j}$ have a positive correlation of 0.01 and of 0.001 with $\psi$, respectively, while and $\log E m p_{j}$ displays a negative correlation of -0.01 .

Table 2 shows that this correlation pattern is not unique to a few sectors. In column 4 we report the correlation between AvWorkerType ${ }_{j}$ and $\psi_{j}$ by two-digit sector, while column 6 displays the analogous correlation between Dom Share ${ }_{j}$ and AvWorkerType ${ }_{j}$. While the first set of correlations is always negative and significant, the second set of correlations is positive and significant, except in one case where the correlation is positive, but not significant. The evidence presented in tables 1 and 2 is consistent with the hypothesis put forward by EK, that the AKM firm fixed effect may not be correlated with the true firm type, although it is still possible that, as in Abowd et al. (2004), there is truly negative assortative matching between workers and firms or that the negative result is purely due to statistical bias arising from the short nature of the panel.

\subsection{Empirical Specification 1: Export Status and Acceptance Set}

We now proceed to illustrate the specifications employed to describe the different matching behaviour of exporting and non-exporting firms. The first implication of our model is that exporting firms hire workers of higher average type. This is a similar prediction to the models of Sampson (2012) and, under the interpretation of permanent worker heterogeneity, Helpman et al. (2010). We believe this is a novel method of corroborating such prediction since it shows directly that an exporter pays higher wages because it employs better workers, not because it shares higher revenues with the same type of workers. The former is the mechanism involved in explaining the exporter wage premium in Helpman et al. (2010), but we believe it has not been tested before. 
In a pooled cross-section of firms over the sample period, the basic specification we employ is the following:

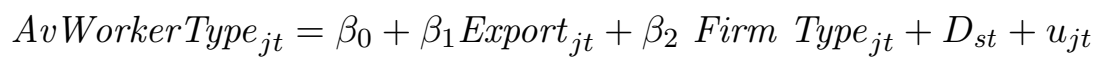

where Export $_{j t}=1$ if firm $j$ exports at time $t$ and Firm Type $_{j t}$ is one or all of the three proxies for firm productivity, $V A p w_{j}, \log E_{m} p_{j}$ and DomShare $_{j}$.

Differences in average worker type between exporters and non-exporters also reflect differences in the occupational structure. If, for example, exporters employ workers in occupations with higher average wage, they might also have higher average type, since the person effect contains all timeinvariant characteristics, like occupation, that rarely change over time for a given worker. ${ }^{24}$ We add the number of occupation, N.occ $j$ and the share of white collar workers, ${ }^{25}$ whiteshare, to specification (10). Similarly, the number of exported products, log Products, which we include in the specification with all controls, is intended to capture structural differences in occupational complexity that might cause a spurious correlation of the exporting status with the average worker type.

In addition, all specifications except the first include a quadratic in the number of sampled workers to control for the precision of our left-hand side estimates. ${ }^{26}$ Finally, all specifications include sector-year dummies, $D_{s t}$.

The novel contribution of this paper is the prediction that exporters match with workers that are characterized by lower relative dispersion of ability. The specification that we employ is the

\footnotetext{
${ }^{24}$ Around $80 \%$ of the workers in the sample do not switch occupation during the time period analysed.

${ }^{25}$ The blue vs white collar classification is based on occupational codes. We report the classification we adopt in Table A2.

${ }^{26}$ In unreported results we simulated the model and verified that differences in the number of observations available for exporters and non-exporters do produce differential biases that can justify the quantitative estimates we obtain. In order words exporting firms do not have a large enough number of observations to mechanically reduce the standard deviation of worker types by the amount we observe.
} 
following:

$$
\text { SdWorkerType }_{j t}=\beta_{0}^{\prime}+\beta_{1}^{\prime} \text { Export }_{j t}+\beta_{2}^{\prime} \text { Firm Type }_{j t}+D_{s t}+u_{j t}^{\prime} \text {. }
$$

The theoretical section shows that the only robust prediction regarding the link between worker type dispersion and export status (and productivity) requires expressing such dispersion either in percentage terms or relative to the average worker type. In this regard, it is essential to remember that the fixed effects are estimated from a log-linearized equation, where types are therefore already expressed in percentage differences from one another. Nevertheless we will add the average worker type in the specification with all controls. ${ }^{27}$

Similarly to specification (10), we include the number of occupations, $N . o c c_{j t}$, the share of white collar workers, white share and the number of exported products, log Products, to control for differences in the occupational structure across firms with different export status. All specifications include sector-year dummies, $D_{s t}$.

Both specifications (10) and (11) are estimated by OLS and standard errors are clustered at the level of the firm.

We develop an alternative strategy to test the prediction that exporters select a set of workers characterized by a lower dispersion. We compare the rank correlation between the average worker type by firm and the firm type among exporters to the rank correlation between the average worker type and firm types among non-exporters. In fact, the rank correlation captures the strength of sorting patterns. A lower dispersion among exporters implies better sorting and should be associated with a larger correlation. We construct the rank correlation separately for exporters and for nonexporters for each sector-year and we test the existence of systematic differences in the correlation according to export status, employing the following specification:

\footnotetext{
${ }^{27}$ All results are very similar if we adopt the coefficient of variation of worker type as our dependent variable.
} 


$$
\operatorname{Corr}\left(\text { AvWorkerType }_{j t}, \text { DomShare }_{j t}\right)_{s t}=\beta_{0}^{\prime \prime}+\beta_{1}^{\prime \prime} \text { Export }_{s t}+D_{s}+D_{t}+u_{s t}^{\prime \prime} \text {. }
$$

where Export $_{s t}=1$ if the correlation is constructed for the set of exporting firms in sector $s$ at time $t$. In addition to sector and time dummies, we also include the average (log) employment and the average domestic market share of firms in the same sector-year-export status cell, because those characteristics might differentially affect the matching patterns and be correlated with export status.

\section{Results}

The estimation results relative to specifications (10) and (11) are presented in Tables 3 and 4. Column 1 of Table 3 reports a positive and statistically significant relationship between export status and the average type of the worker employed by the firm. The positive relationship is of similar strength when we introduce in turn the three controls for firm type (domestic share, value added per worker and employment).

As predicted by theory, the coefficient on all three proxies for firm type is positive and significant, like the one on export status. In the specification reported in column 4 we include the three controls for firm type in the same regression, and the coefficient on export (the one of our interest) remains positive and significant, like the ones on value added per worker and employment.

Table 4 reports the results of the estimation of specification (11) and has a similar structure to Table 3. Starting from column 1 where no controls are added, we document the expected negative and significant relationship between export status and variability of worker type. The effect persists with a similar magnitude when we control for the above mentioned firm type controls (domestic share, employment and value added per worker). The inclusion of all the control variables in column (6) does not alter the negative and significant coefficient on the export dummy. As predicted by 
theory, the coefficient on two proxies for firm type is negative (columns 2 and 3), but the table also documents a positive and significant correlation between value added per worker and the dispersion of worker type (column $4-6$ ) a pattern that is not in line with the predictions of the model.

It is important to quantify the effect at the core of this paper. Based on our preferred specification, column 6 of Table 4, where we include all controls, the expected difference on the dispersion of worker type between exporter and non-exporter firms is about 0.037 points (holding the other variables constant). Considering that the dependent variable has a standard deviation of 0.41 , an exporter features worker variability that is lower by $9 \%$ standard deviations. The effect on the mean worker type can be calculated using the results from Table 3 and is of the same order of magnitude, but slightly smaller: an exporting firm displays an average worker type that is $3.9 \%$ standard deviations higher. ${ }^{28}$

In Tables A5 and A6, we report the result separately for the sample of newly hired workers and for the stayers. Intuitively, the export dummy is negative and significant only when we consider the newly hired sample, as reported in Table A5. This is a reasonable result given that firing costs and other labour market protection measures plausibly make the firing margin less flexible than the hiring one.

Tables 5 and 6 report estimates for the same specifications as in tables 3 and 4, but employ a different proxy for the worker type, i.e. worker fixed effect from the AKM regression. Table 5 reports again a positive relationship between export status and average worker type; the coefficient on export status remains positive but loses its significance when adding controls for firm type and the occupation structure. Table 6 confirms a negative relationship between the dispersion of worker type and export status. Controlling for the type of the firm (by using employment, domestic market share and value added per worker), the coefficient on export is negative and once again we find

\footnotetext{
${ }^{28}$ This magnitude has been computed by using the export coefficient of Table 3 column 6 . The standard deviation of the average worker type is 0.81 .
} 
that firms with higher employment and higher domestic share have tighter worker type dispersion - coherently with the model. But, again, firms with high value added per worker have a wider variation.

\section{Endogeneity of Export Status}

We have not discussed so far the potential endogeneity of export status and the bias resulting from unobserved firm characteristics that may affect the export status and the standard deviation of worker types simultaneously. To address this concern, we develop an instrumental variable strategy. We instrument export status using a firm-level measure of tariff,

$$
\operatorname{Firm}_{\operatorname{Tariff}}^{j t}=\ln \left(1+\frac{1}{\sum_{s r} \tau_{s r t} \frac{\text { Exports }_{j r, t-1}}{\text { Exports }_{j, t-1}}}\right)
$$

where $\tau_{s r t}$ is the tariff faced by firms in sector $s$ exporting to country $r$ at time $t-1$; we aggregate across countries using as weights the share of exports to country $r$ of firm $j$ at time $t$ over the total exports of firm $j$ at time $t-1, \frac{\text { Exports }_{j r, t-1}}{\operatorname{Exports}_{j, t-1}}$. Table 7 reports the second stage results ${ }^{29}$. The coefficient on export status remains negative and significant in all specification. In particular, in our preferred specification, the coefficient is smaller than the coefficient from the OLS regression in Table 4; this is consistent with the idea that more productive firms possess a better technology to search for their workers.

\section{Additional robustness}

Table 8 presents the results for specification (11) with an alternative measure of dispersion, a weighted average of the standard deviation of ability for different groups of workers. In particular, we divide occupations into 'managers', 'executives' (white collar occupations) and 'blue' collar (as

\footnotetext{
${ }^{29}$ The First Stage is reported in Table A13
} 
reported in Table A2) and we construct average employment shares of those occupational groups within firm over time. We then weigh the standard deviation of lifetime wages for each group by its average employment share to construct our new dependent variable. The coefficient on the export dummy remains negative and significant in all specifications; in most columns, the magnitude of the coefficient is not significantly different from what is reported in Table 4 . This suggests that our result is not due to compositional differences between exporters and non-exporters.

Looking at the coefficients on firm's type controls (columns 2, 3 and 4 in Table 8) we discover that employment and domestic market share have the expected sign, i.e. they are negatively related with the standard deviation of workers types. The coefficient on value added per worker is positive and significant only in column 6, suggesting that the 'puzzling' effect discussed above for tables 4 and 6 might be related to changes in employment composition over time.

Table 9 presents a further robustness of the result to the definition of worker type employed as dependent variable. In particular, we employ the interquartile range of worker type at firm $j$, as described earlier. It is easy to verify that all previously described patterns appear again in this table. Exporting firms choose a narrower range of worker types.

Finally, Tables A11 and A12 confirm that differences in dispersions translate into higher rank correlation between average worker types and firm types for exporters compared to non-exporters, controlling for average size differences. Firm and worker types are more tightly correlated among exporters than non-exporters.

\subsection{Empirical specification 2: market access and tariff shocks}

Our first empirical strategy has relied on cross-sectional differences between exporting and nonexporting firms. Plausibly, the export dummy may be capturing the effect of other firms characteristics that are not included in our firm type proxies and that affect the matching behaviour of 
firms.

Our second strategy to detect the impact of exporting on matching between firms and workers aims at addressing this concern. We exploit differences in the opportunities offered by foreign markets, approximated by demand shocks and tariffs across sectors and countries over time. These different shocks, which we indicate as 'market access' should affect exporting firms differentially from non-exporting firms. A positive demand shock in a foreign market or a lower tariff faced by French exporters should induce the exporting firm to select an even less dispersed labor force. The specification that we estimate is the following:

$$
\begin{aligned}
& \text { AvWorkerType }_{j t}= \gamma_{0}+\gamma_{1} \text { Mkt Access }_{s t} \times \text { Export }_{j t}+\gamma_{2} \text { Mkt Access }_{s t} \\
&+\gamma_{3} \text { Export }_{j t}+D_{s t}+v_{j t}, \\
& \text { SdWorkerType }_{j t}= \gamma_{0}^{\prime}+\gamma_{1}^{\prime} \text { Mkt Access } \\
& s t \times \text { Export }_{j t}+\gamma_{2}^{\prime} \text { Mkt Access } \\
& s t \\
&+\gamma_{3}^{\prime} \text { Export }_{j t}+D_{s t}+v_{j t}^{\prime}
\end{aligned}
$$

where

$$
\begin{aligned}
\text { MktAccess }_{\text {st }}= & \sum_{r} \text { MktAccess }_{\text {srt }} \times \frac{\text { French exports }}{\text { sr }, t-1} \\
\text { MktAccesch exports }_{s, t-1} & =\left\{\begin{array}{c}
\text { Tariffs }_{\text {srt }} \\
\text { Imports }_{\text {srt }} \text { or } \\
\text { Imports }_{\text {srt }}
\end{array}\right. \text { or }
\end{aligned}
$$

Imports $_{\text {srt }}$ is the total value of imports by country $r$ from the rest of the world ${ }^{30}$, Tariffs $s_{\text {srt }}$ is the tariff faced by a French firm exporting to country $r$ in sector $s$ at time $t$, and French exports $s_{s r, t-1}$ is the value of exports from France to country $r$ in sector $s$ at time $t-1$ (with total exports in the

\footnotetext{
${ }^{30}$ The inclusion of French exports to country $r$ does not affect the results.
} 
sector in that year indicated as French exports s,$\left.t-1_{1}\right)$. The variable MktAccess $s_{s t}$ measures cost of access or demand size in foreign markets for firms in a given sector $s$, weighted by the importance of French firms in that sector in the previous year. The model predicts that a good export opportunity should result in an increase in the average worker type and further tightening of the acceptance set for an exporting firm, so we expect $\gamma_{1}<0$ and $\gamma_{1}^{\prime}>0$ for the case of MktAccess $_{\text {srt }}=$ Tariffs $_{\text {srt }}$ and the opposite when market access is measured as Imports srt $_{\text {or }} \frac{\text { Imports }_{\text {srt }}}{\text { Tariffs }_{\text {srt }}}$.

\subsubsection{Results}

Table 10 and 11 report estimates of the coefficients in specifications (14) and (15) when market access for a firm in sector $s$ is measured by total demand for imports faced by an exporter in sector $s$ as in equation (16). We do not present results for the case when total import demand is deflated by the tariff faced by French exporters because they are very similar. Table 10 reports results on the average worker type; our coefficient of interest is positive and significant on all specifications. However, if evaluated at the mean of the market access measured by Imports srt an exporter does not feature a higher average worker ability; only exporters in sectors with a degree of openness larger than the average will enjoy an effect on the average worker type.

In Table 11 we find for all specifications that the estimated coefficient $\gamma_{1}^{\prime}$ is negative and significant, so that exporters seem to choose a less dispersed workforce in particular when having better access to foreign markets. The inclusion of firm type controls does not affect the magnitude and significance of this result. The coefficient on export status is negative and significant in all specifications. If evaluated at the mean of the market access measured by Imports $_{\text {srt }}$, an exporter features worker variability that is lower by $3.4 \%$ standard deviations than a non-exporter firm (which is in line with the quantification reported in section 3.5.1).

Tables 12 and 13 report estimates of the coefficients in specifications (14) and (15) when market 
access for a firm in sector $s$ is measured by the average tariff faced by an exporter in sector $s$. Only columns 4-6 of Table 12 report a negative coefficient $\gamma_{1}$ - which is line with the prediction - but not statistically significant.

Table 13 reports very similar results to Table 11: better export market conditions as measured by a lower tariff faced on the export market result in a tighter matching set for exporting firms. So, contrary to Table 12, the effect of export opportunities on standard deviation of worker type seems more robust to the definition of market access. In particular, firms exporting in country-sector with 'mean' market access (mean value equal to $5.58 \%$ in our sample) have a lower worker variability than non-exporters $(13.7 \%$ standard deviation units), with such gap increasing with the market access of the firm.

\section{Welfare implications}

We have so far not discussed the consequences in terms of welfare of the mechanism explored in this paper. Our model predicts that exporting firms tolerate less relative dispersion in worker type, but it does not analyse what happens to exporting and non-exporting firms relative to their autarky matching decisions. In theory the model features two counteracting effects. While newly

exporting firms have stronger incentives to tighten their matching range, non-exporting firms see their revenues decline because of import competition and therefore will see an increase in their normalized matching range. We therefore present our results in two steps. First, we report partial equilibrium results that examine revenue loss as a function of firm productivity and confirm that revenue loss is lower for exporting and more productive firms. Second, we turn to a general equilibrium model where we introduce a second symmetric country and compute overall welfare changes, taking into account variety effects and price changes. 


\subsection{Revenue loss in partial equilibrium}

We start by analysing revenue loss as a function of firm productivity. We choose to present a measure of revenue loss relative to the optimal allocation as in EK. For each firm $\varphi$ and worker $\theta$ we can define a revenue loss relative to the optimum which we also define $L(\varphi, \theta)=\frac{1}{2}\left(\theta^{\alpha}-\varphi^{\alpha}\right)^{2}$. The assumption in creating such a measure is that in the optimal allocation a worker of type $\theta$ would generate a revenue of $\theta^{2 \alpha}$ and is allocated half of that revenue. Holding the type of the firm constant at $\varphi$ we sum the revenue loss, relative to the optimal level, for each possible worker type in the acceptance set. We then divide for the optimal revenue summed across the same range. We obtain the share of revenues lost relative to the optimum for a firm of type $\varphi$ (and the workers in that firm's acceptance range), which we define $R L(\varphi)$ :

$$
R L(\varphi)=\frac{\int_{l(\varphi)}^{u(\varphi)} \frac{1}{2}\left(\theta^{\alpha}-\varphi^{\alpha}\right)^{2} d \theta}{\int_{l(\varphi)}^{u(\varphi)} \frac{1}{2} \theta^{2 \alpha}+\frac{1}{2} \varphi^{2 \alpha} d \theta}
$$

The following proposition shows that such deviations from the optimal revenues are smaller for more productive firms.

Proposition 2 The share of output lost relative to the optimal revenues, $R L(\varphi)$, is decreasing in the type of the firm $\varphi$ :

1. For any $\alpha$, as $c \rightarrow 0$

2. For any $c$ if $\alpha=1$ or $\alpha=2$ or $\alpha=\frac{1}{2}$.

\section{Proof. See Appendix A.3.}

Moreover, we have verified that this result holds for a very wide range or parameters. We have not been able to find instances where proposition 2 does not hold, although a general proof is arduous due to many non-integer exponents in the expressions involved. This proposition is a 
comparison across firm types observed in a given equilibrium, so that for example we can use this proposition to compare revenue losses of an import-competing firm versus an exporting firm of the same original underlying productivity. The exporting firm will feature across all the possible matches in her matching set a lower share of revenues lost because of mismatch. This is a partial equilibrium result that we cannot employ to evaluate the overall welfare impact of trade opening because the two equilibria will feature different type distributions and therefore different shapes of the matching sets. In particular if we want to compare autarky and trade equilibria we can no longer assume that the distribution of types is uniform. If we start with a uniform distribution for firms and workers, only the distribution of worker types will remain unchanged, while the distribution of firms will be affected by the endogenous shock to revenues given by export opportunities and import competition. Once we move away from a uniform distribution and the two distributions of workers and firms are no longer symmetric, the analytical characterization becomes intractable. We therefore resort to a simulation and calibration exercise where we can relax other unrealistic assumptions and that we describe in the next section.

\subsection{Calibration of a general equilibrium model with symmetric countries}

We calibrate the infinite-horizon open-economy version of the model ${ }^{31}$ to match moments of the French Economy. The two main differences from the simple two period model are that: i) successful firms and workers pairs are subject to a exogenous rate of separation $\delta$, and that ii) in each period the probability of meeting a potential match is $\rho$. The parameters to be calibrated are as follows: the elasticity of demand, $\eta$; the curvature of the production function, $\sigma$; the variable trade $\operatorname{cost} \tau$; the distribution of the fixed export costs; the rate at which matches are dissolved, $\delta$; the rate at which matches are created, $\rho$; the search $\operatorname{cost} c$; the worker ability distribution, $g_{\theta}(\theta)$, and the firm

\footnotetext{
${ }^{31}$ See Tito (2014) for details.
} 
productivity distribution, $g_{\psi}(\psi)$. We need to calibrate those parameters for both a domestic and a foreign economy; in what follows, we will assume that the home country and the foreign country share the same characteristics.

In a model with monopolistic competition and CES preferences, the elasticity of demand $\eta$ maps into the trade elasticity, $\varepsilon=\eta-1$. Following the extensive literature on trade elasticity estimates, ${ }^{32}$ we set $\eta=4$, the median value over the range of those estimates.

We calibrate the curvature of the production function to the elasticity of a CES-aggregate of worker types with respect to firm revenues. In our estimation, $\sigma=0.653$.

We use the implied relationship between foreign and domestic shipments at an exporting firm to identify a plausible parametrization of the variable trade cost. From the model, the ratio between the output sold in the domestic market and the exported output depends on the relative market size,

$$
\frac{q_{d d}}{q_{d x}}=\left(\frac{E}{E^{*}}\right)^{1 / \eta} \tau^{\eta-1}
$$

The domestic market size $E$ and the foreign market size $E^{*}$ depend on the set of initial parameters.

However, if the primitives are identical, the domestic and the foreign country have the same size, $E=E^{*}$. Therefore, equation (18) implies $\tau=1.513$.

We normalize $f_{L}=0$ and $f_{H} \rightarrow \infty$; therefore, the fraction of firms $\lambda$ drawing the low fixed export cost corresponds to the fraction of exporters. In our data, $\lambda=0.8 .{ }^{33}$

We set the search cost $c$ to match the average within-firm wage dispersion in the data. This implies $c=0.025$. For the meeting rate and the match dissolution rate, we refer to the estimates from Hairault et al. (2015) for the job finding probability and the separation probability. ${ }^{34}$

\footnotetext{
${ }^{32}$ See Head \& Mayer (2014)

${ }^{33}$ In our dataset, firm-level information is available only for firms with more than 20 employees. This threshold excludes the biggest portion of non-exporting French firms.

${ }^{34}$ Using administrative data on the labour market, Hairault et al. (2015) estimate the job finding probability and the separation probability from 1994 onwards. They find that the average separation probability is $1.7 \%$, while the average job finding probability is $13.5 \%$
} 
Finally, we parametrically estimate the worker ability distribution $g_{\theta}(\theta)$ and the firm productivity distribution $g_{\psi}(\psi)$ using our proxies for agents' types, average lifetime wage for the worker and (the rank of the) domestic market share. We assume that both distributions are Beta with parameters $\left(\alpha_{\theta}, \beta_{\theta}\right)$ for workers and $\left(\alpha_{\psi}, \beta_{\psi}\right)$ for firms. Table 18 summarizes the parameters from the calibration.

Next, we move to the welfare analysis. Our analysis focuses on two welfare proxies: changes in real expenditure and changes in relative deviations from the optimal worker-to-firm assignment, expression (17). We characterize the steady state equilibrium in the model with two symmetric countries under the parametrization from Table 14; we then compare the steady state autarky equilibrium that we derive when setting the share of exporters $\lambda=0$ to the initial equilibrium. In our formulation this is equivalent to a very large increase in the fixed export costs, $f_{L}=f_{H} \rightarrow \infty$. We find that moving to autarky reduces real expenditure by $22 \%$. The change in real expenditure, however, captures 3 effects: the change in the number of available varieties, the change in the worker selection patterns and a price effect. While the first two effects are positively related to welfare, the third effect, instead, acts to reduce welfare after a trade liberalization. This is due to the capacity constraint in our model: the output in a match is fixed and proportional to the agents' types. The demand shock due to the trade liberalization has no impact on the firm's production decision; after trade opening, a firm only reallocates part of its output from the domestic to the foreign market.

The second measure we propose, instead, consists of changes in relative deviations from the optimal worker-to-firm assignment, captures exclusively selection effects. We construct deviations from the optimal worker-to-firm assignment comparing the realized real revenues in the presence of search costs to the real revenues in the frictionless equilibrium; we normalize by the revenues in the frictionless equilibrium. We find that, in an open economy, the losses are $-86.08 \%$ of the 
real revenues under optimal allocation; moving back to autarky implies an increase in the losses to $-87.44 \%$. Therefore, opening to trade is associated with a reduction in the relative deviation from the efficient allocation by $-1.36 \%$.

Further, we look at how our two measures are affected by different levels of search cost $c$ and $\alpha .^{35}$ The results are shown in Tables 15 and 16. The numerical results suggest that gains from trade and frictions are substitutes in our framework. Both changes in real revenues and changes in relative real revenue losses seems to be non-decreasing in the level of search cost, for a given $\alpha$.

\section{Conclusions}

Using linked employer-employee data from France, we show that exporters and non-exporters match with sets of workers that are different. Exporters employ workers of higher average type and lower type dispersion. We rationalize this finding using a model of matching with search frictions where more productive firms and exporting firms match with better workers and tolerate a lower degree of dispersion among the workers employed. We also show numerically that the welfare gains from trade are higher when search costs are higher, which points to a substitutability between trade opening and the lowering of trade frictions. Trade liberalization seems more important when frictions are high and the workers allocation is relatively further away from the optimal. This paper therefore establishes a novel source of gains from trade, where exposure to exports brings the economy closer to the efficient allocation of workers to firms.

\footnotetext{
${ }^{35} \alpha$ collects demand and supply parameters, $\alpha=\sigma \frac{\eta-1}{\eta}$, where $\eta$ is the elasticity of demand and $\sigma$ is the curvature of the production function.
} 


\section{References}

Abowd, J., Haltiwanger, J., \& Lane, J. (2009). Wage structure and labor mobility in the united states. In The Structure of Wages: An International Comparison (pp. 81-100). University of Chicago Press.

Abowd, J., Kramarz, F., Lengermann, P., \& Pérez-Duarte, S. (2004). Are good workers employed by good firms? a test of a simple assortative matching model for france and the united states. Unpublished Manuscript.

Abowd, J., Kramarz, F., Lengermann, P., \& Roux, S. (2005). Persistent inter-industry wage differences: Rent sharing and opportunity costs. In Seminar Paper presented at SFU.

Abowd, J. M., Creecy, R. H., \& Kramarz, F. (2002). Computing person and firm effects using linked longitudinal employer-employee data. Technical report, Center for Economic Studies, US Census Bureau.

Abowd, J. M., Haltiwanger, J., Lane, J., McKinney, K. L., \& Sandusky, K. (2007). Technology and the demand for skill: an analysis of within and between firm differences. Technical report, National Bureau of Economic Research.

Abowd, J. M., Kramarz, F., Lengermann, P., \& Pérez-Duarte, S. (2003). Sorting workers between and within industries. Technical report, mimeo, February 2003, available at http://cep. lse. ac. uk/seminarpapers/28-02-03-KRA1. pdf.

Abowd, J. M., Kramarz, F., \& Margolis, D. N. (1999). High wage workers and high wage firms. Econometrica, 67(2), 251-333.

Abowd, J. M., Kramarz, F., \& Roux, S. (2005). Wages, mobility and firm performance: an analysis using matched employee and employer data from france. Economic Journal. 
Abowd, J. M., Kramarz, F., \& Roux, S. (2006). Wages, mobility and firm performance: Advantages and insights from using matched worker-firm data*. The Economic Journal, 116(512), F245F285.

Abowd, J. M., Kramarz, F., \& Woodcock, S. (2008). Econometric analyses of linked employeremployee data. In The econometrics of panel data (pp. 727-760). Springer.

Abowd, J. M., McKinney, K. L., \& Vilhuber, L. (2009). The link between human capital, mass layoffs, and firm deaths. In producer dynamics: New Evidence from Micro data (pp. 447-472). University of Chicago Press.

Amiti, M. \& Cameron, L. (2012). Trade liberalization and the wage skill premium: Evidence from indonesia. Journal of International Economics, 87(2), 277-287.

Andrews, M., Schank, T., \& Upward, R. (2006). Practical fixed-effects estimation methods for the three-way error-components model. Stata Journal, 6(4), 461.

Atakan, A. E. (2006). Assortative matching with explicit search costs. Econometrica, 74(3), 667680.

Becker, G. S. (1973). A theory of marriage: Part i. The Journal of Political Economy, 813-846.

Bernard, A., Eaton, J., Jensen, J., \& Kortum, S. (2003). Plants and productivity in international trade. The American Economic Review, 93(4), 1268-1290.

Bustos, P. (2012). The impact of trade liberalization on skill upgrading evidence from argentina. Unpublished manuscript.

Card, D., Heining, J., \& Kline, P. (2013). Workplace heterogeneity and the rise of west german wage inequality*. The Quarterly Journal of Economics, 128(3), 967-1015. 
Carneiro, A., Guimarães, P., \& Portugal, P. (2012). Real wages and the business cycle: Accounting for worker, firm, and job title heterogeneity. American Economic Journal: Macroeconomics, $4(2), 133-152$.

Costinot, A. \& Vogel, J. E. (2010). Matching and inequality in the world economy. Journal of Political Economy, 118(4), 747-786.

Davidson, C., Heyman, F., Matusz, S., Sjöholm, F., \& Zhu, S. C. (2012). Globalization and imperfect labor market sorting.

Davidson, C., Matusz, S. J., \& Shevchenko, A. (2008). Globalization and firm level adjustment with imperfect labor markets. Journal of International Economics, 75(2), 295-309.

Davidson, C. \& Sly, N. (2012). Trade and the labor market: Recent developments and new frontiers. In M. Kreinin \& M. G. Plummer (Eds.), Oxford Handbook on International Commercial Policy. Oxford University Press.

Eaton, J., Kortum, S., \& Kramarz, F. (2011). An anatomy of international trade: Evidence from french firms. Econometrica, 79(5), 1453-1498.

Eeckhout, J. \& Kircher, P. (2011). Identifying sortingin theory. The Review of Economic Studies, $78(3), 872-906$.

Feenstra, R. C. \& Hanson, G. H. (1999). The impact of outsourcing and high-technology capital on wages: estimates for the united states, 1979-1990. The Quarterly Journal of Economics, 114(3), 907-940.

Frías, J. A., Kaplan, D. S., \& Verhoogen, E. (2012). Exports and within-plant wage distributions: Evidence from mexico. The American Economic Review, 102(3), 435-440. 
Guimaraes, P. \& Portugal, P. (2010). A simple feasible procedure to fit models with highdimensional fixed effects. Stata Journal, 10(4), 628.

Hagedorn, M., Law, T. H., \& Manovskii, I. (2012). Identifying sorting.

Hairault, J.-O., Le Barbanchon, T., \& Sopraseuth, T. (2015). The cyclicality of the separation and job finding rates in france. European Economic Review, 76(0), 60-84.

Head, K. \& Mayer, T. (2014). Gravity equations: Workhorse, toolkit, and cookbook. Handbook of International Economics, 4, 131.

Helpman, E., Itskhoki, O., \& Redding, S. (2010). Inequality and unemployment in a global economy. Econometrica, 78(4), 1239-1283.

Helpman, E., Itskhoki, O., \& Redding, S. (2013). Trade and inequality: From theory to estimation. Unpublished Manuscript, Harvard University.

Kremer, M. \& Maskin, E. (1996). Wage inequality and segregation by skill. National Bureau of Economic Research.

Krishna, P., Poole, J. P., \& Senses, M. Z. (2014). Wage effects of trade reform with endogenous worker mobility. Journal of International Economics, 93(2), 239-252.

Krugman, P. R. (1979). Increasing returns, monopolistic competition, and international trade. Journal of international Economics, 9(4), 469-479.

Melitz, M. J. (2003). The impact of trade on intra-industry reallocations and aggregate industry productivity. Econometrica, $71(6), 1695-1725$.

Naboulet, A. \& Carlier, A. (2007). principal: Négociations collectives et grèves dans le secteur marchand: en 2005, la moitié des entreprises dau moins 50 salariés a négocié. 
Sampson, T. (2012). Selection into trade and wage inequality. American Economic Journal: Microeconomics, Forthcoming.

Shapley, L. S. \& Shubik, M. (1971). The assignment game i: The core. International Journal of Game Theory, 1(1), 111-130.

Shimer, R. \& Smith, L. (2000). Assortative matching and search. Econometrica, 68(2), 343-369.

Smyth, G. K. (1996). Partitioned algorithms for maximum likelihood and other non-linear estimation. Statistics and Computing, 6(3), 201-216.

Tito, M. D. (2014). Trade and worker sorting under self-selection into exporting. note.

Torres, S., Portugal, P., Addison, J. T., \& Guimarães, P. (2012). The sources of wage variation: a three-way high-dimensional fixed effects model.

Verhoogen, E. A. (2008). Trade, quality upgrading, and wage inequality in the mexican manufacturing sector. The Quarterly Journal of Economics, 123(2), 489-530.

Woodcock, S. D. (2008). Wage differentials in the presence of unobserved worker, firm, and match heterogeneity. Labour Economics, 15(4), 771-793. 
Table 1: Rank Correlation Matrix, proxies for firms' types

\begin{tabular}{l|cccccc} 
& $\psi$ & $\begin{array}{c}\text { Avg. } \\
\text { Type }\end{array}$ & $\begin{array}{c}\text { Avg. } \\
\text { Wage }\end{array}$ & $\begin{array}{c}\text { Avg.Dom. } \\
\text { Share }\end{array}$ & $\begin{array}{c}\text { Avg.VA } \\
\text { per w. }\end{array}$ & $\begin{array}{c}\text { Avg. } \\
\text { Empl. }\end{array}$ \\
\hline$\psi$ & 1 & & & & & \\
Avg. Worker Type by Firm & -0.80 & 1 & & & & \\
Avg. Wage by Firm & 0.13 & 0.35 & 1 & & & \\
Avg. Dom. Share & 0.01 & 0.08 & 0.20 & 1 & & \\
Avg. VA per worker & 0.001 & 0.05 & 0.13 & 0.64 & 1 & \\
Avg. Empl. & -0.01 & 0.06 & 0.12 & 0.78 & 0.72 & 1 \\
\hline
\end{tabular}

$\psi$ : Firms' fixed effects, from the AKM decomposition.

Avg. Wage by Firm: average of the workers' wages over job spells.

Avg. Worker Type by Firm: Average of workers' fixed effects by firm, from the AKM decomposition. Avg. VA per worker: Average value added per worker, normalized by 4-digit industries.

Avg. Dom. Share: Average domestic market share at a 4-digit level.

Avg. Empl.: Average employment, normalized by 4-digit industries.

Notes: Rank correlation between proxies of firms types. We do not report the p-values but all rank correlations are significantly different from zero. 
Table 2: Measuring Sorting Patterns, Manufacturing Sectors

\begin{tabular}{|c|c|c|c|c|c|c|}
\hline NAF & Industry Label & No Firms & $\begin{array}{r}(4) \\
\psi, \\
T ? \\
\rho_{S}{ }^{1}\end{array}$ & $\begin{array}{l}(5) \\
v g \\
p e \\
\text { p- } \text { val }^{2}\end{array}$ & $\begin{array}{l}(6) \\
A v g . \\
A v g . \\
\rho_{S}{ }^{1}\end{array}$ & $\begin{array}{c}(7) \\
\text { hare, } \\
\text { Vage } \\
\text { p-val }\end{array}$ \\
\hline 10 & Food & 9 & -0.96 & 0.00 & - & - \\
\hline 11 & Beverage & 8 & -1 & - & - & - \\
\hline 12 & Tobacco prods & - & - & - & - & - \\
\hline 13 & Textiles & - & - & - & - & - \\
\hline 14 & Clothing & 270 & -0.84 & 0.00 & 0.18 & 0.00 \\
\hline 15 & Leather/shoes & - & - & - & - & - \\
\hline 17 & Paper & 1317 & -0.85 & 0.00 & 0.14 & 0.00 \\
\hline 18 & Printing & 1286 & -0.86 & 0.00 & 0.14 & 0.00 \\
\hline 19 & Refining & 402 & -0.88 & 0.00 & 0.42 & 0.00 \\
\hline 20 & Chemical & 666 & -0.86 & 0.00 & 0.17 & 0.00 \\
\hline 21 & Pharma & 780 & -0.79 & 0.00 & 0.30 & 0.01 \\
\hline 22 & Plastics & 2070 & -0.76 & 0.00 & 0.13 & 0.00 \\
\hline 23 & Non-metallic prods & 59 & -0.64 & 0.00 & 0.13 & 0.33 \\
\hline 24 & Metalworking & 1565 & -0.72 & 0.00 & 0.33 & 0.00 \\
\hline 25 & Metal prods & 1987 & -0.83 & 0.00 & 0.25 & 0.00 \\
\hline 26 & Info/elec/opt & 947 & -0.82 & 0.00 & 0.27 & 0.00 \\
\hline 27 & Elec equip & 595 & -0.84 & 0.00 & 0.14 & 0.00 \\
\hline 28 & Machinery & 5433 & -0.81 & 0.00 & 0.21 & 0.00 \\
\hline 29 & Automotive & 2898 & -0.82 & 0.00 & 0.28 & 0.00 \\
\hline 30 & Other trans equip & 126 & -0.74 & 0.00 & 0.16 & 0.07 \\
\hline 31 & Furniture & 969 & -0.81 & 0.00 & 0.25 & 0.00 \\
\hline 32 & Other mfg & 878 & -0.71 & 0.00 & 0.13 & 0.00 \\
\hline \multirow[t]{2}{*}{33} & Repairs & 1197 & -0.79 & 0.00 & 0.23 & 0.00 \\
\hline & Manufacturing & 23388 & -0.80 & 0.00 & 0.20 & 0.00 \\
\hline
\end{tabular}

${ }^{1}$ Spearman correlation coefficient.

2 p-value from testing independence between the variables.

Notes: Columns (4)-(5): Rank correlation and significance level between the average worker type, (Avg.Worker), and the firm fixed effect $(\psi)$ from an AKM decomposition including a quartic polynomial in experience, a dummy for workers residing in Ile-de-France, time dummies and all the interactions with the gender dummy.

Columns (6)-(7): Rank correlation and significance level between the average lifetime wage of workers, (Avg.Wage), and the firm type, proxied by the average domestic market share in 4-digit sectors Avg. Share. 
Table 3: Pooled Cross-Section Regressions: Average Lifetime Wage, more than 5 workers

\begin{tabular}{|c|c|c|c|c|c|c|}
\hline \multirow[b]{2}{*}{ Variables } & (1) & $(2)$ & $(3)$ & $(4)$ & $(5)$ & $(6)$ \\
\hline & \multicolumn{6}{|c|}{ Average Lifetime Wage, more than 5} \\
\hline Export & $\begin{array}{c}0.167^{a} \\
(0.013)\end{array}$ & $\begin{array}{c}0.073^{a} \\
(0.012)\end{array}$ & $\begin{array}{c}0.078^{a} \\
(0.013)\end{array}$ & $\begin{array}{c}0.097^{a} \\
(0.012)\end{array}$ & $\begin{array}{c}0.050^{a} \\
(0.012)\end{array}$ & $\begin{array}{c}0.034^{b} \\
(0.014)\end{array}$ \\
\hline N.Occ. & & $\begin{array}{l}0.016^{a} \\
(0.002)\end{array}$ & $\begin{array}{c}0.035^{a} \\
(0.002)\end{array}$ & $\begin{array}{c}0.037^{a} \\
(0.002)\end{array}$ & $\begin{array}{l}0.011^{a} \\
(0.002)\end{array}$ & $\begin{array}{l}-0.003 \\
(0.002)\end{array}$ \\
\hline $\log$ empl & & $\begin{array}{c}0.135^{a} \\
(0.007)\end{array}$ & & & $\begin{array}{c}0.133^{a} \\
(0.007)\end{array}$ & $\begin{array}{l}0.139^{a} \\
(0.007)\end{array}$ \\
\hline log dom.share & & & $\begin{array}{c}0.027^{a} \\
(0.002)\end{array}$ & & $\begin{array}{l}0.004^{b} \\
(0.002)\end{array}$ & $\begin{array}{c}0.003 \\
(0.002)\end{array}$ \\
\hline log VA per worker & & & & $\begin{array}{c}0.168^{a} \\
(0.009)\end{array}$ & $\begin{array}{c}0.167^{a} \\
(0.009)\end{array}$ & $\begin{array}{l}0.111^{a} \\
(0.009)\end{array}$ \\
\hline white share & & & & & & $\begin{array}{l}0.496^{a} \\
(0.021)\end{array}$ \\
\hline $\log$ N. Products & & & & & & $\begin{array}{c}0.009^{b} \\
(0.004)\end{array}$ \\
\hline Sector-Year & $\mathrm{y}$ & $\mathrm{y}$ & $\mathrm{y}$ & $\mathrm{y}$ & $\mathrm{y}$ & $\mathrm{y}$ \\
\hline $\begin{array}{l}\text { Obs. } \\
\mathrm{R}^{2}\end{array}$ & $\begin{array}{c}58,541 \\
0.119\end{array}$ & $\begin{array}{c}58,541 \\
0.179\end{array}$ & $\begin{array}{c}58,541 \\
0.164\end{array}$ & $\begin{array}{c}58,541 \\
0.183\end{array}$ & $\begin{array}{c}58,541 \\
0.208\end{array}$ & $\begin{array}{c}58,541 \\
0.254\end{array}$ \\
\hline
\end{tabular}

Export: dummy $=1$ if firm exports

N.Occ.: number of occupations, based on 2 digit occupational codes for France. $\log$ empl: log-employment.

$\log$ VA per worker: log-value added per worker.

log dom.share: log-domestic market share, at the 4 digit sector level.

white share: share of non-production worker.

$\log$ N. Products: $\log$-number of exported products (HS6 codes). This variable is zero for non-exporters.

${ }^{a}$ significant at $1 \%,{ }^{b}$ significant at $5 \%,{ }^{c}$ significant at $10 \%$.

Notes: Cross-Sectional Regressions for firms with more than 5 workers, years 1995-2007. Different specifications in the columns. Standard errors, clustered at the level of the firm, are reported in parenthesis. All specifications but the first include a quadratic in the number of sampled workers, to control for the precision of the left-hand side variable. 
Table 4: Pooled Cross-Section Regressions: Standard Deviation of Lifetime Wage, more than 5 workers

\begin{tabular}{|c|c|c|c|c|c|c|}
\hline \multirow[b]{2}{*}{ Variables } & $(1)$ & (2) & $(3)$ & $(4)$ & $(5)$ & $(6)$ \\
\hline & \multicolumn{6}{|c|}{ Standard Deviation of Lifetime Wage, more than 5} \\
\hline Export & $\begin{array}{c}-0.035^{a} \\
(0.011)\end{array}$ & $\begin{array}{c}-0.020^{c} \\
(0.011)\end{array}$ & $\begin{array}{r}-0.039^{a} \\
(0.011)\end{array}$ & $\begin{array}{c}-0.053^{a} \\
(0.011)\end{array}$ & $\begin{array}{c}-0.024^{b} \\
(0.011)\end{array}$ & $\begin{array}{c}-0.037^{a} \\
(0.013)\end{array}$ \\
\hline N.Occ. & & $\begin{array}{c}0.030^{a} \\
(0.002)\end{array}$ & $\begin{array}{c}0.013^{a} \\
(0.001)\end{array}$ & $\begin{array}{l}0.011^{a} \\
(0.001)\end{array}$ & $\begin{array}{c}0.029^{a} \\
(0.002)\end{array}$ & $\begin{array}{c}0.025^{a} \\
(0.002)\end{array}$ \\
\hline $\log$ empl & & $\begin{array}{r}-0.095^{a} \\
(0.005)\end{array}$ & & & $\begin{array}{r}-0.095^{a} \\
(0.005)\end{array}$ & $\begin{array}{r}-0.091^{a} \\
(0.005)\end{array}$ \\
\hline $\log$ dom.share & & & $\begin{array}{c}-0.007^{a} \\
(0.002)\end{array}$ & & $\begin{array}{c}0.001 \\
(0.002)\end{array}$ & $\begin{array}{c}-0.0001 \\
(0.002)\end{array}$ \\
\hline $\log$ VA per worker & & & & $\begin{array}{l}0.038^{a} \\
(0.006)\end{array}$ & $\begin{array}{l}0.036^{a} \\
(0.006)\end{array}$ & $\begin{array}{l}0.024^{a} \\
(0.006)\end{array}$ \\
\hline white share & & & & & & $\begin{array}{c}0.154^{a} \\
(0.016)\end{array}$ \\
\hline $\log$ N. Products & & & & & & $\begin{array}{c}0.008^{b} \\
(0.003)\end{array}$ \\
\hline Avg Lifetime Wage & & & & & & $\begin{array}{r}-0.087^{a} \\
(0.005)\end{array}$ \\
\hline Sector-Year & $\mathrm{y}$ & $\mathrm{y}$ & $\mathrm{y}$ & $\mathrm{y}$ & $\mathrm{y}$ & $\mathrm{y}$ \\
\hline $\begin{array}{l}\text { Obs. } \\
\mathrm{R}^{2}\end{array}$ & $\begin{array}{c}57,996 \\
0.070\end{array}$ & $\begin{array}{c}57,996 \\
0.091\end{array}$ & $\begin{array}{c}57,996 \\
0.074\end{array}$ & $\begin{array}{c}57,996 \\
0.075\end{array}$ & $\begin{array}{c}57,996 \\
0.093\end{array}$ & $\begin{array}{c}57,996 \\
0.124\end{array}$ \\
\hline
\end{tabular}

Export: dummy $=1$ if firm exports

N.Occ.: number of occupations, based on 2 digit occupational codes for France. log empl: log-employment.

$\log$ VA per worker: log-value added per worker.

log dom.share: log-domestic market share, at the 4 digit sector level.

white share: share of non-production worker.

$\log$ N. Products: $\log$-number of exported products (HS6 codes). This variable is zero for non-exporters.

Avg. Lifetime Wage: workers' lifetime wage, averaged by firm.

${ }^{a}$ significant at $1 \%,{ }^{b}$ significant at $5 \%,{ }^{c}$ significant at $10 \%$.

Notes: Cross-Sectional Regressions for firms with more than 5 workers, years 19952007. Different specifications in the columns. Standard errors, clustered at the level of the firm, are reported in parenthesis. All specifications but the first include a quadratic in the number of sampled workers, to control for the precision of the left-hand side variable. 
Table 5: Pooled Cross-sectional Regressions: Average of Workers' Fixed Effects, more than 5 workers

\begin{tabular}{|c|c|c|c|c|c|c|}
\hline \multirow[b]{2}{*}{ Variables } & (1) & $(2)$ & $(3)$ & $(4)$ & $(5)$ & (6) \\
\hline & \multicolumn{6}{|c|}{ Average of Workers' Fixed Effects, more than 5} \\
\hline Export & $\begin{array}{c}0.079^{a} \\
(0.027)\end{array}$ & $\begin{array}{c}0.030 \\
(0.028)\end{array}$ & $\begin{array}{c}0.036 \\
(0.028)\end{array}$ & $\begin{array}{c}0.039 \\
(0.027)\end{array}$ & $\begin{array}{c}0.025 \\
(0.028)\end{array}$ & $\begin{array}{c}0.013 \\
(0.031)\end{array}$ \\
\hline N.Occ. & & $\begin{array}{l}0.014^{a} \\
(0.004)\end{array}$ & $\begin{array}{l}0.022^{a} \\
(0.004)\end{array}$ & $\begin{array}{l}0.022^{a} \\
(0.004)\end{array}$ & $\begin{array}{l}0.012^{a} \\
(0.004)\end{array}$ & $\begin{array}{c}0.001 \\
(0.004)\end{array}$ \\
\hline $\log$ empl & & $\begin{array}{l}0.053^{a} \\
(0.013)\end{array}$ & & & $\begin{array}{l}0.055^{a} \\
(0.014)\end{array}$ & $\begin{array}{l}0.059^{a} \\
(0.014)\end{array}$ \\
\hline $\log$ dom.share & & & $\begin{array}{c}0.007^{c} \\
(0.004)\end{array}$ & & $\begin{array}{l}-0.002 \\
(0.004)\end{array}$ & $\begin{array}{l}-0.003 \\
(0.005)\end{array}$ \\
\hline log VA per worker & & & & $\begin{array}{l}0.060^{a} \\
(0.014)\end{array}$ & $\begin{array}{l}0.062^{a} \\
(0.015)\end{array}$ & $\begin{array}{c}0.014 \\
(0.015)\end{array}$ \\
\hline white share & & & & & & $\begin{array}{l}0.421^{a} \\
(0.036)\end{array}$ \\
\hline $\log$ N. Products & & & & & & $\begin{array}{c}0.007 \\
(0.009)\end{array}$ \\
\hline Sector-Year & $\mathrm{y}$ & $\mathrm{y}$ & $\mathrm{y}$ & $\mathrm{y}$ & $\mathrm{y}$ & $\mathrm{y}$ \\
\hline Obs. & 54,633 & 54,633 & 54,633 & 54,633 & 54,633 & 54,633 \\
\hline $\mathrm{R}^{2}$ & 0.020 & 0.027 & 0.026 & 0.027 & 0.028 & 0.040 \\
\hline
\end{tabular}

Export: dummy $=1$ if firm exports

N.Occ.: number of occupations, based on 2 digit occupational codes for France. log empl: log-employment.

log VA per worker: log-value added per worker.

log dom.share: log-domestic market share, at the 4 digit sector level.

white share: share of non-production worker.

$\log$ N. Products: log-number of exported products (HS6 codes). This variable is zero for non-exporters.

Avg. Lifetime Wage: workers' lifetime wage, averaged by firm.

${ }^{a}$ significant at $1 \%,{ }^{b}$ significant at $5 \%,{ }^{c}$ significant at $10 \%$.

Notes: Cross-sectional Regressions for firms with more than 5 workers, years 1995-2007. Different specifications in the columns. Standard errors, clustered at the level of the firm, are reported in parenthesis. All specifications but the first include a quadratic in the number of sampled workers, to control for the precision of the left-hand side variable. 
Table 6: Pooled Cross-sectional Regressions: Standard Deviation of Workers' Fixed Effects, more than 5 workers

\begin{tabular}{|c|c|c|c|c|c|c|}
\hline \multirow[b]{2}{*}{ Variables } & $(1)$ & $(2)$ & $(3)$ & $(4)$ & $(5)$ & $(6)$ \\
\hline & \multicolumn{6}{|c|}{ Standard Deviation of Workers' Fixed Effects, more than 5} \\
\hline \multirow[t]{2}{*}{ Export } & $-0.036^{a}$ & $-0.020^{c}$ & $-0.039^{a}$ & $-0.052^{a}$ & $-0.029^{b}$ & $-0.042^{a}$ \\
\hline & $(0.011)$ & $(0.011)$ & $(0.011)$ & $(0.011)$ & $(0.011)$ & $(0.013)$ \\
\hline \multirow[t]{2}{*}{ N.Occ. } & & $0.029^{a}$ & $0.013^{a}$ & $0.010^{a}$ & $0.028^{a}$ & $0.025^{a}$ \\
\hline & & $(0.002)$ & $(0.001)$ & $(0.001)$ & $(0.002)$ & $(0.002)$ \\
\hline \multirow[t]{2}{*}{$\log$ empl } & & $-0.096^{a}$ & & & $-0.096^{a}$ & $-0.092^{a}$ \\
\hline & & $(0.005)$ & & & $(0.006)$ & $(0.006)$ \\
\hline \multirow[t]{2}{*}{ log dom.share } & & & $-0.007^{a}$ & & 0.0004 & -0.001 \\
\hline & & & $(0.002)$ & & $(0.002)$ & $(0.002)$ \\
\hline \multirow[t]{2}{*}{ log VA per worker } & & & & $0.036^{a}$ & $0.035^{a}$ & $0.024^{a}$ \\
\hline & & & & $(0.007)$ & $(0.007)$ & $(0.007)$ \\
\hline \multirow[t]{2}{*}{ white share } & & & & & & $0.130^{a}$ \\
\hline & & & & & & $(0.016)$ \\
\hline \multirow[t]{2}{*}{$\log$ N. Products } & & & & & & $0.010^{a}$ \\
\hline & & & & & & $(0.003)$ \\
\hline \multirow[t]{2}{*}{ Avg Worker Type } & & & & & & $-0.086^{a}$ \\
\hline & & & & & & $(0.005)$ \\
\hline Sector-Year & $\mathrm{y}$ & $\mathrm{y}$ & $\mathrm{y}$ & $\mathrm{y}$ & $\mathrm{y}$ & $\mathrm{y}$ \\
\hline Obs. & 54,633 & 54,633 & 54,633 & 54,633 & 54,633 & 54,633 \\
\hline $\mathrm{R}^{2}$ & 0.065 & 0.087 & 0.069 & 0.070 & 0.088 & 0.120 \\
\hline
\end{tabular}

Export: dummy $=1$ if firm exports

N.Occ.: number of occupations, based on 2 digit occupational codes for France.

log empl: log-employment.

log VA per worker: log-value added per worker.

log dom.share: log-domestic market share, at the 4 digit sector level.

white share: share of non-production worker.

$\log$ N. Products: log-number of exported products (HS6 codes). This variable is zero for non-exporters.

Avg. Lifetime Wage: workers' lifetime wage, averaged by firm.

Avg Worker Type: average worker fixed effect, estimated by the AKM decomposition, by firm.

${ }^{a}$ significant at $1 \%,{ }^{b}$ significant at $5 \%,{ }^{c}$ significant at $10 \%$.

Notes: Cross-sectional Regressions for firms with more than 5 workers, years 19952007. Different specifications in the columns. Standard errors, clustered at the level of the firm, are reported in parenthesis. All specifications but the first include a quadratic in the number of sampled workers, to control for the precision of the lefthand side variable. 
Table 7: IV Regression - First Stage: Standard Deviation of Lifetime Wage, more than 5 workers

\begin{tabular}{|c|c|c|c|c|c|c|}
\hline \multirow[b]{2}{*}{ Variables } & $(1)$ & $(2)$ & $(3)$ & $(4)$ & (5) & (6) \\
\hline & \multicolumn{6}{|c|}{ Standard Deviation of Lifetime Wage, more than 5} \\
\hline Export & $\begin{array}{r}-0.075^{a} \\
(0.019)\end{array}$ & $\begin{array}{c}-0.095^{a} \\
(0.020)\end{array}$ & $\begin{array}{c}-0.061^{a} \\
(0.021)\end{array}$ & $\begin{array}{c}-0.099^{a} \\
(0.022)\end{array}$ & $\begin{array}{c}-0.102^{a} \\
(0.020)\end{array}$ & $\begin{array}{c}-0.153^{a} \\
(0.035)\end{array}$ \\
\hline N.Occ. & & $\begin{array}{l}0.014^{a} \\
(0.002)\end{array}$ & $\begin{array}{l}0.028^{a} \\
(0.002)\end{array}$ & $\begin{array}{l}0.014^{a} \\
(0.002)\end{array}$ & $\begin{array}{c}0.013^{a} \\
(0.002)\end{array}$ & $\begin{array}{l}0.020^{a} \\
(0.002)\end{array}$ \\
\hline $\log$ empl & & & $\begin{array}{r}-0.091^{a} \\
(0.006)\end{array}$ & & & $\begin{array}{r}-0.013^{a} \\
(0.005)\end{array}$ \\
\hline $\log$ dom.share & & & & $\begin{array}{c}-0.002 \\
(0.002)\end{array}$ & & $\begin{array}{l}0.010^{a} \\
(0.001)\end{array}$ \\
\hline log VA per worker & & & & & $\begin{array}{c}0.039^{a} \\
(0.007)\end{array}$ & $\begin{array}{l}0.101^{a} \\
(0.005)\end{array}$ \\
\hline white share & & & & & & $\begin{array}{l}0.465^{a} \\
(0.015)\end{array}$ \\
\hline $\log$ N. Products & & & & & & $\begin{array}{l}0.045^{a} \\
(0.015)\end{array}$ \\
\hline Avg. Lifetime Wage & & & & & & $\begin{array}{c}-0.733^{a} \\
(0.012)\end{array}$ \\
\hline Sector-Year & $\mathrm{y}$ & $\mathrm{y}$ & $\mathrm{y}$ & $\mathrm{y}$ & $\mathrm{y}$ & $\mathrm{y}$ \\
\hline Obs. & 16,072 & 16,072 & 16,072 & 16,072 & 16,072 & 16,072 \\
\hline $\mathrm{R}^{2}$ & 0.058 & 0.062 & 0.081 & 0.062 & 0.064 & 0.544 \\
\hline
\end{tabular}

Export: dummy $=1$ if firm exports

N.Occ.: number of occupations, based on 2 digit occupational codes for France.

log empl: log-employment.

$\log$ VA per worker: log-value added per worker.

log dom.share: log-domestic market share, at the 4 digit sector level.

white share: share of non-production worker.

$\log$ N. Products: log-number of exported products (HS6 codes). This variable is zero for non-exporters.

Avg. Lifetime Wage: workers' lifetime wage, averaged by firm.

${ }^{a}$ significant at $1 \%,{ }^{b}$ significant at $5 \%,{ }^{c}$ significant at $10 \%$.

Notes: Cross-sectional Regressions for firms with more than 5 workers, years 1995-2007. Different specifications in the columns. Standard errors, clustered at the level of the firm, are reported in parenthesis. All specifications but the first include a quadratic in the number of sampled workers, to control for the precision of the left-hand side variable. 
Table 8: Group-Weighted Regressions: Standard Deviation, more than 5 workers

\begin{tabular}{|c|c|c|c|c|c|c|}
\hline \multirow[b]{2}{*}{ Variables } & $(1)$ & $(2)$ & $(3)$ & $(4)$ & $(5)$ & $(6)$ \\
\hline & \multicolumn{6}{|c|}{ Standard Deviation of Average Lifetime Wage, more than 5} \\
\hline \multirow[t]{2}{*}{ Export } & $-0.012^{b}$ & $-0.023^{a}$ & $-0.026^{a}$ & $-0.030^{a}$ & $-0.022^{a}$ & $-0.031^{a}$ \\
\hline & $(0.005)$ & $(0.005)$ & $(0.005)$ & $(0.005)$ & $(0.005)$ & $(0.005)$ \\
\hline \multirow[t]{2}{*}{ N.Occ. } & & $0.016^{a}$ & $0.012^{a}$ & $0.011^{a}$ & $0.016^{a}$ & $0.017^{a}$ \\
\hline & & $(0.001)$ & $(0.000)$ & $(0.000)$ & $(0.001)$ & $(0.001)$ \\
\hline \multirow[t]{2}{*}{$\log$ empl } & & $-0.023^{a}$ & & & $-0.022^{a}$ & $0.025^{a}$ \\
\hline & & $(0.003)$ & & & $(0.003)$ & $(0.003)$ \\
\hline \multirow[t]{2}{*}{ log dom.share } & & & $-0.003^{a}$ & & -0.000 & -0.001 \\
\hline & & & $(0.000)$ & & $(0.001)$ & $(0.001)$ \\
\hline \multirow[t]{2}{*}{ log VA per worker } & & & & -0.002 & -0.001 & $0.117^{a}$ \\
\hline & & & & $(0.003)$ & $(0.003)$ & $(0.003)$ \\
\hline \multirow[t]{2}{*}{ white share } & & & & & & $-0.150^{a}$ \\
\hline & & & & & & $(0.008)$ \\
\hline \multirow[t]{2}{*}{$\log$ N. Products } & & & & & & $0.003^{c}$ \\
\hline & & & & & & $(0.002)$ \\
\hline \multirow[t]{2}{*}{ Avg. Lifetime Wage } & & & & & & $0.011^{a}$ \\
\hline & & & & & & $(0.001)$ \\
\hline Sector-Year & $\mathrm{y}$ & $\mathrm{y}$ & $\mathrm{y}$ & $\mathrm{y}$ & $\mathrm{y}$ & $\mathrm{y}$ \\
\hline Obs. & 54,436 & 54,436 & 54,436 & 54,436 & 54,436 & 54,436 \\
\hline $\mathrm{R}^{2}$ & 0.037 & 0.072 & 0.069 & 0.068 & 0.072 & 0.108 \\
\hline
\end{tabular}

Export: dummy=1 if firm exports

N.Occ.: number of occupations, based on 2 digit occupational codes for France.

log empl: log-employment.

log VA per worker: log-value added per worker.

log dom.share: log-domestic market share, at the 4 digit sector level.

white share: share of non-production worker.

$\log$ N. Products: log-number of exported products (HS6 codes). This variable is zero for non-exporters.

Avg. Lifetime Wage: workers' lifetime wage, averaged by firm.

${ }^{a}$ significant at $1 \%,{ }^{b}$ significant at $5 \%,{ }^{c}$ significant at $10 \%$.

Notes: Group-weighted Regressions for firms with more than 5 workers, years 19952007. The dependent variable is a weighted average of the standard deviations for managers, executives and blue collar workers, using as weights the average employment compositions of those groups within firm over time. Different specifications in the columns. Standard errors, clustered at the level of the firm, are reported in parenthesis. All specifications but the first include a quadratic in the number of sampled workers, to control for the precision of the left-hand side variable. 
Table 9: Pooled Cross-sectional Regressions: Inter-quartile Range, more than 5 workers

\begin{tabular}{|c|c|c|c|c|c|c|}
\hline \multirow[b]{2}{*}{ Variables } & $(1)$ & $(2)$ & $(3)$ & $(4)$ & $(5)$ & (6) \\
\hline & \multicolumn{6}{|c|}{ Inter-quartile of Lifetime Wage, more than 5} \\
\hline Export & $\begin{array}{r}-0.083^{a} \\
(0.015)\end{array}$ & $\begin{array}{l}-0.010 \\
(0.015)\end{array}$ & $\begin{array}{r}-0.049^{a} \\
(0.015)\end{array}$ & $\begin{array}{r}-0.073^{a} \\
(0.015)\end{array}$ & $\begin{array}{l}-0.021 \\
(0.015)\end{array}$ & $\begin{array}{c}-0.024^{b} \\
(0.012)\end{array}$ \\
\hline N.Occ. & & $\begin{array}{l}0.019^{a} \\
(0.002)\end{array}$ & $\begin{array}{c}-0.012^{a} \\
(0.002)\end{array}$ & $\begin{array}{c}-0.016^{a} \\
(0.002)\end{array}$ & $\begin{array}{l}0.016^{a} \\
(0.002)\end{array}$ & $\begin{array}{l}0.005^{a} \\
(0.002)\end{array}$ \\
\hline $\log$ empl & & $\begin{array}{c}-0.178^{a} \\
(0.007)\end{array}$ & & & $\begin{array}{c}-0.179^{a} \\
(0.007)\end{array}$ & $\begin{array}{r}-0.068^{a} \\
(0.006)\end{array}$ \\
\hline log dom.share & & & $\begin{array}{c}-0.011^{a} \\
(0.002)\end{array}$ & & $\begin{array}{c}0.003 \\
(0.002)\end{array}$ & $\begin{array}{l}0.004^{a} \\
(0.002)\end{array}$ \\
\hline log VA per worker & & & & $\begin{array}{l}0.084^{a} \\
(0.010)\end{array}$ & $\begin{array}{c}0.079^{a} \\
(0.010)\end{array}$ & $\begin{array}{l}0.142^{a} \\
(0.007)\end{array}$ \\
\hline white share & & & & & & $\begin{array}{l}0.789^{a} \\
(0.019)\end{array}$ \\
\hline $\log$ N. Products & & & & & & $\begin{array}{c}0.019^{a} \\
(0.003)\end{array}$ \\
\hline Avg. Lifetime Wage & & & & & & $\begin{array}{r}-0.930^{a} \\
(0.016)\end{array}$ \\
\hline Sector-Year & $\mathrm{y}$ & $\mathrm{y}$ & $\mathrm{y}$ & $\mathrm{y}$ & $\mathrm{y}$ & $\mathrm{y}$ \\
\hline $\begin{array}{l}\text { Obs. } \\
\mathrm{R}^{2}\end{array}$ & $\begin{array}{c}57,469 \\
0.056\end{array}$ & $\begin{array}{c}57,469 \\
0.094 \\
\end{array}$ & $\begin{array}{c}57,469 \\
0.062 \\
\end{array}$ & $\begin{array}{c}57,469 \\
0.066\end{array}$ & $\begin{array}{c}57,469 \\
0.099 \\
\end{array}$ & $\begin{array}{c}57,469 \\
0.493 \\
\end{array}$ \\
\hline
\end{tabular}

Export: dummy $=1$ if firm exports

N.Occ.: number of occupations, based on 2 digit occupational codes for France.

log empl: log-employment.

log VA per worker: log-value added per worker.

log dom.share: log-domestic market share, at the 4 digit sector level.

white share: share of non-production worker.

$\log$ N. Products: log-number of exported products (HS6 codes). This variable is zero for non-exporters.

Avg. Lifetime Wage: workers' lifetime wage, averaged by firm.

${ }^{a}$ significant at $1 \%,{ }^{b}$ significant at $5 \%,{ }^{c}$ significant at $10 \%$.

Notes: Cross-sectional Regressions for firms with more than 5 workers, years 19952007. Different specifications in the columns. Standard errors, clustered at the level of the firm, are reported in parenthesis. All specifications but the first include a quadratic in the number of sampled workers, to control for the precision of the left-hand side variable. 
Table 10: Market Access Regressions: Average, more than 5 workers

\begin{tabular}{|c|c|c|c|c|c|c|}
\hline \multirow[b]{2}{*}{ Variables } & $(1)$ & $(2)$ & $(3)$ & $(4)$ & $(5)$ & $(6)$ \\
\hline & \multicolumn{6}{|c|}{ Average Lifetime Wage, more than 5 workers } \\
\hline \multirow[t]{2}{*}{ Market Access*Export } & $0.014^{a}$ & $0.012^{a}$ & $0.011^{a}$ & $0.012^{a}$ & $0.013^{a}$ & $0.013^{a}$ \\
\hline & $(0.003)$ & $(0.003)$ & $(0.003)$ & $(0.003)$ & $(0.003)$ & $(0.003)$ \\
\hline \multirow[t]{2}{*}{ Market Access } & $-0.016^{a}$ & $-0.014^{a}$ & $-0.013^{a}$ & $-0.012^{a}$ & $-0.015^{a}$ & $-0.018^{a}$ \\
\hline & $(0.004)$ & $(0.004)$ & $(0.003)$ & $(0.004)$ & $(0.004)$ & $(0.003)$ \\
\hline \multirow[t]{2}{*}{ Export } & -0.052 & -0.078 & $-0.106^{b}$ & $-0.114^{b}$ & $-0.108^{b}$ & $-0.168^{a}$ \\
\hline & $(0.051)$ & $(0.050)$ & $(0.047)$ & $(0.050)$ & $(0.050)$ & $(0.050)$ \\
\hline \multirow[t]{2}{*}{ N.Occ. } & & $0.039^{a}$ & $0.015^{a}$ & $0.032^{a}$ & $0.035^{a}$ & -0.002 \\
\hline & & $(0.002)$ & $(0.002)$ & $(0.001)$ & $(0.001)$ & $(0.001)$ \\
\hline \multirow[t]{2}{*}{$\log$ empl } & & & $0.125^{a}$ & & & $0.125^{a}$ \\
\hline & & & $(0.005)$ & & & $(0.005)$ \\
\hline \multirow[t]{2}{*}{ log dom.share } & & & & $0.031^{a}$ & & $0.004^{b}$ \\
\hline & & & & $(0.002)$ & & $(0.002)$ \\
\hline \multirow[t]{2}{*}{ log VA per worker } & & & & & $0.158^{a}$ & $0.096^{a}$ \\
\hline & & & & & $(0.008)$ & $(0.006)$ \\
\hline \multirow[t]{2}{*}{ white share } & & & & & & $0.500^{a}$ \\
\hline & & & & & & $(0.024)$ \\
\hline \multirow[t]{2}{*}{$\log$ N. Products } & & & & & & $0.008^{b}$ \\
\hline & & & & & & $(0.003)$ \\
\hline Sector-Year & $\mathrm{y}$ & $\mathrm{y}$ & $\mathrm{y}$ & $\mathrm{y}$ & $\mathrm{y}$ & $\mathrm{y}$ \\
\hline Observations & 44,728 & 44,728 & 44,728 & 44,728 & 44,728 & 44,728 \\
\hline R-squared & 0.142 & 0.184 & 0.209 & 0.196 & 0.215 & 0.299 \\
\hline
\end{tabular}

Export: dummy=1 if firm exports

N.Occ.: number of occupations, based on 2 digit occupational codes for France.

log empl: log-employment.

log VA per worker: log-value added per worker.

log dom.share: log-domestic market share, at the 4 digit sector level.

white share: share of non-production worker.

$\log$ N. Products: log-number of exported products (HS6 codes). This variable is zero for non-exporters.

Avg. Lifetime Wage: workers' lifetime wage, averaged by firm.

Market Access: weighted-average - across destinations - of the demand faced by a given industry $i$ at time $t$, where the weights are the share of world exports to that particular destination in that industry the previous year.

${ }^{a}$ significant at $1 \%,{ }^{b}$ significant at $5 \%,{ }^{c}$ significant at $10 \%$.

Notes: Cross-sectional Regressions for firms with more than 5 workers, years 19952007. Different specifications in the columns. Standard errors, clustered at the level of the firm, are reported in parenthesis. All specifications but the first include a quadratic in the number of sampled workers, to control for the precision of the left-hand side variable. 
Table 11: Market Access Regressions: Standard Deviation, more than 5 workers

\begin{tabular}{|c|c|c|c|c|c|c|}
\hline \multirow[b]{2}{*}{ Variables } & (1) & $(2)$ & $(3)$ & $(4)$ & $(5)$ & $(6)$ \\
\hline & \multicolumn{6}{|c|}{ Standard Deviation of Lifetime Wage, more than 5} \\
\hline Market Access*Export & $\begin{array}{c}-0.009^{a} \\
(0.003)\end{array}$ & $\begin{array}{c}-0.009^{a} \\
(0.003)\end{array}$ & $\begin{array}{c}-0.009^{a} \\
(0.003)\end{array}$ & $\begin{array}{c}-0.009^{a} \\
(0.003)\end{array}$ & $\begin{array}{c}-0.009^{a} \\
(0.003)\end{array}$ & $\begin{array}{c}-0.009^{a} \\
(0.003)\end{array}$ \\
\hline Market Access & $\begin{array}{c}0.011^{a} \\
(0.003)\end{array}$ & $\begin{array}{c}0.012^{a} \\
(0.003)\end{array}$ & $\begin{array}{l}0.011^{a} \\
(0.003)\end{array}$ & $\begin{array}{l}0.011^{a} \\
(0.003)\end{array}$ & $\begin{array}{l}0.012^{a} \\
(0.003)\end{array}$ & $\begin{array}{c}0.011^{a} \\
(0.003)\end{array}$ \\
\hline Export & $\begin{array}{c}0.096^{b} \\
(0.048)\end{array}$ & $\begin{array}{c}0.089^{c} \\
(0.047)\end{array}$ & $\begin{array}{c}0.113^{b} \\
(0.046)\end{array}$ & $\begin{array}{c}0.096^{b} \\
(0.048)\end{array}$ & $\begin{array}{c}0.080^{c} \\
(0.046)\end{array}$ & $\begin{array}{l}0.094^{b} \\
(0.041)\end{array}$ \\
\hline N.Occ. & & $\begin{array}{l}0.011^{a} \\
(0.001)\end{array}$ & $\begin{array}{l}0.031^{a} \\
(0.001)\end{array}$ & $\begin{array}{l}0.012^{a} \\
(0.001)\end{array}$ & $\begin{array}{l}0.010^{a} \\
(0.001)\end{array}$ & $\begin{array}{l}0.026^{a} \\
(0.001)\end{array}$ \\
\hline $\log$ empl & & & $\begin{array}{r}-0.107^{a} \\
(0.004)\end{array}$ & & & $\begin{array}{r}-0.105^{a} \\
(0.004)\end{array}$ \\
\hline $\log$ dom.share & & & & $\begin{array}{c}-0.006^{a} \\
(0.002)\end{array}$ & & $\begin{array}{c}0.002 \\
(0.002)\end{array}$ \\
\hline $\log$ VA per worker & & & & & $\begin{array}{l}0.050^{a} \\
(0.006)\end{array}$ & $\begin{array}{l}0.033^{a} \\
(0.005)\end{array}$ \\
\hline white share & & & & & & $\begin{array}{c}0.158^{a} \\
(0.018)\end{array}$ \\
\hline Avg Lifetime Wage & & & & & & $\begin{array}{r}-0.104^{a} \\
(0.004)\end{array}$ \\
\hline $\log$ N. Products & & & & & & $\begin{array}{c}0.009^{a} \\
(0.003)\end{array}$ \\
\hline Sector-Year & $\mathrm{y}$ & $\mathrm{y}$ & $\mathrm{y}$ & $\mathrm{y}$ & $\mathrm{y}$ & $\mathrm{y}$ \\
\hline Obs. & 44,728 & 44,728 & 44,728 & 44,728 & 44,728 & 44,552 \\
\hline $\mathrm{R}^{2}$ & 0.068 & 0.071 & 0.094 & 0.072 & 0.075 & 0.143 \\
\hline
\end{tabular}

Export: dummy $=1$ if firm exports

N.Occ.: number of occupations, based on 2 digit occupational codes for France.

log empl: log-employment.

$\log$ VA per worker: log-value added per worker.

log dom.share: log-domestic market share, at the 4 digit sector level.

white share: share of non-production worker.

$\log$ N. Products: log-number of exported products (HS6 codes). This variable is zero for non-exporters.

Avg. Lifetime Wage: workers' lifetime wage, averaged by firm.

Market Access: weighted-average - across destinations - of the demand faced by a given industry $i$ at time $t$, where the weights are the share of world exports to that particular destination in that industry the previous year.

${ }^{a}$ significant at $1 \%,{ }^{b}$ significant at $5 \%,{ }^{c}$ significant at $10 \%$.

Notes: Cross-sectional Regressions for firms with more than 5 workers, years 19952007. Different specifications in the columns. Standard errors, clustered at the level of the firm, are reported in parenthesis. All specifications but the first include a quadratic in the number of sampled workers, to control for the precision of the left-hand side variable. 
Table 12: Tariff Regressions: Average, more than 5 workers

\begin{tabular}{|c|c|c|c|c|c|c|}
\hline \multirow[b]{2}{*}{ Variables } & (1) & $(2)$ & $(3)$ & $(4)$ & $(5)$ & $(6)$ \\
\hline & \multicolumn{6}{|c|}{ Average Lifetime Wage, more than 5} \\
\hline Weighted Tariff*Export & $\begin{array}{c}0.002 \\
(0.004)\end{array}$ & $\begin{array}{c}0.001 \\
(0.003)\end{array}$ & $\begin{array}{c}0.001 \\
(0.003)\end{array}$ & $\begin{array}{c}-0.001 \\
(0.003)\end{array}$ & $\begin{array}{l}-0.001 \\
(0.003)\end{array}$ & $\begin{array}{c}-0.004 \\
(0.003)\end{array}$ \\
\hline Weighted Tariff & $\begin{array}{c}0.001 \\
(0.004)\end{array}$ & $\begin{array}{c}0.002 \\
(0.003)\end{array}$ & $\begin{array}{c}0.002 \\
(0.003)\end{array}$ & $\begin{array}{c}0.00395 \\
(0.003)\end{array}$ & $\begin{array}{l}0.006^{c} \\
(0.003)\end{array}$ & $\begin{array}{c}0.012^{a} \\
(0.003)\end{array}$ \\
\hline Export & $\begin{array}{c}0.128^{a} \\
(0.023)\end{array}$ & $\begin{array}{l}0.082^{a} \\
(0.021)\end{array}$ & $\begin{array}{l}0.045^{b} \\
(0.020)\end{array}$ & $\begin{array}{c}0.050^{b} \\
(0.020)\end{array}$ & $\begin{array}{l}0.071^{a} \\
(0.021)\end{array}$ & $\begin{array}{c}0.039^{c} \\
(0.021)\end{array}$ \\
\hline N.Occ. & & $\begin{array}{l}0.039^{a} \\
(0.001)\end{array}$ & $\begin{array}{l}0.016^{a} \\
(0.002)\end{array}$ & $\begin{array}{l}0.033^{a} \\
(0.001)\end{array}$ & $\begin{array}{l}0.035^{a} \\
(0.001)\end{array}$ & $\begin{array}{l}-0.002 \\
(0.001)\end{array}$ \\
\hline $\log$ empl & & & $\begin{array}{c}0.123^{a} \\
(0.005)\end{array}$ & & & $\begin{array}{c}0.124^{a} \\
(0.005)\end{array}$ \\
\hline log dom.share & & & & $\begin{array}{l}0.031^{a} \\
(0.002)\end{array}$ & & $\begin{array}{c}0.005^{a} \\
(0.002)\end{array}$ \\
\hline white share & & & & & & $\begin{array}{l}0.512^{a} \\
(0.021)\end{array}$ \\
\hline $\log$ VA per worker & & & & & $\begin{array}{c}0.161^{a} \\
(0.008)\end{array}$ & $\begin{array}{c}0.099^{a} \\
(0.007)\end{array}$ \\
\hline $\log$ N. Products & & & & & & $\begin{array}{c}0.004 \\
(0.003)\end{array}$ \\
\hline Sector-Year & $\mathrm{y}$ & $\mathrm{y}$ & $\mathrm{y}$ & $\mathrm{y}$ & $\mathrm{y}$ & $\mathrm{y}$ \\
\hline Observations & 48,280 & 48,280 & 48,280 & 48,280 & 48,280 & 48,280 \\
\hline R-squared & 0.143 & 0.185 & 0.210 & 0.197 & 0.217 & 0.303 \\
\hline
\end{tabular}

Export: dummy=1 if firm exports

N.Occ.: number of occupations, based on 2 digit occupational codes for France.

log empl: log-employment.

log VA per worker: log-value added per worker.

log dom.share: log-domestic market share, at the 4 digit sector level.

white share: share of non-production worker.

$\log$ N. Products: log-number of exported products (HS6 codes). This variable is zero for non-exporters.

Weighted Tariff: weighted average - across destination - of tariff levels in a given industry $i$ at time $t$, where weights are the share of world exports to that particular destination in that industry and year.

${ }^{a}$ significant at $1 \%,{ }^{b}$ significant at $5 \%,{ }^{c}$ significant at $10 \%$.

Notes: Cross-sectional Regressions for firms with more than 5 workers, years 1995-2007. Different specifications in the columns. Standard errors, clustered at the level of the firm, are reported in parenthesis. All specifications but the first include a quadratic in the number of sampled workers, to control for the precision of the left-hand side variable. 
Table 13: Tariff Regressions: Standard Deviation, more than 5 workers

\begin{tabular}{|c|c|c|c|c|c|c|}
\hline \multirow[b]{2}{*}{ Variables } & $(1)$ & $(2)$ & $(3)$ & $(4)$ & $(5)$ & $(6)$ \\
\hline & \multicolumn{6}{|c|}{ Standard Deviation of Lifetime Wages, more than 5} \\
\hline Weighted Tariff*Export & $\begin{array}{c}0.007^{b} \\
(0.003)\end{array}$ & $\begin{array}{c}0.007^{b} \\
(0.003)\end{array}$ & $\begin{array}{c}0.007^{b} \\
(0.003)\end{array}$ & $\begin{array}{c}0.007^{b} \\
(0.003)\end{array}$ & $\begin{array}{c}0.006^{b} \\
(0.003)\end{array}$ & $\begin{array}{c}0.002 \\
(0.002)\end{array}$ \\
\hline Weighted Tariff & $\begin{array}{r}-0.013^{a} \\
(0.003)\end{array}$ & $\begin{array}{r}-0.012^{a} \\
(0.003)\end{array}$ & $\begin{array}{r}-0.012^{a} \\
(0.003)\end{array}$ & $\begin{array}{r}-0.013^{a} \\
(0.003)\end{array}$ & $\begin{array}{r}-0.011^{a} \\
(0.003)\end{array}$ & $\begin{array}{l}-0.001 \\
(0.002)\end{array}$ \\
\hline Export & $\begin{array}{c}-0.059^{a} \\
(0.017)\end{array}$ & $\begin{array}{c}-0.069^{a} \\
(0.017)\end{array}$ & $\begin{array}{c}-0.037^{b} \\
(0.017)\end{array}$ & $\begin{array}{c}-0.062^{a} \\
(0.017)\end{array}$ & $\begin{array}{r}-0.073^{a} \\
(0.017)\end{array}$ & $\begin{array}{c}-0.032^{b} \\
(0.013)\end{array}$ \\
\hline N.Occ. & & $\begin{array}{l}0.011^{a} \\
(0.001)\end{array}$ & $\begin{array}{l}0.031^{a} \\
(0.001)\end{array}$ & $\begin{array}{c}0.013^{a} \\
(0.001)\end{array}$ & $\begin{array}{l}0.010^{a} \\
(0.001)\end{array}$ & $\begin{array}{l}0.025^{a} \\
(0.001)\end{array}$ \\
\hline $\log$ empl & & & $\begin{array}{r}-0.108^{a} \\
(0.004)\end{array}$ & & & $\begin{array}{r}-0.022^{a} \\
(0.003)\end{array}$ \\
\hline $\log$ dom.share & & & & $\begin{array}{c}-0.007^{a} \\
(0.002)\end{array}$ & & $\begin{array}{l}0.005^{a} \\
(0.001)\end{array}$ \\
\hline white share & & & & & & $\begin{array}{l}0.480^{a} \\
(0.010)\end{array}$ \\
\hline $\log$ VA per worker & & & & & $\begin{array}{l}0.047^{a} \\
(0.006)\end{array}$ & $\begin{array}{c}0.103^{a} \\
(0.004)\end{array}$ \\
\hline $\log$ N. Products & & & & & & $\begin{array}{l}0.014^{a} \\
(0.002)\end{array}$ \\
\hline Avg Lifetime Wage & & & & & & $\begin{array}{r}-0.727^{a} \\
(0.010)\end{array}$ \\
\hline Sector-Year & $\mathrm{y}$ & $\mathrm{y}$ & $\mathrm{y}$ & $\mathrm{y}$ & $\mathrm{y}$ & $\mathrm{y}$ \\
\hline Observations & 48,280 & 48,280 & 48,280 & 48,280 & 48,280 & 48,280 \\
\hline R-squared & 0.068 & 0.071 & 0.094 & 0.072 & 0.074 & 0.550 \\
\hline
\end{tabular}

Export: dummy=1 if firm exports

N.Occ.: number of occupations, based on 2 digit occupational codes for France.

log empl: log-employment.

$\log$ VA per worker: log-value added per worker.

log dom.share: log-domestic market share, at the 4 digit sector level.

white share: share of non-production worker.

$\log$ N. Products: log-number of exported products (HS6 codes). This variable is zero for non-exporters.

Avg. Lifetime Wage: workers' lifetime wage, averaged by firm.

Weighted Tariff: weighted average - across destination - of tariff levels in a given industry $i$ at time $t$, where weights are the share of world exports to that particular destination in that industry and year.

${ }^{a}$ significant at $1 \%,{ }^{b}$ significant at $5 \%,{ }^{c}$ significant at $10 \%$.

Notes: Cross-sectional Regressions for firms with more than 5 workers, years 1995-2007. Different specifications in the columns. Standard errors, clustered at the level of the firm, are reported in parenthesis. All specifications but the first include a quadratic in the number of sampled workers, to control for the precision of the left-hand side variable. 
Table 14: Model Calibration

\begin{tabular}{|l|l|l|}
\hline Parameter & Model & Data Moment \\
\hline \hline$\eta=4$ & Demand Elasticity & Average trade elasticity \\
$\sigma=0.653$ & Production Curvature & Worker type elasticity \\
$\tau=1.513$ & Variable trade cost & Average foreign to domestic shipments \\
$\lambda=0.8$ & Share of exporters & Average share of exporters \\
$\delta=1.7 \%$ & Destruction rate & Average separation probability \\
& & Hairault et al. (2015) \\
$\rho=13.5 \%$ & Meeting rate & Average number of new hires \\
$c=0.025$ & Search cost & Hairault et al. (2015) \\
$B\left(\alpha_{\theta}=39.92, \beta_{\theta}=28.96\right)$ & Worker distribution & Empirical distribution \\
$B\left(\alpha_{\psi}=0.89, \beta_{\psi}=1.09\right)$ & Firm distribution & Empirical distribution \\
\hline
\end{tabular}

Table 15: Changes in Real Expenditure

\begin{tabular}{|l|c|c|c|}
\hline & $\alpha=0.75$ & $\alpha=1$ & $\alpha=1.25$ \\
\hline \hline$c_{H}=0.025$ & $22.0 \%$ & $27.2 \%$ & $34.1 \%$ \\
$c_{M}=0.005$ & $15.6 \%$ & $16 \%$ & $16.1 \%$ \\
$c_{L}=0.001$ & $15.4 \%$ & $15.2 \%$ & $15.9 \%$ \\
\hline
\end{tabular}

Notes: Changes in real expenditure relative to autarky, by search cost, $c_{i}, i=\{H, M, L\}$ and $\alpha$. $\alpha$ collects demand and supply parameters, $\alpha=$ $\sigma \frac{\eta-1}{\eta}$, where $\eta$ is the elasticity of demand and $\sigma$ is the curvature of the production function. Simulated results with variable trade $\operatorname{cost} \tau=1.513$, share of exporters (after trade opening) $\lambda=0.8$ and empirical distributions for worker and firm types.

Table 16: Real Relative Revenue Losses

\begin{tabular}{|l|c|c|c|}
\hline & $\alpha=0.75$ & $\alpha=1$ & $\alpha=1.25$ \\
\hline \hline$c_{H}=0.025$ & $-1.36 \%$ & $-1.11 \%$ & $-1.01 \%$ \\
$c_{M}=0.005$ & $-1.12 \%$ & $-0.95 \%$ & $-0.85 \%$ \\
$c_{L}=0.001$ & $-1.05 \%$ & $-0.95 \%$ & $-0.82 \%$ \\
\hline
\end{tabular}

Notes: changes in relative revenue losses compared to autarky, by search cost, $c_{i}, i=\{H, M, L\}$ and $\alpha . \alpha$ collects demand and supply parameters, $\alpha=\sigma \frac{\eta-1}{\eta}$, where $\eta$ is the elasticity of demand and $\sigma$ is the curvature of the production function. The revenue losses are relative deviation of the realized from the revenues under the optimal assignment; we normalized by the revenues under the optimal assignment. Simulated results with variable trade cost $\tau=1.513$, share of exporters (after trade opening) $\lambda=0.8$ and empirical distributions for worker and firm types. 


\section{A Appendix}

\section{A.1 Proof of decreasing normalized matching range under assumption of ho- mogeneity of revenue function}

Assume revenue function $f(\theta, \varphi)$ is increasing, symmetric, supermodular and homogeneous in $\theta$ and $\varphi$.

\section{A.1.1 Outside options: wages and profits}

At the optimum, the marginal benefit from hiring a better worker has to equalize the marginal increase in wage:

$$
\frac{d w^{*}}{d \theta}=\frac{\partial f(\theta, \varphi)}{\partial \theta}
$$

Outside option for the worker is given by:

$$
w^{*}(\theta)=\left.\int_{0}^{\theta} \frac{\partial f(t, x)}{\partial t}\right|_{x=\mu(t)} d t
$$

where, because of symmetry, $\mu(t)=t$.

It is useful to use the following result relating the partial and total derivatives of $f$ :

$$
\frac{d f(\theta, \theta)}{d \theta}=\left.\frac{\partial f(\theta, x)}{\partial \theta}\right|_{x=\theta}+\left.\frac{\partial f(x, \theta)}{\partial \theta}\right|_{x=\theta}
$$

Again, symmetry implies that the two partial derivatives are identical:

$$
\left.\frac{\partial f(\theta, x)}{\partial \theta}\right|_{x=\theta}=\left.\frac{\partial f(x, \theta)}{\partial \theta}\right|_{x=\theta}
$$


therefore the wage $w^{*}(\theta)$ can be rewritten as:

$$
w^{*}(\theta)=\int_{0}^{\theta} \frac{1}{2} \frac{d f(t, t)}{d t} d t=\frac{1}{2} f(\theta, \theta)
$$

The profit function is derived residually as:

$$
\pi^{*}(\varphi)=\frac{1}{2} f(\varphi, \varphi)
$$

The matching range is defined by the set of $\theta$ that satifies the following inequality:

$$
f(\theta, \varphi)-\frac{1}{2} f(\theta, \theta)-\frac{1}{2} f(\varphi, \varphi)+2 c \geq 0
$$

\section{A.1.2 Normalized matching range}

Let us normalize the matching range by the firm type $\varphi$ :

$$
f\left(\frac{\theta}{\varphi}, 1\right)-\frac{1}{2} f\left(\frac{\theta}{\varphi}, \frac{\theta}{\varphi}\right)-\frac{1}{2} f(1,1)+\frac{2 c}{\varphi} \geq 0
$$

Assuming that the function is well behaved and that (A-1) is satisfied with equality for only two values of $\theta$, we can study the behavior of the normalized upper bound $u_{1}(\varphi)=\frac{u(\varphi)}{a(\varphi)}$ and the normalized lower bound $l_{1}(\varphi)=\frac{l(\varphi)}{a(\varphi)}$. In particular we are interested in proving the following proposition.

Proposition A-1 The normalized matching range $d_{1}(\varphi)=u_{1}(\varphi)-l_{1}(\varphi)$ is decreasing in $\varphi$.

Proof. Define normalized worker type as $\widehat{\theta}=\frac{\theta}{\varphi}$ and rewrite (A-1) with equality as a function of $\widehat{\theta}:$

$$
f(\widehat{\theta}, 1)-\frac{1}{2} f(\widehat{\theta}, \widehat{\theta})-\frac{1}{2} f(1,1)+\frac{2 c}{\varphi}=0
$$


We apply the implicit function theorem to study how $\widehat{\theta}$ varies with $\varphi$.

$$
\frac{\partial f(\widehat{\theta}, 1)}{\partial \widehat{\theta}} \frac{d \widehat{\theta}}{d \varphi}-\frac{1}{2} \frac{d f(\widehat{\theta}, \widehat{\theta})}{d \widehat{\theta}} \frac{d \widehat{\theta}}{d \varphi}-\frac{2 c}{\varphi^{2}}=0
$$

Solving for $\frac{d \widehat{\theta}}{d \varphi}$ we find the following:

$$
\frac{d \widehat{\theta}}{d \varphi}=\frac{\frac{2 c}{\varphi^{2}}}{\frac{\partial f(\widehat{\theta}, 1)}{\partial \widehat{\theta}}-\frac{1}{2} \frac{d f(\widehat{\theta}, \widehat{\theta})}{d \widehat{\theta}}}
$$

The sign of the denominator in (A-2) determines the sign of the derivative of interest $\frac{d \widehat{\theta}}{d \varphi}$. It convenient to rewrite $\frac{d f(\widehat{\theta} \widehat{\theta})}{d \widehat{\theta}}$ as follows:

$$
\frac{d f(\widehat{\theta}, \widehat{\theta})}{d \widehat{\theta}}=\left.\frac{\partial f(x, \widehat{\theta})}{\partial \widehat{\theta}}\right|_{x=\widehat{\theta}}+\left.\frac{\partial f(\widehat{\theta}, x)}{\partial \widehat{\theta}}\right|_{x=\widehat{\theta}}
$$

where by symmetry:

$$
\left.\frac{\partial f(x, \widehat{\theta})}{\partial \widehat{\theta}}\right|_{x=\widehat{\theta}}=\left.\frac{\partial f(\widehat{\theta}, x)}{\partial \widehat{\theta}}\right|_{x=\widehat{\theta}}
$$

We can therefore rewrite (A-2) as:

$$
\frac{d \widehat{\theta}}{d \varphi}=\frac{\frac{2 c}{\varphi^{2}}}{\frac{\partial f(\widehat{\theta}, 1)}{\partial \widehat{\theta}}-\left.\frac{\partial f(\widehat{\theta}, x)}{\partial \widehat{\theta}}\right|_{x=\widehat{\theta}}}
$$

The assumption of supermodularity of function $f(\cdot, \cdot)$ implies that:

$$
\frac{\partial f(\widehat{\theta}, 1)}{\partial \widehat{\theta}}>\left.\frac{\partial f(\widehat{\theta}, x)}{\partial \widehat{\theta}}\right|_{x=\widehat{\theta}}
$$

for $\widehat{\theta}<1$ and viceversa if $\widehat{\theta}>1$ which in turn implies that $u_{1}$ is decreasing in $\varphi$ (case $\widehat{\theta}>1$ ) and $l_{1}$ is increasing in $\varphi($ case $\widehat{\theta}<1)$. 


\section{A.2 Identification of Worker Type: Average Lifetime Wage}

Agents' types are positively correlated with the average realization of their pay-offs over their job spells. In particular, a more productive worker makes larger contribution to revenues and tends to match with a better firm in the frictionless equilibrium, obtaining, on average, a higher pay-offs. Following the model, we propose to identify the agents' type using the average wage. In fact, there exists a well-defined relation. In fact, the average wage of a worker of type $\theta$,

$$
\begin{aligned}
\bar{w}(\theta) & =\frac{1}{\left(\theta^{\alpha}+2 \sqrt{c}\right)^{1 / \alpha}-\left(\theta^{\alpha}-2 \sqrt{c}\right)^{1 / \alpha}} \int_{\left(\theta^{\alpha}-2 \sqrt{c}\right)^{1 / \alpha}}^{\left(\theta^{\alpha}+2 \sqrt{c}\right)^{1 / \alpha}}\left[\frac{\theta^{2 \alpha}}{4}+\frac{\theta^{\alpha} y^{\alpha}}{2}-\frac{y^{2 \alpha}}{4}\right] \mathrm{d} y \\
& =\frac{\theta^{2 \alpha}}{4}+\frac{\theta^{\alpha}\left[\left(\theta^{\alpha}+2 \sqrt{c}\right)^{\frac{\alpha+1}{\alpha}}-\left(\theta^{\alpha}-2 \sqrt{c}\right)^{\frac{\alpha+1}{\alpha}}\right]}{2(\alpha+1)\left[\left(\theta^{\alpha}+2 \sqrt{c}\right)^{\frac{1}{\alpha}}-\left(\theta^{\alpha}-2 \sqrt{c}\right)^{\frac{1}{\alpha}}\right]}-\frac{\left(\theta^{\alpha}+2 \sqrt{c}\right)^{\frac{2 \alpha+1}{\alpha}}-\left(\theta^{\alpha}-2 \sqrt{c}\right)^{\frac{2 \alpha+1}{\alpha}}}{4(2 \alpha+1)\left[\left(\theta^{\alpha}+2 \sqrt{c}\right)^{\frac{1}{\alpha}}-\left(\theta^{\alpha}-2 \sqrt{c}\right)^{\frac{1}{\alpha}}\right]}
\end{aligned}
$$

In particular, if $\alpha=1$,

$$
\bar{w}(\theta)=\frac{\theta^{2}}{4}-\frac{c}{3}
$$

If the demand elasticity $\alpha$ and the search cost $c$ were known, we could back up exactly the worker types. In order to prove that the average wage is increasing in $\theta$, we'll break the proof into two parts. First, it is trivial to prove that the outside option is increasing in the worker type. The second part of the proof will show that a worker of higher ability generates a larger surplus and obtains a 
larger share of it. In the two-period model, under the assumption of a uniform distribution,

$$
\begin{aligned}
\frac{\int_{l(\theta)}^{u(\theta)} s(\theta, y) \mathrm{d} y}{\int_{l(\theta)}^{u(\theta)} \mathrm{d} y}= & \frac{\int_{\left(\theta^{\alpha}-2 \sqrt{c}\right)^{1 / \alpha}}^{\left(\theta^{\alpha}+2 \sqrt{c}\right)^{1 / \alpha}}\left[\theta^{\alpha} \cdot y^{\alpha}-\frac{\theta^{2 \alpha}}{2}-\frac{y^{2 \alpha}}{2}\right] \mathrm{d} y}{\left(\theta^{\alpha}+2 \sqrt{c}\right)^{1 / \alpha}-\left(\theta^{\alpha}-2 \sqrt{c}\right)^{1 / \alpha}} \\
& =\frac{y\left[\frac{\theta^{\alpha} \cdot y^{\alpha}}{\alpha+1}-\frac{\theta^{2 \alpha}}{2}-\frac{y^{2 \alpha}}{2(2 \alpha+1)}\right] \mid \begin{array}{l}
\left(\theta^{\alpha}+2 \sqrt{c}\right)^{1 / \alpha} \\
\left(\theta^{\alpha}-2 \sqrt{c}\right)^{1 / \alpha}
\end{array}}{\left(\theta^{\alpha}+2 \sqrt{c}\right)^{1 / \alpha}-\left(\theta^{\alpha}-2 \sqrt{c}\right)^{1 / \alpha}} \\
& =\frac{\left.y\left[\theta^{\alpha} \cdot y^{\alpha}-\frac{\theta^{2 \alpha}}{2}-\frac{y^{2 \alpha}}{2}+\alpha \frac{\theta^{\alpha} \cdot y^{\alpha}}{\alpha+1}+\frac{2 \alpha y^{2 \alpha}}{2(2 \alpha+1)}\right]\right|_{\left(\theta^{\alpha}-2 \sqrt{c}\right)^{1 / \alpha}} ^{\left(\theta^{\alpha}+2 \sqrt{c}\right)^{1 / \alpha}}}{\left(\theta^{\alpha}+2 \sqrt{c}\right)^{1 / \alpha}-\left(\theta^{\alpha}-2 \sqrt{c}\right)^{1 / \alpha}} \\
& =-2 c+\alpha \frac{\left.\left(\theta^{\alpha}+2 \sqrt{c}\right)^{\frac{1+\alpha}{\alpha}}-\left(\theta^{\alpha}-2 \sqrt{c}\right)^{\frac{1+\alpha}{\alpha}}\right]}{\left(\theta^{\alpha}+2 \sqrt{c}\right)^{\frac{1}{\alpha}}-\left(\theta^{\alpha}-2 \sqrt{c}\right)^{\frac{1}{\alpha}}} \frac{(3 \alpha+2) \theta^{\alpha}}{(\alpha+1)(2 \alpha+1)} \\
& +\alpha \frac{2 \sqrt{c}}{(2 \alpha+1)} \frac{\left[\left(\theta^{\alpha}+2 \sqrt{c}\right)^{\frac{1+\alpha}{\alpha}}+\left(\theta^{\alpha}-2 \sqrt{c}\right)^{\frac{1+\alpha}{\alpha}}\right]}{\left(\theta^{\alpha}+2 \sqrt{c}\right)^{\frac{1}{\alpha}}-\left(\theta^{\alpha}-2 \sqrt{c}\right)^{\frac{1}{\alpha}}}
\end{aligned}
$$

The surplus is increasing for all $\alpha>0$. In fact,

$$
\begin{aligned}
\frac{\partial}{\partial \theta}\left[\frac{\left[\left(\theta^{\alpha}+2 \sqrt{c}\right)^{\frac{1+\alpha}{\alpha}}-\left(\theta^{\alpha}-2 \sqrt{c}\right)^{\frac{1+\alpha}{\alpha}}\right]}{\left.\left(\theta^{\alpha}+2 \sqrt{c}\right)^{\frac{1}{\alpha}}-\left(\theta^{\alpha}-2 \sqrt{c}\right)^{\frac{1}{\alpha}}\right]=}\right. & \alpha \theta^{\alpha-1}\left[\frac{1+\alpha}{\alpha}-\frac{1}{\alpha} \frac{\left(\theta^{\alpha}+2 \sqrt{c}\right)^{\frac{2}{\alpha}}+\left(\theta^{\alpha}-2 \sqrt{c}\right)^{\frac{2}{\alpha}}}{\left(\left(\theta^{\alpha}+2 \sqrt{c}\right)^{\frac{1}{\alpha}}-\left(\theta^{\alpha}-2 \sqrt{c}\right)^{\frac{1}{\alpha}}\right)^{2}}\right]+ \\
& +\alpha \theta^{\alpha-1}\left[\frac{1}{\alpha} \frac{\left(\theta^{\alpha}+2 \sqrt{c}\right)^{\frac{1}{\alpha}}\left(\theta^{\alpha}-2 \sqrt{c}\right)^{\frac{1}{\alpha}}\left[\frac{\theta^{\alpha}+2 \sqrt{c}}{\theta^{\alpha}-2 \sqrt{c}}+\frac{\theta^{\alpha}-2 \sqrt{c}}{\theta^{\alpha}+2 \sqrt{c}}\right]}{\left(\left(\theta^{\alpha}+2 \sqrt{c}\right)^{\frac{1}{\alpha}}-\left(\theta^{\alpha}-2 \sqrt{c}\right)^{\frac{1}{\alpha}}\right)^{2}}\right] \\
= & \alpha \theta^{\alpha-1}+\theta^{\alpha-1} \frac{\left(\theta^{\alpha}+2 \sqrt{c}\right)^{\frac{1}{\alpha}}\left(\theta^{\alpha}-2 \sqrt{c}\right)^{\frac{1}{\alpha}}\left[\frac{\theta^{\alpha}+2 \sqrt{c}}{\theta^{\alpha}-2 \sqrt{c}}+\frac{\theta^{\alpha}-2 \sqrt{c}}{\theta^{\alpha}+2 \sqrt{c}}-2\right]}{\left(\left(\theta^{\alpha}+2 \sqrt{c}\right)^{\frac{1}{\alpha}}-\left(\theta^{\alpha}-2 \sqrt{c}\right)^{\frac{1}{\alpha}}\right)^{2}}
\end{aligned}
$$

and

$$
\begin{aligned}
\frac{\partial}{\partial \theta}\left[\frac{\left[\left(\theta^{\alpha}+2 \sqrt{c}\right)^{\frac{1+\alpha}{\alpha}}+\left(\theta^{\alpha}-2 \sqrt{c}\right)^{\frac{1+\alpha}{\alpha}}\right]}{\left.\left(\theta^{\alpha}+2 \sqrt{c}\right)^{\frac{1}{\alpha}}-\left(\theta^{\alpha}-2 \sqrt{c}\right)^{\frac{1}{\alpha}}\right]=}\right. & \alpha \theta^{\alpha-1}\left[\frac{\left(\theta^{\alpha}+2 \sqrt{c}\right)^{\frac{1}{\alpha}}+\left(\theta^{\alpha}-2 \sqrt{c}\right)^{\frac{1}{\alpha}}}{\left(\theta^{\alpha}+2 \sqrt{c}\right)^{\frac{1}{\alpha}}-\left(\theta^{\alpha}-2 \sqrt{c}\right)^{\frac{1}{\alpha}}}\right]+ \\
& +\alpha \theta^{\alpha-1}\left[\frac{1}{\alpha} \frac{\left(\theta^{\alpha}+2 \sqrt{c}\right)^{\frac{1}{\alpha}}\left(\theta^{\alpha}-2 \sqrt{c}\right)^{\frac{1}{\alpha}}\left[\frac{\theta^{\alpha}+2 \sqrt{c}}{\theta^{\alpha}-2 \sqrt{c}}-\frac{\theta^{\alpha}-2 \sqrt{c}}{\theta^{\alpha}+2 \sqrt{c}}\right]}{\left(\left(\theta^{\alpha}+2 \sqrt{c}\right)^{\frac{1}{\alpha}}-\left(\theta^{\alpha}-2 \sqrt{c}\right)^{\frac{1}{\alpha}}\right)^{2}}\right]
\end{aligned}
$$


are both positive.

\section{A.3 Relative Losses: Variation by Firm Type}

Proof of proposition 2 In order to show that $R L(\varphi)$ is decreasing in $\varphi$ it is convenient to rewrite it as follows:

$$
R L(\varphi)=1-\frac{2(1+2 \alpha)\left[\left(\varphi^{\alpha}+b\right)^{\frac{1+\alpha}{\alpha}}-\left(\varphi^{\alpha}-b\right)^{\frac{1+\alpha}{\alpha}}\right] \varphi^{\alpha}}{(1+\alpha)\left\{\left(\varphi^{\alpha}+b\right)^{\frac{1+2 \alpha}{\alpha}}-\left(\varphi^{\alpha}-b\right)^{\frac{1+2 \alpha}{\alpha}}+\varphi^{2 \alpha}(1+2 \alpha)\left[\left(\varphi^{\alpha}+b\right)^{\frac{1}{\alpha}}-\left(\varphi^{\alpha}-b\right)^{\frac{1}{\alpha}}\right]\right\}} .
$$

It is easy to verify that $R L(\varphi)$ is decreasing if and only if:

$$
\frac{N^{\prime}(\varphi)}{N(\varphi)}>\frac{D^{\prime}(\varphi)}{D(\varphi)}
$$

where

$$
\begin{aligned}
& N(\varphi)=\left[\left(\varphi^{\alpha}+b\right)^{\frac{1+\alpha}{\alpha}}-\left(\varphi^{\alpha}-b\right)^{\frac{1+\alpha}{\alpha}}\right] \varphi^{\alpha} \\
& D(\varphi)=\left(\varphi^{\alpha}+b\right)^{\frac{1+2 \alpha}{\alpha}}-\left(\varphi^{\alpha}-b\right)^{\frac{1+2 \alpha}{\alpha}}+\varphi^{2 \alpha}(1+2 \alpha)\left[\left(\varphi^{\alpha}+b\right)^{\frac{1}{\alpha}}-\left(\varphi^{\alpha}-b\right)^{\frac{1}{\alpha}}\right]
\end{aligned}
$$

and

$$
\begin{aligned}
N^{\prime}(\varphi)= & \varphi^{\alpha-1}(\alpha+1) \varphi^{\alpha}\left(\left(\varphi^{\alpha}+b\right)^{\frac{1}{\alpha}}-\left(\varphi^{\alpha}-b\right)^{\frac{1}{\alpha}}\right)+\alpha\left(\left(\varphi^{\alpha}+b\right)^{\frac{1+\alpha}{\alpha}}-\left(\varphi^{\alpha}-b\right)^{\frac{1+\alpha}{\alpha}}\right) \\
D^{\prime}(\varphi)= & \varphi^{\alpha-1}(2 \alpha+1)\left[\left(\varphi^{\alpha}+b\right)^{\frac{1+\alpha}{\alpha}}-\left(\varphi^{\alpha}-b\right)^{\frac{1+\alpha}{\alpha}}+2 \alpha \varphi^{\alpha}\left(\left(\varphi^{\alpha}+b\right)^{\frac{1}{\alpha}}-\left(\varphi^{\alpha}-b\right)^{\frac{1}{\alpha}}\right)\right] \\
& +\varphi^{\alpha-1}(2 \alpha+1) \varphi^{2 \alpha}\left[\left(\varphi^{\alpha}+b\right)^{\frac{1-\alpha}{\alpha}}-\left(\varphi^{\alpha}-b\right)^{\frac{1-\alpha}{\alpha}}\right]
\end{aligned}
$$

We can now operate a change of variables as follows: 


$$
\begin{aligned}
& h=\left(\frac{\varphi^{\alpha}+b}{\varphi^{\alpha}}\right)^{\frac{1}{\alpha}} \\
& d=\left(\frac{\varphi^{\alpha}-b}{\varphi^{\alpha}}\right)^{\frac{1}{\alpha}}
\end{aligned}
$$

and substitute in inequality (A-3) to obtain the following inequality:

$$
\frac{(\alpha+1)(h-d)+\alpha\left(h^{1+\alpha}-d^{1+\alpha}\right)}{h^{1+\alpha}-d^{1+\alpha}}>\frac{(2 \alpha+1)\left(h^{1+\alpha}-d^{1+\alpha}+2 \alpha(h-d)+\left(h^{1-\alpha}-d^{1-\alpha}\right)\right)}{h^{1+2 \alpha}-d^{1+2 \alpha}+(1+2 \alpha)(h-d)} .
$$

If we multiply each sides by the two denominators and divide by $(h-d)$ we obtain a simplified inequality:

$$
\begin{aligned}
& (\alpha+1) \frac{h^{1+2 \alpha}-d^{1+2 \alpha}}{h-d}+(\alpha+1)(1+2 \alpha)+\alpha \frac{h^{1+\alpha}-d^{1+\alpha}}{h-d} \frac{h^{1+2 \alpha}-d^{1+2 \alpha}}{h-d}> \\
& (2 \alpha+1)\left[\left(\frac{h^{1+\alpha}-d^{1+\alpha}}{h-d}\right)^{2}+\alpha \frac{h^{1+\alpha}-d^{1+\alpha}}{h-d}+\left(\frac{h^{1-\alpha}-d^{1-\alpha}}{h-d}\right)\left(\frac{h^{1+\alpha}-d^{1+\alpha}}{h-d}\right)\right]
\end{aligned}
$$

1. For $c \rightarrow 0$, using an approximation of $h$ around $d$ :

$$
\begin{aligned}
\frac{h^{1+2 \alpha}-d^{1+2 \alpha}}{h-d} & \approx(1+2 \alpha) d^{2 \alpha}, \\
\frac{h^{1+\alpha}-d^{1+\alpha}}{h-d} & \approx(1+\alpha) d^{\alpha}, \\
\frac{h^{1-\alpha}-d^{1-\alpha}}{h-d} & \approx(1-\alpha) d^{-\alpha} .
\end{aligned}
$$


We can therefore simplify inequality (A-4) as follows:

$$
\begin{aligned}
& (\alpha+1)(1+2 \alpha) d^{2 \alpha}+(\alpha+1)(1+2 \alpha)+\alpha(1+\alpha) d^{\alpha}(1+2 \alpha) d^{2 \alpha}> \\
& (2 \alpha+1)\left[(1+\alpha)^{2} d^{2 \alpha}+\alpha(1+\alpha) d^{\alpha}+(1-\alpha) d^{-\alpha}(1+\alpha) d^{\alpha}\right]
\end{aligned}
$$

which further simplifies to:

$$
\left(d^{\alpha}-1\right)^{2}\left(d^{\alpha}+1\right) \geq 0
$$

which is verified for all $\alpha$.

2. If we do not put any restrictions on the search costs, the proof simplifies for specific values of $\alpha$. For $\alpha=1$,

$$
\begin{aligned}
2\left(h^{2}+h d+d^{2}\right)+6+(h+d)\left(h^{2}+h d+d^{2}\right) & >3\left[(h+d)^{2}+h+d\right] \\
2\left(h^{2}+h d+d^{2}\right)+6+(h+d)\left(h^{2}+h d+d^{2}\right) & >3\left[h^{2}+2 h d+d^{2}+h+d\right] \\
(2+d+h) \cdot\left[3+d^{2}+(d+h)(h-3)\right] & >0
\end{aligned}
$$

Using the definition of $h$ and $d$,

$$
(2+2) \cdot\left[3+\left(1-\frac{b}{\varphi}\right)^{2}+2 \cdot\left(1+\frac{b}{\varphi}-3\right)\right]=4 \frac{b^{2}}{\varphi^{2}}>0
$$


- For $\alpha=2$,

$$
\begin{array}{r}
3 \frac{h^{5}-d^{5}}{h-d}+15+2 \cdot \frac{h^{3}-d^{3}}{h-d} \frac{h^{5}-d^{5}}{h-d}> \\
5\left[\left(\frac{h^{3}-d^{3}}{h-d}\right)^{2}+2 \frac{h^{3}-d^{3}}{h-d}+\left(\frac{h^{-1}-d^{-1}}{h-d}\right)\left(\frac{h^{3}-d^{3}}{h-d}\right)\right] \\
3\left(h^{4}+h^{3} d+h^{2} d^{2}+h d^{3}+d^{4}\right)+15+2\left(h^{4}+h^{3} d+h^{2} d^{2}+h d^{3}+d^{4}\right)\left(h^{2}+h d+d^{2}\right)> \\
5\left[\left(h^{2}+h d+d^{2}\right)^{2}+2\left(h^{2}+h d+d^{2}\right)-\frac{\left(h^{2}+h d+d^{2}\right)}{h d}\right]
\end{array}
$$

Using the definition of $h$ and $d$,

$$
\frac{-2 b^{4}+4 b^{2}\left[3+2\left(1-\frac{b^{2}}{\varphi^{4}}\right)^{1 / 2}\right] \varphi^{4}}{\left(1-\frac{b^{2}}{\varphi^{4}}\right)^{1 / 2} \varphi^{8}} \geq 0 \Leftrightarrow\left[3+2\left(1-\frac{b^{2}}{\varphi^{4}}\right)^{1 / 2}\right] \varphi^{4} \geq \frac{b^{2}}{2}
$$

Recalling that $\varphi^{2} \geq b$, the inequality is always verified.

- For $\alpha=\frac{1}{2}$, the expression simplifies to

$$
\frac{b^{2}}{\varphi} \geq 0
$$

under the assumptions on $b$.

\section{A.4 Numerical simulation}

We simulate the model using the empirical distribution of worker and firm types to show that the properties of matching bounds are verified under this specification (see Figure A5 for the distribution of worker types and A6 for the distribution of firm types). Figure A1 shows the matching set of the economy when normalizing the aggregate price index to unity and assuming the search $\operatorname{cost} c=0.01$, the meeting rate $\rho=1$ and the exogenous separation rate $\delta=1$. Using 
the simulation results, we construct two measures of dispersions of worker types by firm, the length and the standard deviation ${ }^{36}$ of the firm matching set. Figure A2 and A3 show that both measures are decreasing in firm type, when normalized by the average worker type.

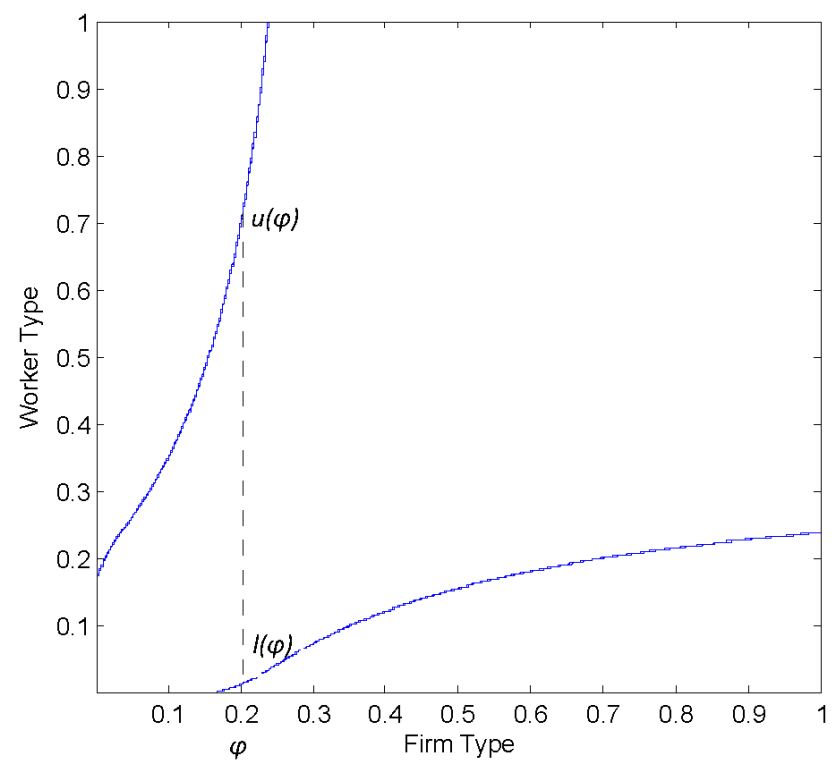

Figure A1: Matching Set for the Simulated Economy. For a given firm type $\varphi$, the matching set is $[l(\varphi), u(\varphi)]$.

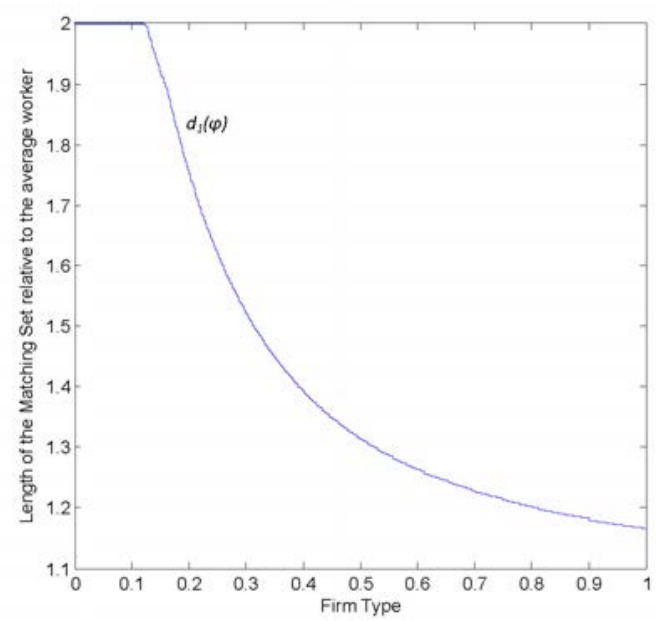

Figure A2: Standard Deviation of the Matching Set by firm type, normalized by the average worker type $\left(d_{1}(\varphi)\right)$

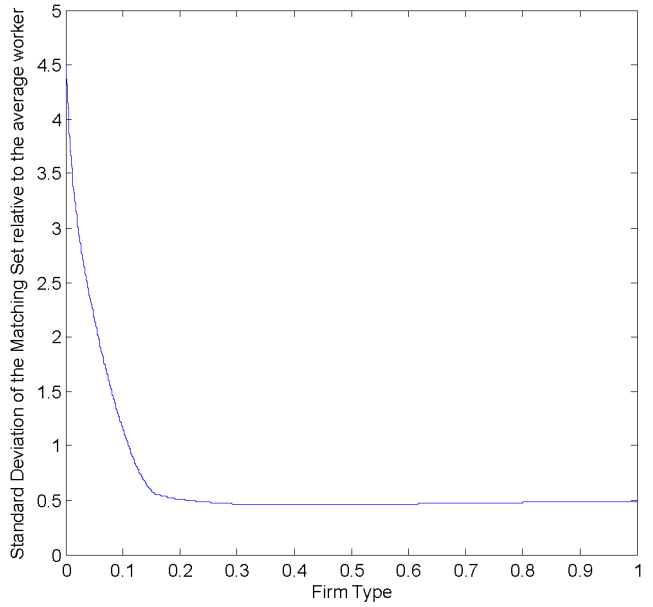

Figure A3: Standard Deviation of the Matching Set by firm type, normalized by the average worker type

\footnotetext{
${ }^{36}$ In the empirical analysis, our preferred measure of dispersion is the standard deviation of the worker types by firm, since it is less sensitive to outliers.
} 


\section{A.5 Additional empirical results}

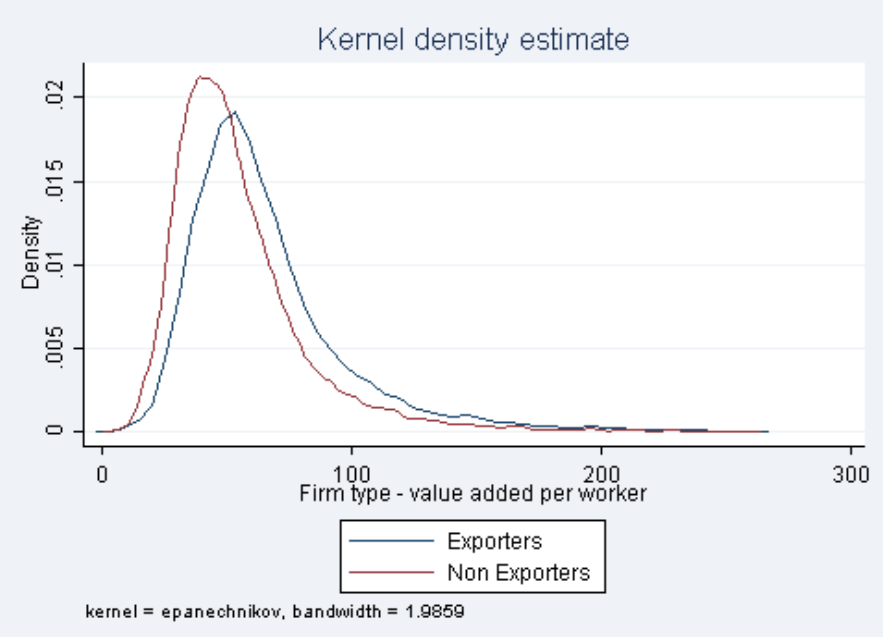

Figure A4: Distribution of Value Added per Worker in Exporting and Non-Exporting Firms

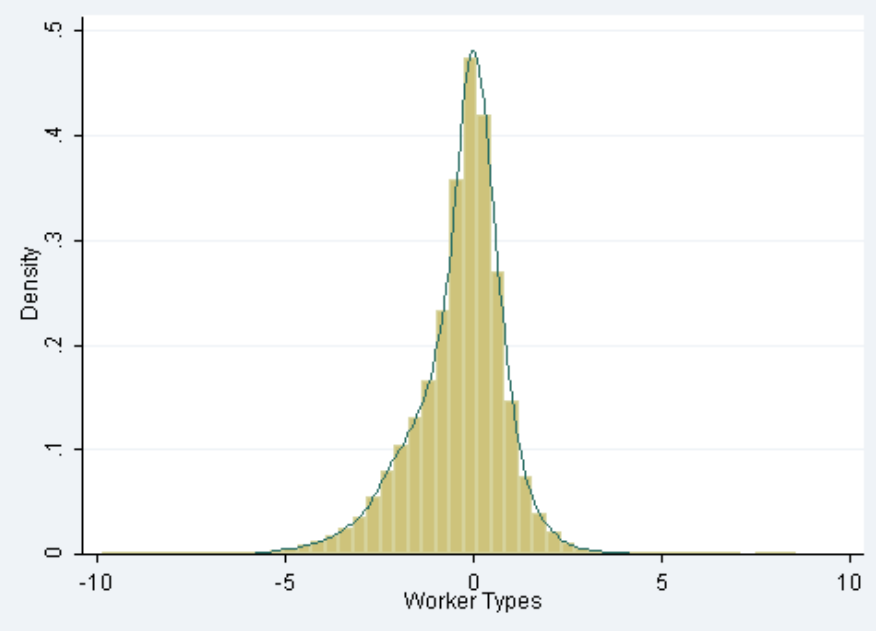

Figure A5: Distribution of Individual Effects, largest connected group 


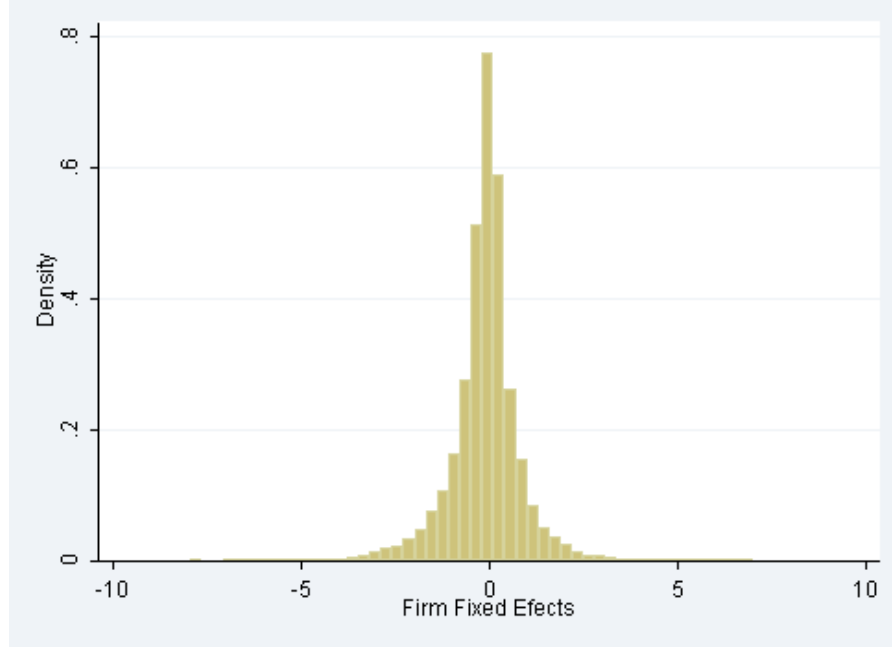

Figure A6: Distribution of Firm Effects, largest connected group

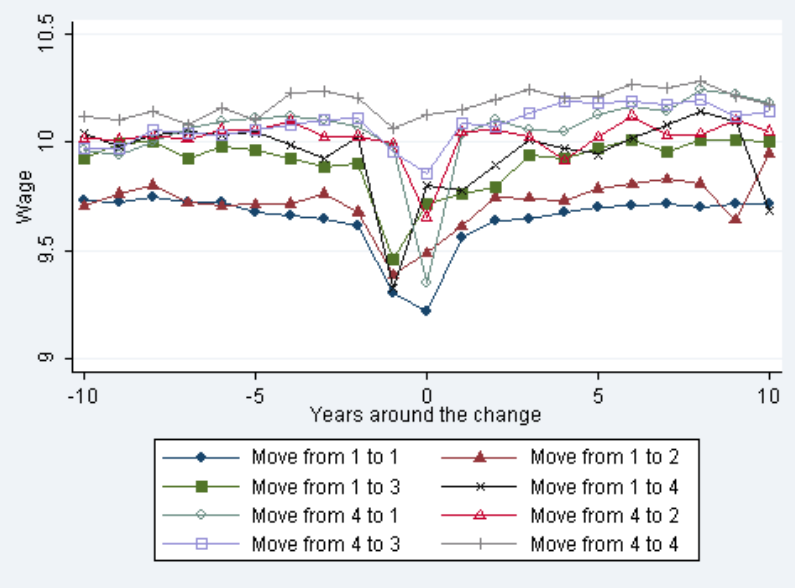

Figure A7: Wage changes by wage quartile 
Table A1: Wage changes when moving to a new job.

\begin{tabular}{l|c} 
Wage Change & Percentage \\
\hline Positive & $54.82 \%$ \\
Negative & $45.18 \%$
\end{tabular}

Table A2: Classification of CS Occupation into 'white' and 'blue' collar workers.

\begin{tabular}{l|l}
\hline \hline CS code & White Collar Jobs \\
\hline 3 & Executives and Higher Intellectual Professions \\
31 & Health Professionals and Lawyers \\
33 & Senior Official in Public Administration \\
34 & Teachers, Scientific Professions \\
35 & Information, arts and entertainment \\
37 & Administrative and Commercial skilled workers \\
38 & Engineers and technical managers \\
4 & Intermediate Occupations \\
42 & Teachers and related \\
43 & Intermediate occupations, health and social work \\
44 & Religious \\
45 & Intermediate administrative professions in Public Administration \\
46 & Intermediate administrative and commercial occupation in Enterprises \\
47 & Technicians \\
48 & Foremen, supervisors \\
\hline CS code & Blue Collar Jobs \\
\hline 5 & Clericals \\
52 & Civilian Employees and officers in Public Service \\
53 & Protective Services \\
54 & Administrative Employees \\
55 & Commercial workers \\
56 & Personal services workers \\
6 & Labourers \\
62 & Qualified Industrial Labourers \\
63 & Qualified craft labourers \\
64 & Drivers \\
67 & Storage and Transport workers \\
68 & Non-Qualified Industrial Labourers \\
\hline 6 & Non-Qualified craft labourers \\
\hline & Farm Workers \\
\hline 5 &
\end{tabular}


Table A3: Summary Statistics

\begin{tabular}{|c|c|c|c|}
\hline & Mean & Median & Std Deviation \\
\hline Avg. Worker Type & -0.04 & -0.02 & 0.86 \\
\hline Std Dev. Worker Fixed Effects & 0.62 & 0.52 & 0.41 \\
\hline Std Dev. Worker Fixed Effects, White Collars & 0.55 & 0.47 & 0.36 \\
\hline Std Dev. Worker Fixed Effects, Blue Collars & 0.50 & 0.36 & 0.41 \\
\hline Std Dev. Worker Fixed Effects ${ }^{\mathrm{a}}$ & 0.62 & 0.52 & 0.41 \\
\hline Std Dev. Worker Fixed Effects, White Collars & 0.55 & 0.47 & 0.36 \\
\hline Std Dev. Worker Fixed Effects, Blue Collars ${ }^{\mathrm{a}}$ & 0.50 & 0.36 & 0.41 \\
\hline Num. Occupation & 4.90 & 4.00 & 2.44 \\
\hline Domestic Market Share & 0.03 & 0.01 & 0.08 \\
\hline Employment & 290.48 & 134.00 & 715.65 \\
\hline Products & 8.57 & 9.01 & 4.22 \\
\hline Share of Non Production Worker & 0.34 & 0.29 & 0.25 \\
\hline Value Added per worker & 70.76 & 45.71 & 161.35 \\
\hline
\end{tabular}

${ }^{a}$ Conditioning on a sample of firms with more than 5 sampled workers.

Table A4: Summary Statistics: Market Access Shocks

\begin{tabular}{|c|c|c|c|}
\hline & Mean & Median & Std Deviation \\
\hline Weighted Tariff & 5.58 & 5.03 & 3.49 \\
\hline Market Access Shock 1 & 12.93 & 14.32 & 6.15 \\
\hline Market Access Shock ${ }_{2}$ & 12.89 & 14.27 & 6.12 \\
\hline
\end{tabular}

Weighted Tariff: Weighted average - across destination - of tariff levels in a given industry $i$ at time $t$, where weights are the share of world exports to that particular destination in that industry and year.

Market Access Shock ${ }_{1}$ : Weighted average - across destinations, excluding France - of the demand faced by a given industry $i$ at time $t$, where the weights are the share of world exports to that particular destination in that industry the previous year.

Market Access Shock ${ }_{2}$ : Weighted-average - across destinations - of the demand faced by a given industry $i$ at time $t$, where the weights are the share of world exports to that particular destination in that industry the previous year. 
Table A5: Pooled Cross-sectional Regressions: Standard Deviation of newly hired workers

\begin{tabular}{|c|c|c|c|c|c|c|}
\hline \multirow[b]{2}{*}{ Variables } & (1) & $(2)$ & $(3)$ & $(4)$ & $(5)$ & (6) \\
\hline & \multicolumn{6}{|c|}{ Standard Deviation of lifetime wage, hired } \\
\hline Export & $\begin{array}{l}-0.025 \\
(0.020)\end{array}$ & $\begin{array}{c}-0.048^{b} \\
(0.020)\end{array}$ & $\begin{array}{c}-0.057^{a} \\
(0.020)\end{array}$ & $\begin{array}{c}-0.063^{a} \\
(0.020)\end{array}$ & $\begin{array}{c}-0.056^{a} \\
(0.020)\end{array}$ & $\begin{array}{c}-0.057^{a} \\
(0.017)\end{array}$ \\
\hline N.Occ. & & $\begin{array}{c}0.031^{a} \\
(0.00289)\end{array}$ & $\begin{array}{c}0.024^{a} \\
(0.00234)\end{array}$ & $\begin{array}{c}0.022^{a} \\
(0.00223)\end{array}$ & $\begin{array}{c}0.030^{a} \\
(0.00289)\end{array}$ & $\begin{array}{c}0.0198^{a} \\
(0.00209)\end{array}$ \\
\hline $\log$ empl & & $\begin{array}{l}-0.028^{a} \\
(0.007)\end{array}$ & & & $\begin{array}{l}-0.031^{a} \\
(0.008)\end{array}$ & $\begin{array}{c}-0.023^{a} \\
(0.006)\end{array}$ \\
\hline log dom.share & & & $\begin{array}{r}-0.0002 \\
(0.003)\end{array}$ & & $\begin{array}{c}0.002 \\
(0.003)\end{array}$ & $\begin{array}{l}0.004^{c} \\
(0.002)\end{array}$ \\
\hline $\log$ VA per worker & & & & $\begin{array}{l}0.038^{a} \\
(0.010)\end{array}$ & $\begin{array}{l}0.038^{a} \\
(0.010)\end{array}$ & $\begin{array}{l}0.048^{a} \\
(0.008)\end{array}$ \\
\hline white share & & & & & & $\begin{array}{c}0.332^{a} \\
(0.019)\end{array}$ \\
\hline $\log$ N. Products & & & & & & $\begin{array}{l}0.018^{a} \\
(0.004)\end{array}$ \\
\hline Avg. Lifetime Wage & & & & & & $\begin{array}{c}-0.444^{a} \\
(0.011)\end{array}$ \\
\hline Sector-Year & $\mathrm{y}$ & $\mathrm{y}$ & $\mathrm{y}$ & $\mathrm{y}$ & $\mathrm{y}$ & $\mathrm{y}$ \\
\hline Obs. & 14,971 & 14,971 & 14,971 & 14,971 & 14,971 & 14,971 \\
\hline $\mathrm{R}^{2}$ & 0.154 & 0.168 & 0.166 & 0.168 & 0.169 & 0.483 \\
\hline
\end{tabular}

Export: dummy $=1$ if firm exports

N.Occ.: number of occupations, based on 2 digit occupational codes for France.

log empl: log-employment.

$\log$ VA per worker: log-value added per worker.

log dom.share: log-domestic market share, at the 4 digit sector level.

white share: share of non-production worker.

$\log$ N. Products: log-number of exported products (HS6 codes). This variable is zero for nonexporters.

Avg. Lifetime Wage: workers' lifetime wage, averaged by firm.

Legend: ${ }^{a}$ significant at $1 \%,{ }^{b}$ significant at $5 \%,{ }^{c}$ significant at $10 \%$.

Notes: Cross-sectional Regressions for firms with more than 5 workers, years 1995-2007. Different specifications in the columns. Standard errors, clustered at the level of the firm, are reported in parenthesis. All specifications but the first include a quadratic in the number of sampled workers, to control for the precision of the left-hand side variable. 
Table A6: Pooled Cross-sectional Regressions: Standard Deviation of current workers

\begin{tabular}{|c|c|c|c|c|c|c|}
\hline \multirow[b]{2}{*}{ Variables } & (1) & $(2)$ & $(3)$ & $(4)$ & $(5)$ & (6) \\
\hline & \multicolumn{6}{|c|}{ Standard Deviation of lifetime wage, stayers } \\
\hline Export & $\begin{array}{c}0.020^{b} \\
(0.009)\end{array}$ & $\begin{array}{c}0.010 \\
(0.009)\end{array}$ & $\begin{array}{c}0.002 \\
(0.009)\end{array}$ & $\begin{array}{l}-0.003 \\
(0.009)\end{array}$ & $\begin{array}{c}0.006 \\
(0.009)\end{array}$ & $\begin{array}{l}-0.014 \\
(0.010)\end{array}$ \\
\hline N.Occ. & & $\begin{array}{c}0.025^{a} \\
(0.001)\end{array}$ & $\begin{array}{c}0.020^{a} \\
(0.001)\end{array}$ & $\begin{array}{c}0.018^{a} \\
(0.001)\end{array}$ & $\begin{array}{c}0.024^{a} \\
(0.001)\end{array}$ & $\begin{array}{l}0.018^{a} \\
(0.001)\end{array}$ \\
\hline $\log$ empl & & $\begin{array}{r}-0.032^{a} \\
(0.004)\end{array}$ & & & $\begin{array}{r}-0.033^{a} \\
(0.004)\end{array}$ & $\begin{array}{r}-0.017^{a} \\
(0.004)\end{array}$ \\
\hline $\log$ dom.share & & & $\begin{array}{c}-0.001 \\
(0.001)\end{array}$ & & $\begin{array}{c}-8.06 e^{-5} \\
(0.001)\end{array}$ & $\begin{array}{c}0.001 \\
(0.001)\end{array}$ \\
\hline log VA per worker & & & & $\begin{array}{l}0.040^{a} \\
(0.005)\end{array}$ & $\begin{array}{l}0.041^{a} \\
(0.005)\end{array}$ & $\begin{array}{l}0.080^{a} \\
(0.005)\end{array}$ \\
\hline white share & & & & & & $\begin{array}{c}0.381^{a} \\
(0.013)\end{array}$ \\
\hline $\log$ N. Products & & & & & & $\begin{array}{l}0.011^{a} \\
(0.002)\end{array}$ \\
\hline Avg. Lifetime Wage & & & & & & $\begin{array}{r}-0.447^{a} \\
(0.012)\end{array}$ \\
\hline Sector-Year & $\mathrm{y}$ & $\mathrm{y}$ & $\mathrm{y}$ & $\mathrm{y}$ & $\mathrm{y}$ & $\mathrm{y}$ \\
\hline Obs. & 40,579 & 40,579 & 40,579 & 40,579 & 40,579 & 40,579 \\
\hline $\mathrm{R}^{2}$ & 0.043 & 0.071 & 0.066 & 0.072 & 0.077 & 0.253 \\
\hline
\end{tabular}

Export: dummy=1 if firm exports

N.Occ.: number of occupations, based on 2 digit occupational codes for France.

log empl: log-employment.

$\log$ VA per worker: log-value added per worker.

log dom.share: log-domestic market share, at the 4 digit sector level.

white share: share of non-production worker.

$\log$ N. Products: log-number of exported products (HS6 codes). This variable is zero for non-exporters.

Avg. Lifetime Wage: workers' lifetime wage, averaged by firm.

${ }^{a}$ significant at $1 \%,{ }^{b}$ significant at $5 \%,{ }^{c}$ significant at $10 \%$.

Notes: Cross-sectional Regressions for firms with more than 5 workers, years 19952007. Different specifications in the columns. Standard errors, clustered at the level of the firm, are reported in parenthesis. All specifications but the first include a quadratic in the number of sampled workers, to control for the precision of the lefthand side variable. 
Table A7: Pooled GLS Regressions: Average Lifetime Wage

\begin{tabular}{|c|c|c|c|c|c|c|}
\hline \multirow[b]{2}{*}{ Variables } & (1) & $(2)$ & $(3)$ & $(4)$ & $(5)$ & (6) \\
\hline & \multicolumn{6}{|c|}{ Average Lifetime Wage } \\
\hline \multirow[t]{2}{*}{ Export } & $0.174^{a}$ & $0.047^{a}$ & $0.050^{a}$ & $0.072^{a}$ & $0.021^{b}$ & -0.009 \\
\hline & $(0.011)$ & $(0.010)$ & $(0.010)$ & $(0.010)$ & $(0.010)$ & $(0.012)$ \\
\hline \multirow[t]{2}{*}{ N.Occ. } & & -0.004 & $0.013^{a}$ & $0.019^{a}$ & $-0.006^{b}$ & $-0.009^{a}$ \\
\hline & & $(0.003)$ & $(0.002)$ & $(0.002)$ & $(0.003)$ & $(0.003)$ \\
\hline \multirow[t]{2}{*}{$\log$ empl } & & $0.097^{a}$ & & & $0.085^{a}$ & $0.075^{a}$ \\
\hline & & $(0.007)$ & & & $(0.006)$ & $(0.006)$ \\
\hline \multirow[t]{2}{*}{ log dom.share } & & & $0.032^{a}$ & & $0.006^{a}$ & $0.004^{b}$ \\
\hline & & & $(0.003)$ & & $(0.002)$ & $(0.002)$ \\
\hline \multirow[t]{2}{*}{$\log$ VA per worker } & & & & $0.177^{a}$ & $0.167^{a}$ & $0.103^{a}$ \\
\hline & & & & $(0.010)$ & $(0.009)$ & $(0.009)$ \\
\hline \multirow[t]{2}{*}{ white share } & & & & & & $0.559^{a}$ \\
\hline & & & & & & $(0.022)$ \\
\hline \multirow[t]{2}{*}{$\log$ N. Products } & & & & & & $0.014^{a}$ \\
\hline & & & & & & $(0.004)$ \\
\hline Sector-Year & $\mathrm{y}$ & $\mathrm{y}$ & $\mathrm{y}$ & $\mathrm{y}$ & $\mathrm{y}$ & $\mathrm{y}$ \\
\hline Obs. & 148,784 & 148,784 & 148,784 & 148,784 & 148,784 & 148,784 \\
\hline $\mathrm{R}^{2}$ & 0.181 & 0.253 & 0.244 & 0.268 & 0.289 & 0.360 \\
\hline
\end{tabular}

Export: dummy=1 if firm exports

N.Occ.: number of occupations, based on 2 digit occupational codes for France.

log empl: log-employment.

$\log$ VA per worker: log-value added per worker.

log dom.share: log-domestic market share, at the 4 digit sector level.

white share: share of non-production worker.

$\log$ N. Products: log-number of exported products (HS6 codes). This variable is zero for non-exporters.

${ }^{a}$ significant at $1 \%,{ }^{b}$ significant at $5 \%,{ }^{c}$ significant at $10 \%$.

Notes: Cross-sectional Regressions for firms with more than 5 workers, years 19952007. Different specifications in the columns. Standard errors, clustered at the level of the firm, are reported in parenthesis. All specifications but the first include a quadratic in the number of sampled workers, to control for the precision of the left-hand side variable. 
Table A8: Pooled GLS Regressions: Average of Workers Fixed Effects

\begin{tabular}{|c|c|c|c|c|c|c|}
\hline \multirow[b]{2}{*}{ Variables } & (1) & $(2)$ & $(3)$ & $(4)$ & $(5)$ & $(6)$ \\
\hline & \multicolumn{6}{|c|}{ Average of Workers Fixed Effects } \\
\hline \multirow[t]{2}{*}{ Export } & $0.107^{a}$ & 0.030 & 0.026 & 0.035 & 0.018 & -0.004 \\
\hline & $(0.025)$ & $(0.024)$ & $(0.024)$ & $(0.024)$ & $(0.025)$ & $(0.028)$ \\
\hline \multirow[t]{2}{*}{ N.Occ. } & & 0.007 & $0.011^{a}$ & $0.013^{a}$ & 0.007 & 0.0057 \\
\hline & & $(0.005)$ & $(0.003)$ & $(0.003)$ & $(0.005)$ & $(0.005)$ \\
\hline \multirow[t]{2}{*}{$\log$ empl } & & $0.028^{b}$ & & & 0.021 & 0.010 \\
\hline & & $(0.014)$ & & & $(0.013)$ & $(0.014)$ \\
\hline \multirow[t]{2}{*}{ log dom.share } & & & $0.012^{b}$ & & 0.005 & 0.003 \\
\hline & & & $(0.005)$ & & $(0.005)$ & $(0.005)$ \\
\hline \multirow[t]{2}{*}{$\log$ VA per worker } & & & & $0.065^{a}$ & $0.060^{a}$ & 0.013 \\
\hline & & & & $(0.017)$ & $(0.016)$ & $(0.016)$ \\
\hline \multirow[t]{2}{*}{ white share } & & & & & & $0.404^{a}$ \\
\hline & & & & & & $(0.037)$ \\
\hline \multirow[t]{2}{*}{$\log$ N. Products } & & & & & & 0.011 \\
\hline & & & & & & $(0.008)$ \\
\hline Sector-Year & $\mathrm{y}$ & $\mathrm{y}$ & $\mathrm{y}$ & $\mathrm{y}$ & $\mathrm{y}$ & $\mathrm{y}$ \\
\hline Obs. & 79,689 & 79,689 & 79,689 & 79,689 & 79,689 & 79,689 \\
\hline $\mathrm{R}^{2}$ & 0.052 & 0.073 & 0.073 & 0.075 & 0.076 & 0.089 \\
\hline
\end{tabular}

Export: dummy=1 if firm exports

N.Occ.: number of occupations, based on 2 digit occupational codes for France. log empl: log-employment.

$\log$ VA per worker: log-value added per worker.

log dom.share: log-domestic market share, at the 4 digit sector level.

white share: share of non-production worker.

$\log$ N. Products: log-number of exported products (HS6 codes). This variable is zero for non-exporters.

Avg. Lifetime Wage: workers' lifetime wage, averaged by firm.

${ }^{a}$ significant at $1 \%,{ }^{b}$ significant at $5 \%,{ }^{c}$ significant at $10 \%$.

Notes: Cross-sectional Regressions for firms with more than 5 workers, years 1995-2007. Different specifications in the columns. Standard errors, clustered at the level of the firm, are reported in parenthesis. All specifications but the first include a quadratic in the number of sampled workers, to control for the precision of the left-hand side variable. 
Table A9: Pooled GLS Regressions: Standard Deviation of Lifetime Wage

\begin{tabular}{|c|c|c|c|c|c|c|}
\hline \multirow[b]{2}{*}{ Variables } & (1) & (2) & (3) & (4) & (5) & (6) \\
\hline & \multicolumn{6}{|c|}{ Standard Deviation of Lifetime Wage } \\
\hline \multirow[t]{2}{*}{ Export } & -0.017 & -0.017 & $-0.038^{a}$ & $-0.050^{a}$ & $-0.025^{b}$ & $-0.035^{a}$ \\
\hline & $(0.011)$ & $(0.012)$ & $(0.012)$ & $(0.012)$ & $(0.012)$ & $(0.010)$ \\
\hline \multirow[t]{2}{*}{ N.Occ. } & & $0.024^{a}$ & $0.012^{a}$ & $0.010^{a}$ & $0.024^{a}$ & $0.017^{a}$ \\
\hline & & $(0.003)$ & $(0.002)$ & $(0.002)$ & $(0.003)$ & $(0.003)$ \\
\hline \multirow[t]{2}{*}{ log empl } & & $-0.055^{a}$ & & & $-0.060^{a}$ & -0.004 \\
\hline & & $(0.009)$ & & & $(0.008)$ & $(0.006)$ \\
\hline \multirow[t]{2}{*}{$\log$ dom.share } & & & -0.004 & & $0.004^{c}$ & $0.006^{a}$ \\
\hline & & & $(0.003)$ & & $(0.002)$ & $(0.002)$ \\
\hline \multirow[t]{2}{*}{ log VA per worker } & & & & $0.037^{a}$ & $0.040^{a}$ & $0.095^{a}$ \\
\hline & & & & $(0.008)$ & $(0.009)$ & $(0.007)$ \\
\hline \multirow[t]{2}{*}{ white share } & & & & & & $0.508^{a}$ \\
\hline & & & & & & $(0.016)$ \\
\hline \multirow[t]{2}{*}{$\log$ N. Products } & & & & & & $0.014^{a}$ \\
\hline & & & & & & $(0.003)$ \\
\hline \multirow[t]{2}{*}{ Avg. Lifetime Wage } & & & & & & $-0.713^{a}$ \\
\hline & & & & & & $(0.012)$ \\
\hline Sector-Year & $\mathrm{y}$ & $\mathrm{y}$ & $\mathrm{y}$ & $\mathrm{y}$ & $\mathrm{y}$ & $\mathrm{y}$ \\
\hline Obs. & 88,790 & 88,790 & 88,790 & 88,790 & 88,790 & 88,790 \\
\hline $\mathrm{R}^{2}$ & 0.099 & 0.119 & 0.108 & 0.111 & 0.123 & 0.553 \\
\hline
\end{tabular}

Export: dummy $=1$ if firm exports

N.Occ.: number of occupations, based on 2 digit occupational codes for France. log empl: log-employment.

log VA per worker: log-value added per worker.

log dom.share: log-domestic market share, at the 4 digit sector level.

white share: share of non-production worker.

$\log$ N. Products: log-number of exported products (HS6 codes). This variable is zero for non-exporters.

Avg. Lifetime Wage: workers' lifetime wage, averaged by firm.6 codes). This variable is zero for non-exporters.

Avg. Lifetime Wage: workers' lifetime wage, averaged by firm.

${ }^{a}$ significant at $1 \%,{ }^{b}$ significant at $5 \%,{ }^{c}$ significant at $10 \%$.

Notes: Cross-sectional Regressions for firms with more than 5 workers, years 19952007. Different specifications in the columns. Standard errors, clustered at the level of the firm, are reported in parenthesis. All specifications but the first include a quadratic in the number of sampled workers, to control for the precision of the left-hand side variable. 
Table A10: Pooled GLS Regressions: Standard Deviation of Worker Fixed Effects

\begin{tabular}{|c|c|c|c|c|c|c|}
\hline \multirow[b]{2}{*}{ Variables } & $(1)$ & $(2)$ & $(3)$ & $(4)$ & $(5)$ & $(6)$ \\
\hline & \multicolumn{6}{|c|}{ Standard Deviation of Worker Fixed Effects } \\
\hline \multirow[t]{2}{*}{ Export } & $-0.023^{c}$ & $-0.026^{b}$ & $-0.045^{a}$ & $-0.054^{a}$ & $-0.034^{a}$ & $-0.043^{a}$ \\
\hline & $(0.012)$ & $(0.013)$ & $(0.013)$ & $(0.013)$ & $(0.013)$ & $(0.014)$ \\
\hline \multirow[t]{2}{*}{ N.Occ. } & & $0.022^{a}$ & $0.011^{a}$ & $0.010^{a}$ & $0.021^{a}$ & $0.021^{a}$ \\
\hline & & $(0.003)$ & $(0.002)$ & $(0.002)$ & $(0.003)$ & $(0.003)$ \\
\hline \multirow[t]{2}{*}{$\log$ empl } & & $-0.048^{a}$ & & & $-0.053^{a}$ & $-0.056^{a}$ \\
\hline & & $(0.009)$ & & & $(0.008)$ & $(0.008)$ \\
\hline \multirow[t]{2}{*}{ log dom.share } & & & -0.004 & & 0.003 & 0.003 \\
\hline & & & $(0.003)$ & & $(0.002)$ & $(0.002)$ \\
\hline \multirow[t]{2}{*}{ log VA per worker } & & & & $0.032^{a}$ & $0.035^{a}$ & $0.023^{a}$ \\
\hline & & & & $(0.008)$ & $(0.008)$ & $(0.008)$ \\
\hline \multirow[t]{2}{*}{ white share } & & & & & & $0.152^{a}$ \\
\hline & & & & & & $(0.020)$ \\
\hline \multirow[t]{2}{*}{$\log$ N. Products } & & & & & & 0.005 \\
\hline & & & & & & $(0.004)$ \\
\hline \multirow[t]{2}{*}{ Avg Worker Type } & & & & & & $-0.092^{a}$ \\
\hline & & & & & & $(0.006)$ \\
\hline Sector-Year & $\mathrm{y}$ & $\mathrm{y}$ & $\mathrm{y}$ & $\mathrm{y}$ & $\mathrm{y}$ & $\mathrm{y}$ \\
\hline Obs. & 79,689 & 79,689 & 79,689 & 79,689 & 79,689 & 79,689 \\
\hline $\mathrm{R}^{2}$ & 0.106 & 0.123 & 0.115 & 0.117 & 0.126 & 0.158 \\
\hline
\end{tabular}

Export: dummy=1 if firm exports

N.Occ.: number of occupations, based on 2 digit occupational codes for France. log empl: log-employment.

log VA per worker: log-value added per worker.

log dom.share: log-domestic market share, at the 4 digit sector level.

white share: share of non-production worker.

$\log$ N. Products: log-number of exported products (HS6 codes). This variable is zero for non-exporters.

${ }^{a}$ significant at $1 \%,{ }^{b}$ significant at $5 \%,{ }^{c}$ significant at $10 \%$.

Notes: Cross-sectional Regressions for firms with more than 5 workers, years 1995-2007. Different specifications in the columns. Standard errors, clustered at the level of the firm, are reported in parenthesis. All specifications but the first include a quadratic in the number of sampled workers, to control for the precision of the left-hand side variable. 
Table A11: Sectoral Rank Correlations

\begin{tabular}{|c|c|c|c|c|c|c|c|c|}
\hline Variables & \multicolumn{8}{|c|}{ Rank Correlation } \\
\hline Export & $\begin{array}{l}0.042^{a} \\
(0.008)\end{array}$ & $\begin{array}{c}0.029^{a} \\
(0.010)\end{array}$ & $\begin{array}{l}0.023^{b} \\
(0.010)\end{array}$ & $\begin{array}{l}0.017^{c} \\
(0.010)\end{array}$ & $\begin{array}{l}0.042^{a} \\
(0.008)\end{array}$ & $\begin{array}{c}0.037^{a} \\
(0.014)\end{array}$ & $\begin{array}{c}0.026^{a} \\
(0.010)\end{array}$ & $\begin{array}{c}0.027^{c} \\
(0.014)\end{array}$ \\
\hline log empl & & $\begin{array}{c}0.009^{c} \\
(0.005)\end{array}$ & & $\begin{array}{c}0.004 \\
(0.005)\end{array}$ & & $\begin{array}{c}0.003 \\
(0.009)\end{array}$ & & $\begin{array}{l}-0.001 \\
(0.009)\end{array}$ \\
\hline log VA per worker & & & $\begin{array}{c}0.077^{a} \\
(0.017)\end{array}$ & $\begin{array}{l}0.075^{a} \\
(0.017)\end{array}$ & & & $\begin{array}{l}0.064^{a} \\
(0.023)\end{array}$ & $\begin{array}{l}0.064^{a} \\
(0.024)\end{array}$ \\
\hline Sector, Year & $\mathrm{y}^{1}$ & $y^{1}$ & $y^{1}$ & $y^{1}$ & $\mathrm{y}^{2}$ & $\mathrm{y}^{2}$ & $\mathrm{y}^{2}$ & $\mathrm{y}^{2}$ \\
\hline $\begin{array}{l}\text { Obs. } \\
\mathrm{R}^{2}\end{array}$ & $\begin{array}{l}3,836 \\
0.041\end{array}$ & $\begin{array}{l}3,836 \\
0.042\end{array}$ & $\begin{array}{l}3,836 \\
0.049\end{array}$ & $\begin{array}{l}3,836 \\
0.049\end{array}$ & $\begin{array}{l}3,836 \\
0.195\end{array}$ & $\begin{array}{l}3,836 \\
0.195\end{array}$ & $\begin{array}{l}3,836 \\
0.198\end{array}$ & $\begin{array}{l}3,836 \\
0.198\end{array}$ \\
\hline $\begin{array}{l}2 \text { digit sector dum } \\
4 \text { digit sector dum } \\
\text { log empl: log-emplo } \\
\text { log VA per worker: } \\
\text { a significant at } 1 \% \text {, } \\
\text { Notes: Industry re } \\
\text { ceported in parenthe }\end{array}$ & $\begin{array}{l}\text { es. } \\
\text { es. } \\
\text { ent. } \\
\text {-value a } \\
\text { ignificar } \\
\text { ssions, } \\
\text {. }\end{array}$ & $\begin{array}{c}\text { ded per } \\
\text { at } 5 \% \text {, } \\
\text { ears } 199\end{array}$ & $\begin{array}{l}\text { orker. } \\
\text { significa } \\
2007 \text {. }\end{array}$ & $\begin{array}{l}\text { at } 10 \% \\
\text { ndard }\end{array}$ & ors, cl & red & & eve \\
\hline
\end{tabular}

Table A12: GLS Regressions: Sectoral Rank Correlations

\begin{tabular}{|c|c|c|c|c|c|c|c|}
\hline \multirow[b]{2}{*}{ Variables } & $(1)$ & $(2)$ & $(3)$ & $(4)$ & $(5)$ & $(6)$ & $(7)$ \\
\hline & \multicolumn{7}{|c|}{ Rank Correlation } \\
\hline Export & $\begin{array}{c}0.037^{a} \\
(0.009)\end{array}$ & $\begin{array}{c}0.033^{a} \\
(0.009)\end{array}$ & $\begin{array}{c}0.018^{b} \\
(0.009)\end{array}$ & $\begin{array}{l}0.024^{a} \\
(0.009)\end{array}$ & $\begin{array}{c}0.035^{a} \\
(0.011)\end{array}$ & $\begin{array}{c}0.011 \\
(0.007)\end{array}$ & $\begin{array}{c}0.022^{b} \\
(0.011)\end{array}$ \\
\hline log empl & & $\begin{array}{c}0.002 \\
(0.004)\end{array}$ & & $\begin{array}{l}-0.004 \\
(0.004)\end{array}$ & $\begin{array}{l}-0.001 \\
(0.007)\end{array}$ & & $\begin{array}{l}-0.008 \\
(0.007)\end{array}$ \\
\hline $\log$ VA per worker & & & $\begin{array}{l}0.074^{a} \\
(0.014)\end{array}$ & $\begin{array}{l}0.078^{a} \\
(0.015)\end{array}$ & & $\begin{array}{l}0.096^{a} \\
(0.020)\end{array}$ & $\begin{array}{l}0.100^{a} \\
(0.021)\end{array}$ \\
\hline Sector, Year & $\mathrm{y}^{1}$ & $\mathrm{y}^{1}$ & $\mathrm{y}^{1}$ & $\mathrm{y}^{1}$ & $\mathrm{y}^{2}$ & $\mathrm{y}^{2}$ & $\mathrm{y}^{2}$ \\
\hline $\begin{array}{l}\text { Obs. } \\
\mathrm{R}^{2}\end{array}$ & $\begin{array}{l}3,812 \\
0.082\end{array}$ & $\begin{array}{l}3,812 \\
0.082\end{array}$ & $\begin{array}{l}3,812 \\
0.094\end{array}$ & $\begin{array}{l}3,812 \\
0.094\end{array}$ & $\begin{array}{l}3,812 \\
0.333\end{array}$ & $\begin{array}{l}3,812 \\
0.343\end{array}$ & $\begin{array}{l}3,812 \\
0.343\end{array}$ \\
\hline $\begin{array}{l}{ }^{1} 2 \text { digit sector dum } \\
24 \text { digit sector dum } \\
\text { log empl: log-employ } \\
\text { log VA per worker: } \\
{ }^{a} \text { significant at } 1 \% \text {, }\end{array}$ & $\begin{array}{l}\text { lies. } \\
\text { ties. } \\
\text { ment. } \\
\text { g-value } \\
\text { significa }\end{array}$ & $\begin{array}{l}\text { dded per } \\
\text { t at } 5 \% \text {, }\end{array}$ & $\begin{array}{l}\text { rorker. } \\
\text { signific }\end{array}$ & at $10 \%$ & & & \\
\hline $\begin{array}{l}\text { Notes: Industry reg } \\
\text { dard errors, clustere }\end{array}$ & $\begin{array}{l}\text { ssions, } \\
\text { at the s }\end{array}$ & $\begin{array}{l}\text { trs } 1995- \\
\text { tor-level }\end{array}$ & $\begin{array}{l}\text { 07. Dif } \\
\text { are repo }\end{array}$ & ent spec & ation & & ns. Stal \\
\hline
\end{tabular}


Table A13: IV Regressions: Standard Deviation of Lifetime Wage, more than 5 workers

\begin{tabular}{lcccccc}
\hline \hline \multirow{2}{*}{ Variables } & $(1)$ & $(2)$ & $(3)$ & $(4)$ & $(5)$ & $(6)$ \\
& \multicolumn{7}{c}{ Standard Deviation of Lifetime Wage, more than 5} \\
\hline \hline Export & $-0.075^{a}$ & $-0.095^{a}$ & $-0.061^{a}$ & $-0.099^{a}$ & $-0.102^{a}$ & $-0.153^{a}$ \\
& $(0.019)$ & $(0.020)$ & $(0.021)$ & $(0.022)$ & $(0.020)$ & $(0.035)$ \\
& $0.120^{a}$ & $0.112^{a}$ & $0.106^{a}$ & $0.099^{a}$ & $0.110^{a}$ & $0.043^{a}$ \\
& $(0.005)$ & $(0.004)$ & $(0.004)$ & $(0.004)$ & $(0.004)$ & $(0.001)$ \\
Firm Tariff & 528 & 551 & 543 & 540 & 551 & 599 \\
\hline F-stat (First Stage) & 16,072 & 16,072 & 16,072 & 16,072 & 16,072 & 16,072 \\
\hline Obs. & & & \multicolumn{7}{c}{ Second Stage } \\
\hline
\end{tabular}

Firm Tariff: (inverse of) average applied tariff across industry-destination, weighted by the share of firm $j$ exports to each industry-destination the previous period.

${ }^{a}$ significant at $1 \%,{ }^{b}$ significant at $5 \%,{ }^{c}$ significant at $10 \%$.

Notes: IV Regressions for firms with more than 5 workers, years 1995-2007. Different specifications in the columns. Standard errors, clustered at the level of the firm, are reported in parenthesis. All specifications but the first include a quadratic in the number of sampled workers, to control for the precision of the left-hand side variable. 